\title{
Physical Properties and Drying Behavior of Hydrothermally Treated Yellow-Poplar
}

\author{
Sohrab Rahimi
}

Follow this and additional works at: https://researchrepository.wvu.edu/etd

\section{Recommended Citation}

Rahimi, Sohrab, "Physical Properties and Drying Behavior of Hydrothermally Treated Yellow-Poplar" (2017). Graduate Theses, Dissertations, and Problem Reports. 6466.

https://researchrepository.wvu.edu/etd/6466

This Thesis is protected by copyright and/or related rights. It has been brought to you by the The Research Repository @ WVU with permission from the rights-holder(s). You are free to use this Thesis in any way that is permitted by the copyright and related rights legislation that applies to your use. For other uses you must obtain permission from the rights-holder(s) directly, unless additional rights are indicated by a Creative Commons license in the record and/ or on the work itself. This Thesis has been accepted for inclusion in WVU Graduate Theses, Dissertations, and Problem Reports collection by an authorized administrator of The Research Repository @ WVU. For more information, please contact researchrepository@mail.wvu.edu. 


\title{
Physical Properties and Drying Behavior of Hydrothermally Treated Yellow-Poplar
}

\author{
Sohrab Rahimi
}

\author{
Thesis submitted \\ to Davis College of Agriculture, Natural Resources and Design \\ at West Virginia University
}

in partial fulfillment of the requirements for the degree of

Master of Science in

Forestry
Kaushlendra Singh, Ph.D., Chair
David DeVallance, Ph.D.
Jingxin Wang, Ph.D.
Wood Science and Technology Program, School of Natural Resources, Morgantown, West Virginia 2017

Key words: Physical Characteristics, Drying Behavior, Mechanical Properties, Hydrothermal Treatment, Yellow-Poplar Copyright 2017 Sohrab Rahimi 


\section{Abstract \\ Physical Properties and Drying Behavior of Hydrothermally Treated Yellow-Poplar}

\section{Sohrab Rahimi}

Non-chemical treatments (steam and ultrasonic vibrations) have been intensively researched and commercialized to make chemical-free wood products with enhanced mechanical properties and decay resistance; however, utilization of high-pressure steam medium involves vapor-phase reactions using high-temperature steam generated at the expense of high energy input. In this research, drying behavior, mechanical properties, and physical characteristics of wood (yellowpoplar) were compared to evaluate influence of reaction media (steam and hot-compressed water) and temperatures $\left(100^{\circ} \mathrm{C}\right.$ and $\left.140^{\circ} \mathrm{C}\right)$. The control (no treatment) was used for reference comparison. For experiments, green samples of yellow-poplar heartwood were used for treatment. The average size of length (longitudinal direction), width (radial direction), and thickness (tangential direction) of the specimens were 22.53, 17.18, and $16.72 \mathrm{~mm}$, respectively. After the treatment, the samples were dried under isothermal temperature condition of $105^{\circ} \mathrm{C}$ under nitrogen atmosphere to minimize the influence of humidity. Data from drying experiments were used to prepare drying curves, which were fitted with unsteady state molecular transport equation to calculate overall liquid diffusion coefficients. Dimensions, weight, and true volume (excluding pores) of samples were measured for green, treated, and dried samples and this data was used to calculate selected physical characteristics (moisture content, volumetric shrinkage, specific gravity, and total porosity). The dried samples were evaluated for water absorption, volumetric 
swelling, modulus of elasticity, and compression strength. Statistical analysis of experimental data showed that the reaction media had significantly influenced moisture content, total porosity, diffusion coefficient, and compression strength. Intensified hot-compressed water treated and control samples had the most and least moisture contents (101.10\% and 43.56\%), respectively. In addition, wet and oven-dry specific gravity of the samples were in range of 0.42 to 0.44 and 0.49 to 0.50 , respectively. Additionally, Intensified steam treated and control samples had the most and least total porosity ( $94.94 \%$ and $82.36 \%$ ), respectively. Furthermore, mild hot-compressed water treated samples showed the greatest compression strength (47.75 MPa). Overall liquid diffusion coefficient of the untreated yellow-poplar was $3.15 \times 10^{-8} \mathrm{~m}^{2} / \mathrm{s}$. Except steam treatment at $140^{\circ} \mathrm{C}$, other treatments significantly decreased diffusion coefficient. 


\section{Acknowledgement}

First and foremost, I thank God for his strength and grace on my life to successfully complete this research work.

I would like to express my sincere gratitude to my major advisor, Dr. Kaushlendra Singh, for all of his support and advice throughout my graduate program. My appreciation also goes to my committee members, Dr. David DeVallance and Dr. Jingxin Wang for their guidance in the successful completion of my graduate research work. Special thanks to Dr. Ida Holaskova for her generous assistance and spending so many long hours, helping me over statistical analysis.

My sincere unreserved appreciation to all my family members, home and abroad for standing by me during this phase of my life and their unwavering support to ensure I achieve my dream of becoming an academician.

Lastly, I would like to express my profound gratitude to my dear friends and colleagues John Vance, Nick Robertson, Oluwatosin Oginni, and Felix Akherum for their friendship and academic help. 


\section{Table of Content}

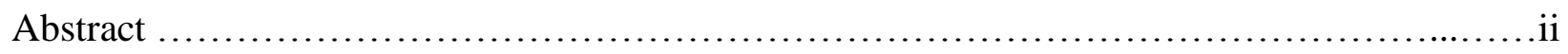

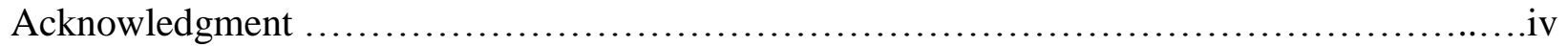

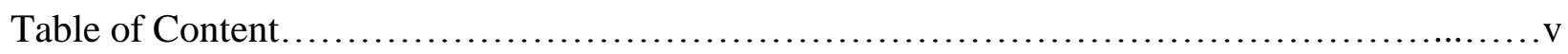

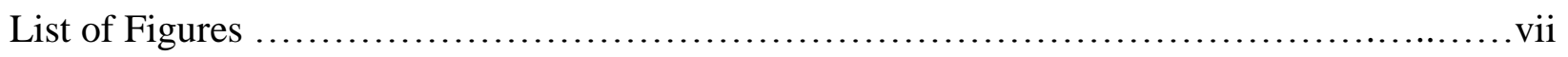

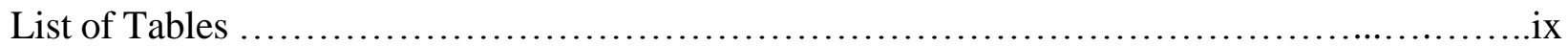

Chapter 1. Introduction and Background Knowledge ...................................

1.1. Problems Related to Wood Drying ..................................................

1.2. Various Physical Treatments Performed on Wood ......................................

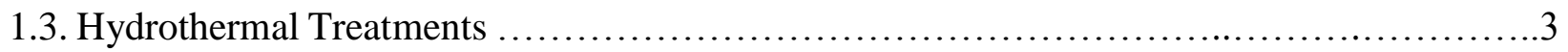

1.4. Effect of Hydrothermal Treatments on Physical Properties and Drying behavior...............7

1.5. Effect of Hydrothermal Treatments on Anatomical Structure...............................12

1.6. Effect of Hydrothermal Treatments on Mechanical Properties ...............................16

1.7. Effect of Hydrothermal Treatments on Drying Behavior and Diffusion Coefficient...........16

1.8. Effect of Hydrothermal Treatments on Chemical Make-up............................... 18

1.9. Synthesis of Literature Review and Objective ........................................... 19

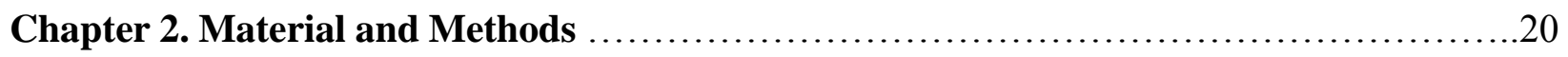

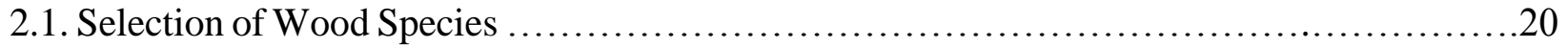

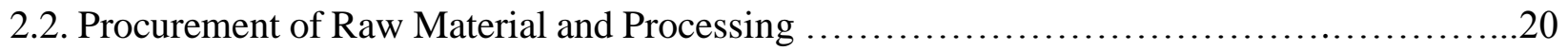

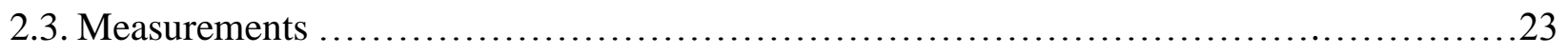

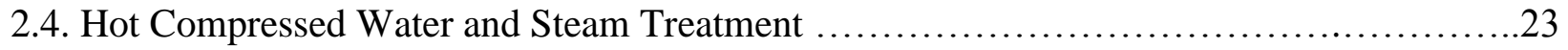

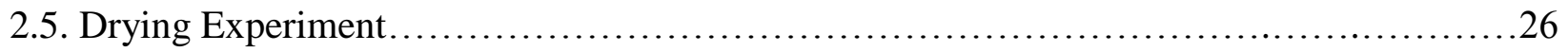

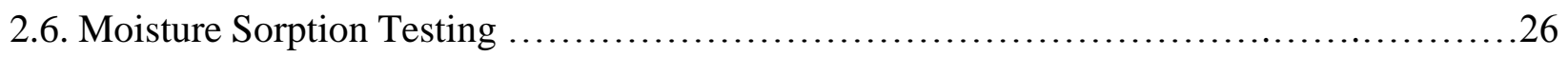

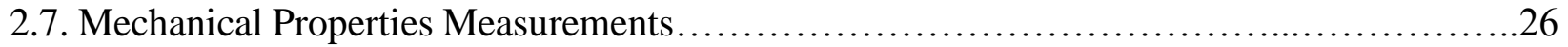

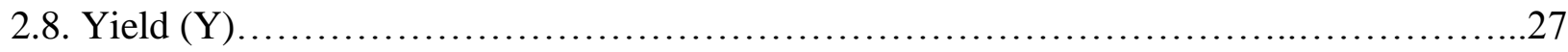

2.9. Physical Characteristics and Mechanical Properties ....................................28

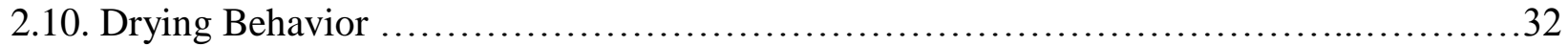

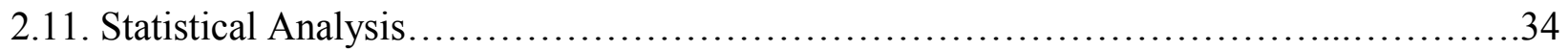




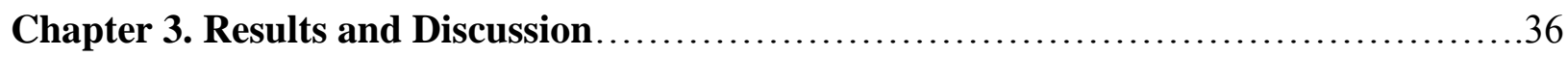

3.1. Determination of the Maturity of Wood Samples..................................... 36

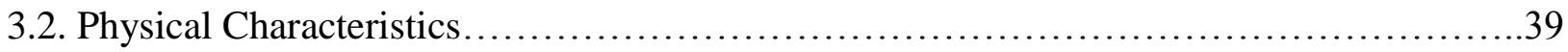

3.3. Mechanical Properties........................................................52

3.4. Drying Behavior and Overall Liquid Diffusion Coefficient............................54

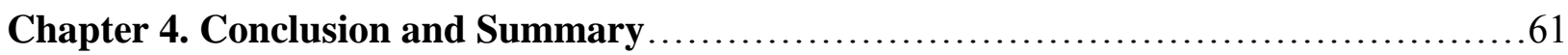

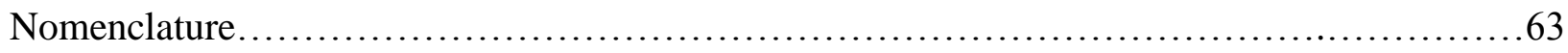

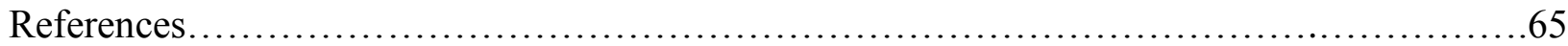




\section{List of Figures}

Figure 1. Steam treatment process.................................................

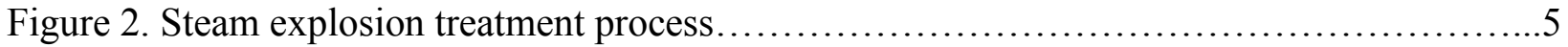

Figure 3. Micro explosion processing equipment..................................... 6

Figure 4. The working states of micro explosion device................................6

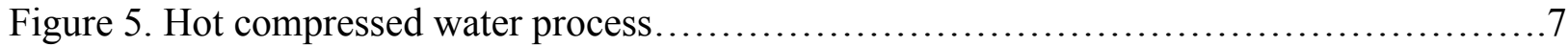

Figure 6. Distribution of macro, micro, and mesospores for selected softwoods................11

Figure 7. Cross-section view of untreated birch..................................... 12

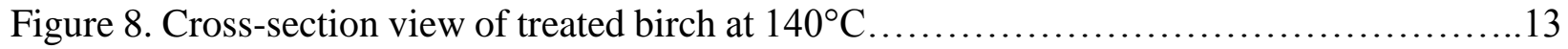

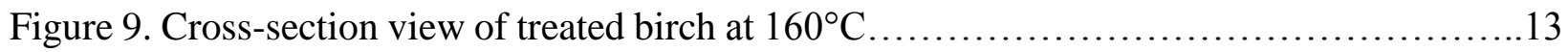

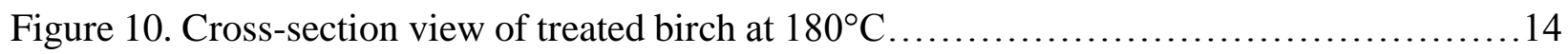

Figure 11. Ray parenchyma cells and earlywood tracheids of an untreated fir..........................14

Figure 12. Collapses on pit membranes (a) and splits between pit borders and tracheid walls (b) in

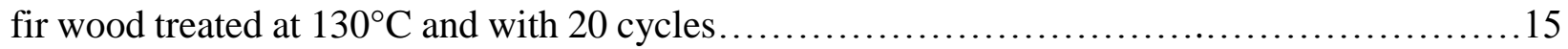

Figure 13. Splits in cross field pits of ray parenchyma cells and latewood tracheids (a) and damages on tracheid walls (b) in fir treated at $160^{\circ} \mathrm{C}$ with 10 cycles.................................. 15

Figure 14. (a) Cutting pattern of the discs from a log (b) cutting pattern of the cubic samples from

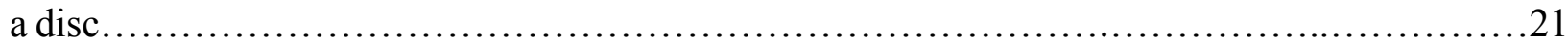

Figure 15. Yellow-poplar control samples (upper left) and $\mathrm{HCW}$ treated samples in $100^{\circ} \mathrm{C}$ (upper

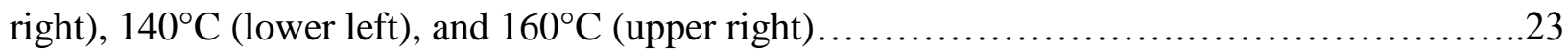

Figure 16. temperature and pressure as a function of time over the period of hydrothermal

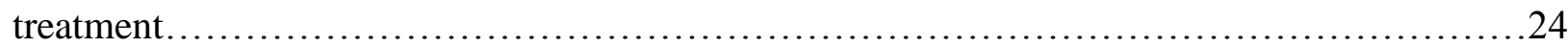

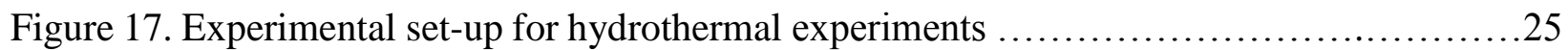

Figure 18. Instron machine for compression test....................................27

Figure 19. MC (dry-basis) (mean \pm standard error) of untreated and hydrothermally treated yellowpoplar. .40

Figure 20. Volumetric shrinkage (mean \pm standard error) of untreated and hydrothermally treated yellow-poplar.

Figure 21. Green specific gravity (mean \pm standard error) of untreated and hydrothermally treated yellow-poplar. .44 
Figure 22. Oven-dry specific gravity (mean \pm standard error) of untreated and hydrothermally treated yellow-poplar..................................................................

Figure 23. Total porosity (mean \pm standard error) of untreated and hydrothermally treated yellow-

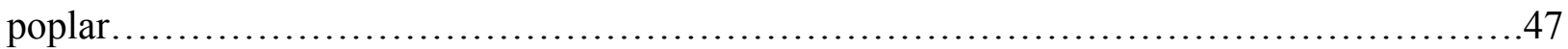

Figure 24. Water absorption (mean \pm standard error) of untreated and hydrothermally treated

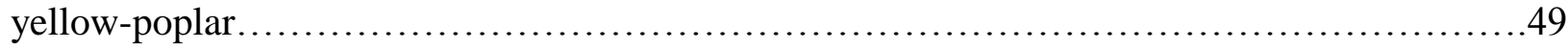

Figure 25. Volumetric swelling (mean \pm standard error) of untreated and hydrothermally treated

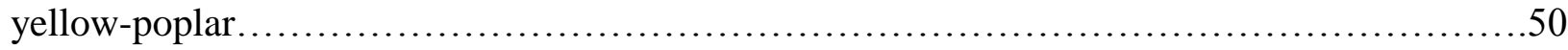

Figure 26. Modulus of elasticity (mean \pm standard error) of untreated and hydrothermally treated yellow-poplar................................................................ 52

Figure 27. Compression strength (mean \pm standard error) of untreated and hydrothermally treated

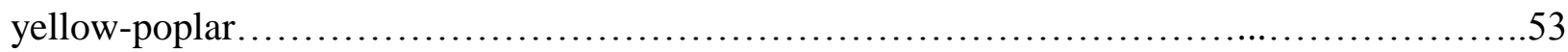

Figure 28. Moisture ratio as a function of time elapsed during drying at $105^{\circ} \mathrm{C}$ for untreated and hydrothermally treated samples of yellow-poplar.......................................55

Figure 29. Drying rate as a function of moisture ratio for untreated and hydrothermally treated samples of yellow-poplar........................................................ 57

Figure 30. Overall liquid diffusion coefficient (mean \pm standard error) of untreated and hydrothermally treated yellow-poplar. 


\section{List of Tables}

Table 1. Frequency of juvenile wood in different replications..............................36

Table 2. MC (dry basis) and volumetric shrinkage (mean \pm standard error) of untreated and

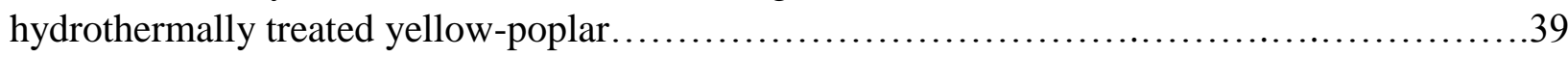

Table 3. Green specific gravity and oven-dry specific gravity (mean \pm standard error) of untreated and hydrothermally treated yellow-poplar...

Table 4. Total porosity (mean \pm standard error) of untreated and hydrothermally treated yellow-

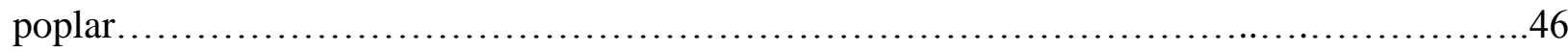

Table 5. Water absorption and volumetric swelling (mean \pm standard error) of untreated and hydrothermally treated yellow-poplar............................................. 48

Table 6. Modulus of elasticity and compression strength (mean \pm standard error) of untreated and hydrothermally treated yellow-poplar.

Table 7. Drying time (mean \pm standard error) of untreated and hydrothermally treated yellow-

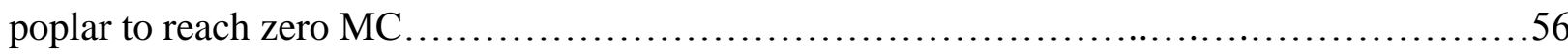

Table 8. Overall liquid diffusion coefficient (mean \pm standard error) of untreated and hydrothermally treated yellow-poplar. 


\section{Chapter 1. Introduction and Background Knowledge}

\subsection{Problems Related to Wood Drying}

Wood drying consumes about $40 \%$ to $70 \%$ of the total energy consumed in wood manufacturing (Zhang and Liu, 2006). For this reason, much effort has been made on fast drying method with high drying quality. Vacuum drying is a good example, which can achieve drying rates 3 to 17 times faster than conventional drying (Ressel, 1994; Harris and Taras, 1984). Beside improvement of drying process itself, numerous studies have been devoted to treat wood prior to drying in order to enhance drying quality. Of all various modification processes, thermal treatment is by far the most commercially advanced that has long been known as a prospective effective method to boost dimensional consistency, improve decay resistance (Hill, 2006), and improve permeability by destroying pore blockage caused by tylosis in wood.

Tylosis is observed in several hardwood species, such as, white oak, black locust, and American black walnut due to accumulation of deposits and extractives during transition from sapwood to heartwood (Hoadley, 1990; Hoadley, 1980). Tylosis is an undesirable phenomenon, which reduces permeability and diffusion coefficient and consequently drying rate, by blocking the pathway of liquid water and vapor to move through wood medium. Several pretreatments have been offered to solve this issue. Alexiou et al. (1990) did pre-steaming treatment on eucalyptus heartwood before conventional drying and observed that it increased drying rate by $7-16 \%$. In addition, volumetric shrinkage was not changed by pre-steaming. Dashti et al. (2012a) did microwave treatment on aleppe oak and observed distortion of the tylosis structure in the heartwood, resulting in a considerable climb in the air permeability. He et al. (2014) reported that ultrasound treatment prior to vacuum drying increased drying rate by opening the bordered pits and reducing the amount of extractives on the inner wood pores. 
Like tylosis, wet pockets (wetwood) is a growth defect frequently observed in some wood species like sub-alpine fir (about $40 \%$ of fir boards). Wetwood is of high MC and concentration of bacteria, showing different physical, chemical, and biological properties than normal wood. Fir lumber containing wet pocket is very difficult to dry, creating highly stressed lumber with wide variations in final moisture content (MC) (Hartley et al., 1997). In addition, more extractives (Bourchier, 1967 and Haygreen and Wang, 1966) and more aspirated and encrusted pit membranes on tracheid cell walls (Bauch, 1973 and Wilcox and Schlink, 1971) were observed in wetwood than normal wood. Steam explosion treatment had been applied to Japanese cedar (Kanagawa et al., 1992) and subalpine fir (Zhang and Cai, 2006) to mitigate wetwood related issues. Treated samples showed more uniform final MC than untreated samples after drying using conventional kiln (Cai, 2006).

Another factor which affects drying is presence of false heartwood. Red heartwood or false heartwood is a growth defect frequently occurs in beech trees. The reason of its occurrence is not clear. Presence of false heartwood decreases drying rate, increases shrinkage, and possibility of drying defects such as casehardening (Shahverdi et al., 2013). Steaming or specific drying schedules have been recommended as a remedy to mitigate issues related to false heart issue (Trenciansky and Hansmann, 2007).

\subsection{Various Physical Treatments Performed on Wood}

To improve physical properties (water absorption, dimensional stability, permeability and diffusivity, and mechanical strength) and decay resistance of wood, several treatments, for example, high-pressure steam (Dashti et al., 2012 a; Dashti et al., 2012 b; Sayar and Tarmian, 2013; and Peng et al., 2012), steam explosion (Zhang and Cai, 2006), ultrasonic treatment (He et al., 2013 and He et al., 2014), heat treatment (Rousset et al., 2011) have been reported. 
Another physical treatment involves use of ultrasound technology. Ultrasound technology is based on mechanical waves at a frequency beyond the threshold of human hearing, which is above 20 KHz (Chandrapala et al., 2013). In order to perform ultrasonic treatment, the material (wood) needs to be submerged in liquid medium such as water (Fernandes et al., 2008). Wood undergoes rapid succession of alternate compression and tension. Besides, ultrasound wave can create microcrack and very tiny cavitation, which might help eliminate strongly attached moisture from wood substance (Wan, 1992). He et al. (2013) performed ultrasonic treatment to improve quality of Chinese catalpa during vacuum drying. They reported that the ultrasonically treated $(0.05)$ samples took only $41 \mathrm{~h}$ to dry from $99 \%$ to $11 \%$ of $\mathrm{MC}$, compared to $52 \mathrm{~h}$ for the control specimens. Diffusion coefficients of the ultrasound treated samples at $0.05 \mathrm{MPa}$ were $2.91 \mathrm{X} 10^{-8}$ and $1.12 \mathrm{X}$ $10^{-8} \mathrm{~m}^{2} \cdot \mathrm{s}^{-1}$ beyond and below the FSP, respectively. The diffusion coefficients of the control samples were lesser than those of treated ones whether below or above FSP.

More recently, renewed interest has been found in heat treatment processes to improve wood quality due to growing demand for sustainable building materials and due to regulations diminishing the application of toxic chemicals. Some of the commercial heat treatments are following: thermowood (Finland), platoWood (Netherland), OHT-oil treatment (Germany), bois perdure (France), and rectification (France) (Esteves and Pereira, 2009). The typical range of the temperature for heat treatment of wood is from $160^{\circ} \mathrm{C}$ to $260^{\circ} \mathrm{C}$ in presence or absence of moisture. In some methods, a shielding gas like Nitrogen is applied to remove or minimize the effect of relative himidity (Militz, 2002).

\subsection{Hydrothermal Treatments}

Several researches were focused on heat treatment in presence of steam or water, also referred as hydrothermal treatments. Different types of hydrothermal treatment were applied to improve wood 
quality and drying process and consequently reduce energy consumption. Following are some examples: steam treatment (Peng et al., 2012; Sayar and Tarmian, 2013; Alexiou et al., 1990; and Dashti et al. (2012a), steam explosion (Cai, 2006 and Kanagawa, 1992), and micro-explosion (Ma et al., 2015).

\subsubsection{Steam Treatment}

Steam treatment is done in a laboratory steaming vessel equipped with heat and pressure indicators. Wood samples are placed inside the vessel and steam is injected into the vessel to reach desired temperature and pressure conditions. Samples are exposed to steam with desired temperature and pressure and kept inside the chamber for certain time (Peng et al., 2012) (Figure 1). After holding time, steam is gradually released.

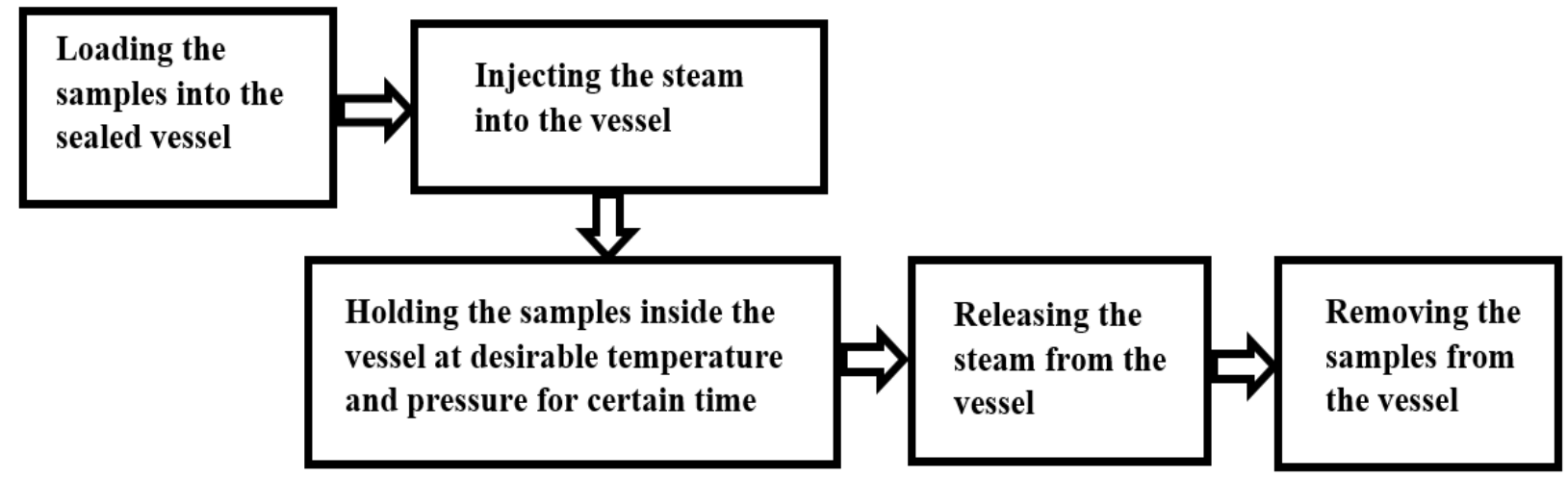

Figure 1. Steam treatment process.

\subsubsection{Steam Explosion Treatment}

Steam explosion treatment is another technique used to improve drying quality (Zhang and Cai, 2006; and Kanagawa, 1992). In this process, wood samples are placed in a chamber to be heated with steam, which builds up pressure inside the chamber. Once the temperature and pressure reach the desirable point, samples are kept inside the chamber for a certain period of time. Following the 
holding time, steam is released very rapidly in few seconds. Then, the steam-releasing valve is closed again and treatment cycle is repeated several times (Cai, 2006). Repeated treatment cycles lead to rupture of cell walls, thereby increasing porosity and mass transfer rate (Figure 2)

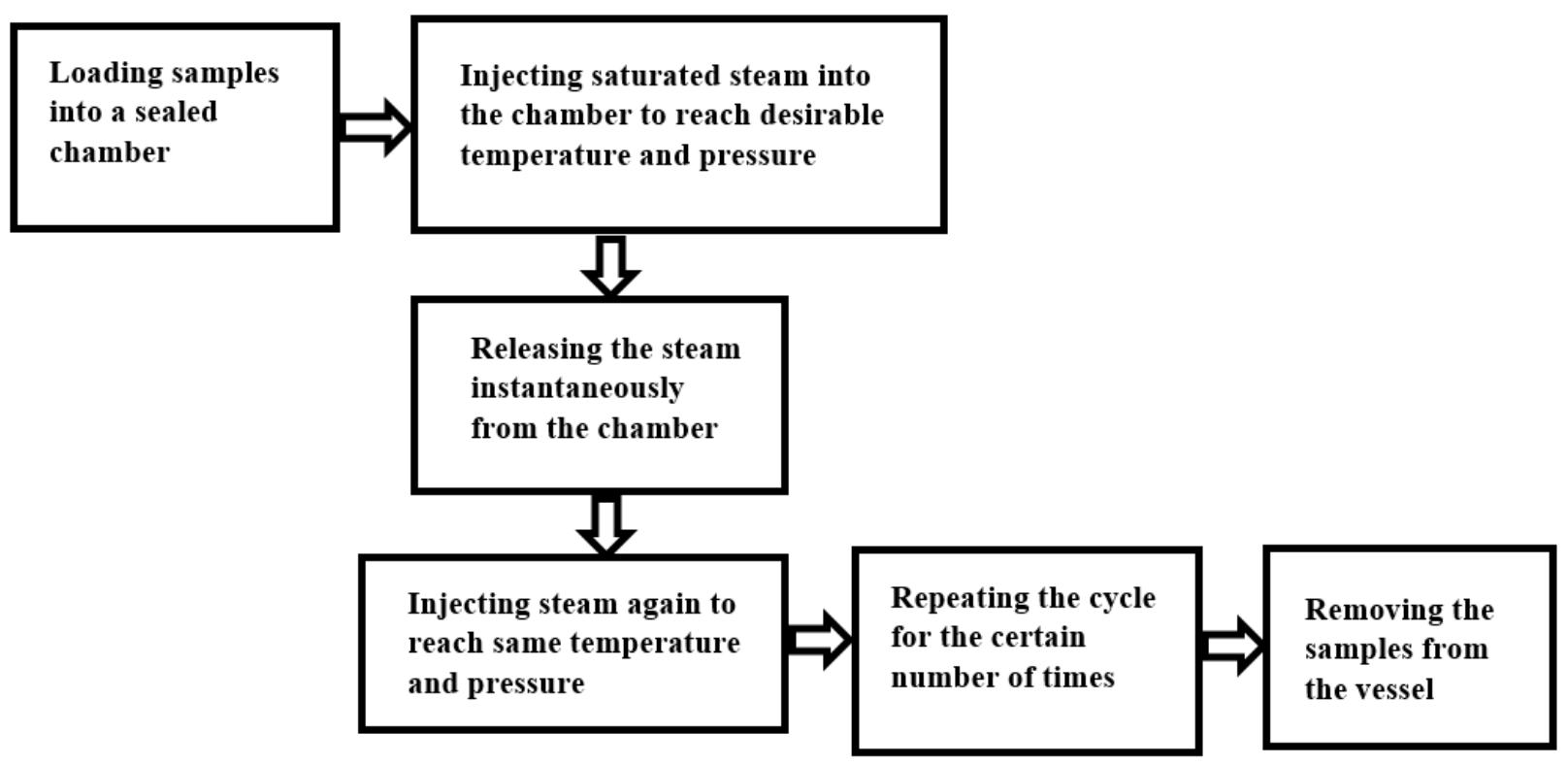

Figure 2. Steam explosion treatment process.

\subsubsection{Micro-Explosion Treatment}

More recently, micro-explosion technique is applied prior to wood drying. This technique is similar to steam explosion but safer and more convenient. In this process, specimens are placed inside a hermetical chamber. Bursts of high-pressure, room temperature air is injected inside the chamber. The pressure of the chamber is monitored using a pressure gauge located at the crest of the chamber. Following a quiescent state, the burst of air is rapidly ejected in a fraction of a second. The treatment cycle is repeated for a specified number of times (Figure 3 and 4) (Ma et al., 2016). 


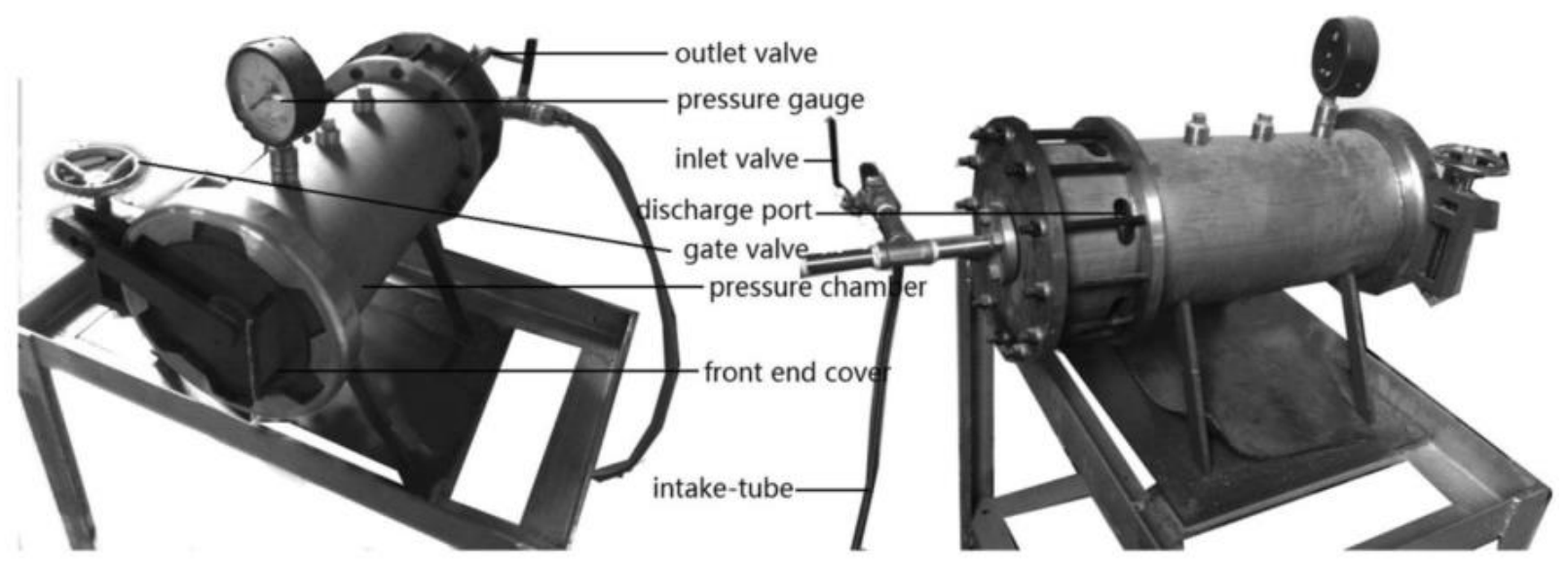

Figure 3. Micro explosion processing equipment (Ma et al., 2016).

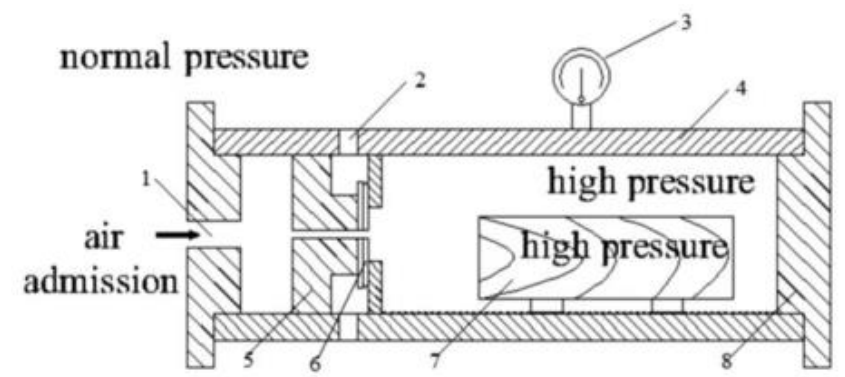

a Pressurized state

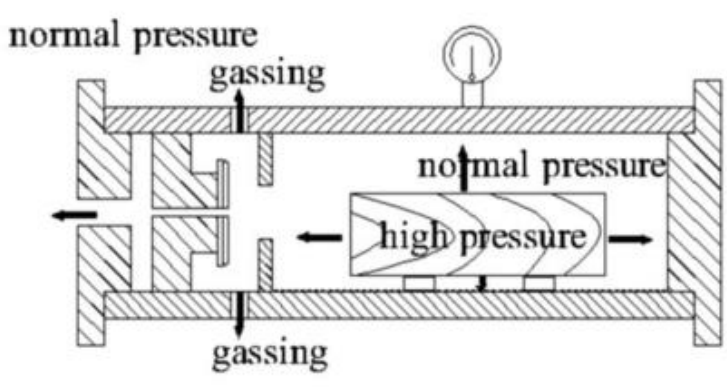

b Pressure relief

Figure 4. The working states of micro-explosion device: 1) inlet port, 2) outlet port, 3) pressure gauge, 4) chamber, 5) piston, 6) rubber gasket, 7) wood, and 8) front-end cover (Ma et al., 2016).

\subsubsection{Hot Compressed Water Treatment}

For hot compressed water treatment, wood samples are placed in an autoclave, filled up with distilled water, or buffered hot water with $\mathrm{pH}$ of 7 or 8 , and desirable holding time and temperature. Since the $\mathrm{pH}$ value of water medium changes during hydrothermal treatment, buffered hot water (pH 7 and 8) were used to keep $\mathrm{pH}$ of the medium constant over the period of hydrothermal treatment. Buffered hot water with $\mathrm{pH}$ equal to 7 comprised $411.75 \mathrm{ml} \mathrm{Na}_{2} \mathrm{Hpo}_{4} .2 \mathrm{H}_{2} \mathrm{O}(0.2 \mathrm{M})+$ 
$88.25 \mathrm{ml} \mathrm{C}_{6} \mathrm{H}_{8} \mathrm{O}_{7} . \mathrm{H}_{2} \mathrm{O}$; and with $\mathrm{pH}$ equal to 8 comprised $483.25 \mathrm{ml} \mathrm{Na} \mathrm{Hpo}_{4} .2 \mathrm{H}_{2} \mathrm{O}(0.2 \mathrm{M})+$ 13.75 $\mathrm{C}_{6} \mathrm{H}_{8} \mathrm{O}_{7} . \mathrm{H}_{2} \mathrm{O}$ (Figure 5) (Taghiyari et al., 2011).

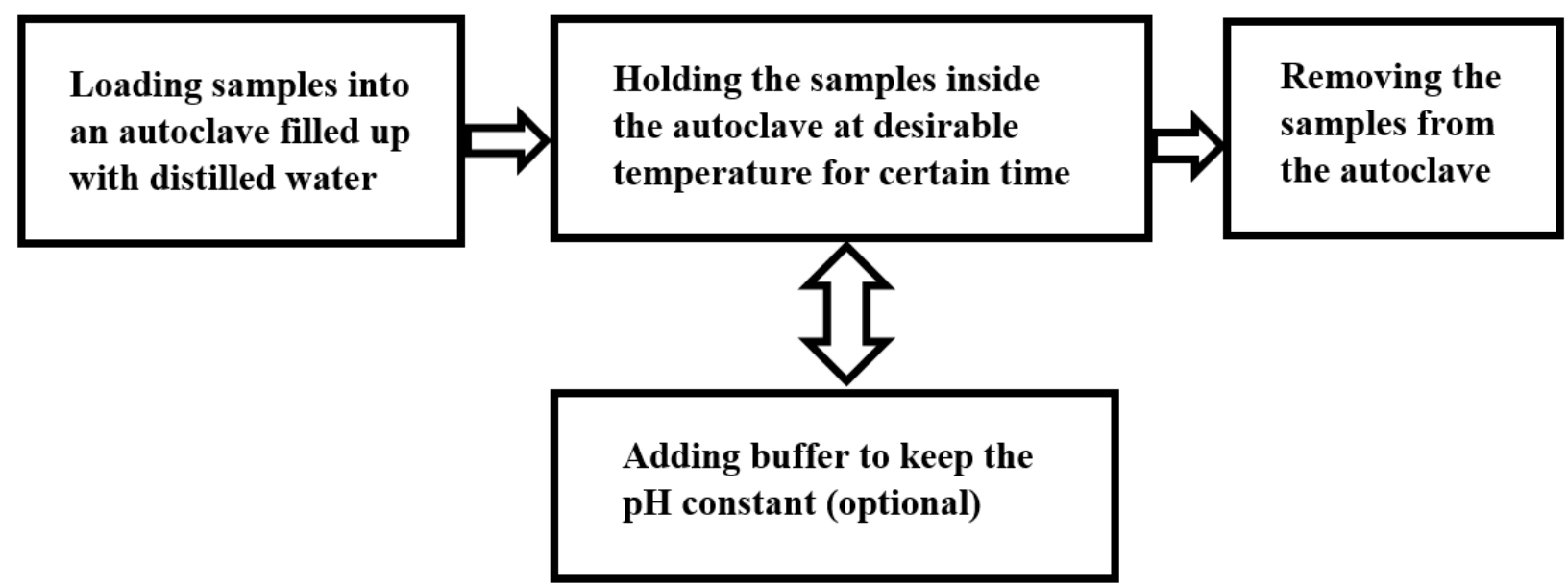

Figure 5. Hot compressed water process.

\subsection{Effect of Hydrothermal Treatment on Physical Properties and Drying Behavior}

Physical properties of wood have been classified into following six major categories: physical characteristics, mechanical properties, thermal properties, electrical properties, optical properties, and acoustical properties. The physical characteristics and mechanical properties are focus of current research.

Various types of hydrothermal treatments affect physical characteristics as well as mechanical properties and consequently drying behavior of wood. The influence of hydrothermal treatment on wood vary based on temperature, pressure, holding time, number of cycles, and medium.

\subsubsection{Effect of Hydrothermal Treatments on Physical Characteristics}

Physical characteristics of interest are moisture content, specific gravity, porosity, and shrinkage/swelling. It has been shown that steam treatment reduces MC of hardwoods. Peng et al. (2012) applied steam treatment on poplar at $100^{\circ} \mathrm{C}$ and $140^{\circ} \mathrm{C}$ and observed greater $\mathrm{MC}$ reduction 
after steaming at $140^{\circ} \mathrm{C}$ than $100^{\circ} \mathrm{C}$. They reported that steaming at $100^{\circ} \mathrm{C}$ mitigated $\mathrm{MC}$ of poplar boards of 2,4 , and $6 \mathrm{~cm}$ by $33.05 \%, 24.63 \%$, and $23.00 \%$, respectively; whereas, steaming at $140^{\circ} \mathrm{C}$ reduced $\mathrm{MC}$ of poplar boards of 2,4 , and $6 \mathrm{~cm}$ by $67.82 \%, 52.94 \%$, and $78.27 \%$, respectively. More reduction in MC took place when steaming was performed at $140^{\circ} \mathrm{C}$ than at $100^{\circ} \mathrm{C}$ because superheated steam at $140^{\circ} \mathrm{C}$ acted as a drying medium while at $100^{\circ} \mathrm{C}$ steam was effectively saturated and did not have the potential to gain extra moisture vapor. Similarly, Cai (2006) reported reduced MC after steam explosion treatment on subalpine fir in the temperature range of $120^{\circ} \mathrm{C}$ to $160^{\circ} \mathrm{C}$.

Zhang and Cai (2006) reported that only reduction in MC takes place as results of steam treatment, post kiln drying results in wood products with uniform moisture distribution. For example, they reported that samples treated at $160^{\circ} \mathrm{C}$ and 2.6 bar had standard deviation of $4.6 \%$ for $\mathrm{MC}$ whereas it was $7.4 \%$ for untreated samples.

Most steam explosion treated samples resulted in better dryability and more uniform moisture distribution after drying them in conventional kiln using conservative and accelerated schedules. Standard deviation of final MC after conservative drying schedule for control samples was $7.4 \%$ while it improved for mild steam explosion treated samples (5.8\%) and intensified steam explosion treated samples (4.6\%). In addition, standard deviation of final MC for mild (5.4\%) and intensified (3.8\%) steam explosion treated samples followed by accelerated drying schedule were lower than that of control samples (7.4\%) followed by accelerated drying schedule (Cai, 2006). Peng et al. (2006) performed steam treatment for $2 \mathrm{~h}$ on poplar species with $20 \mathrm{~mm}$ thickness and reported reduced MC. Rate of reduction in $\mathrm{MC}$ for the samples treated at $100^{\circ} \mathrm{C}$ and $140^{\circ} \mathrm{C}$ were 16.53 and $33.91 \% / \mathrm{h}$. 
Hydrothermal treatment also affects dimensional stability. For example, steam explosion treatment at $160^{\circ} \mathrm{C}$ (6.2 bars of pressure) followed by conservative drying schedule has shown thickness shrinkage and width shrinkage of $3.85 \%$ and $3.92 \%$, respectively, which were significantly greater than thickness shrinkage (2.57\%) and width shrinkage (2.73\%) of control samples. Likewise, steam explosion treatment at $160^{\circ} \mathrm{C}(6.2$ bars of pressure $)$ followed by accelerated drying schedule has shown thickness shrinkage and width shrinkage of $4.14 \%$ and $3.27 \%$, which in turn, were considerably greater the values of control samples. However, drying schedule (conservative and accelerated) did not show significant difference. Notwithstanding, milder treatments i.e. at $120^{\circ} \mathrm{C}$ ( 2 bars of pressure) and $130^{\circ} \mathrm{C}$ ( 2 bars of pressure) did not significantly change shrinkage values compared to control samples (Cai, 2006). Dundar et al. (2012) performed heat treatment at $180^{\circ} \mathrm{C}$ and $210^{\circ}$ for $3 \mathrm{~h}$ on Black pine (Pinus nigra Arnold). After $48 \mathrm{~h}$ of water immersion, the volumetric swelling of the control samples reported $13.88 \%$. Heat treatment at $180^{\circ} \mathrm{C}$ resulted in volumetric shrinkage of $9.96 \%$, which was considerably lower than the value of control sample. In addition, heat treatment at $210^{\circ} \mathrm{C}$ showed pronouncedly considerable reduced volumetric shrinkage $(7.81 \%)$.

Specific gravity or density is perhaps the most important feature in wood heat (hydrothermal) treatments which is affected mainly by loss of mass. Loss of mass, as a result of hydrothermal treatment depends on several factors such as wood species, heating medium, temperature, and treatment time (Esteves et al., 2009). Mazela et al. (2003) studied the mass loss of heat treated pine species (Pinus sylvesteris) at $160^{\circ} \mathrm{C}$, and $190^{\circ} \mathrm{C}$, and $220^{\circ} \mathrm{C}$ during 6 and $24 \mathrm{~h}$ in presence and absence of vapor. They observed similar mass loss in different heating media after $6 \mathrm{~h}$; however, after $24 \mathrm{~h}$ the mass losses in air is greater than in vapor especially at the temperatures of $190^{\circ} \mathrm{C}$ 
and $220^{\circ} \mathrm{C}$. Bourgois and Guyonnet (1988) claimed mass loss of maritime pine treated at $260^{\circ} \mathrm{C}$ was quite high, that was, $18.5 \%$ and $30 \%$ after treatment time of 15 and 60 min, respectively.

\subsubsection{Effect of Hydrothermal Treatments on Pore Characteristics}

Drying has remarkable impact on pore characteristics and consequently density and specific gravity of wood. Wood is a porous material with micropores, mesopores, and macropores present. The porosity of wood largely depends on the density and anatomy of the wood species. Typically, porosity or fractional pore volume of wood ranges from $54.29 \%$ to $80.41 \%$ for hardwoods having a green specific gravity in the range of 0.30 to 0.70 (Plotze and Niemz, 2011 and Siau, 1995). Compaction of bound water has been neglected in these calculations. Typically, wood has micropores $(<80 \mathrm{~nm})$, mesopores $(500-80 \mathrm{~nm})$, and macropores $(>500 \mathrm{~nm})$. The micropore volume varied from $1.6 \%$ to $4.8 \%$ for the 18 wood species tested (Weatherwax and Tarkow, 1968).

Plotze and Niemz, (2011) tested air dried samples of several ring porous, diffused porous, and softwoods for porosity and pore size distributions (Figure 6). On average, wood samples contain cumulative pore volume of $821 \mathrm{~mm}^{3} / \mathrm{g}$ and hardwoods had on average $60 \%$ of the pore volume of softwoods. While softwoods had low microporosity, the hardwoods showed varying combinations of all three types of pores; however, all the woods tested had mesopores below $50 \%$. High pore volume was observed for white alder, common birch, and sycamore maple hardwoods due to the presence of macropores (79\% to $90 \%$ ) as well as for Gavoon and Opepe hardwoods due to the presence of micropores (about $80 \%$ ). On average, the specific surface area for white alder, common birch, and sycamore maple hardwoods was $70 \mathrm{~m}^{2} / \mathrm{g}$ and total pore volume was 1173 $\mathrm{mm}^{3} / \mathrm{g}$. 


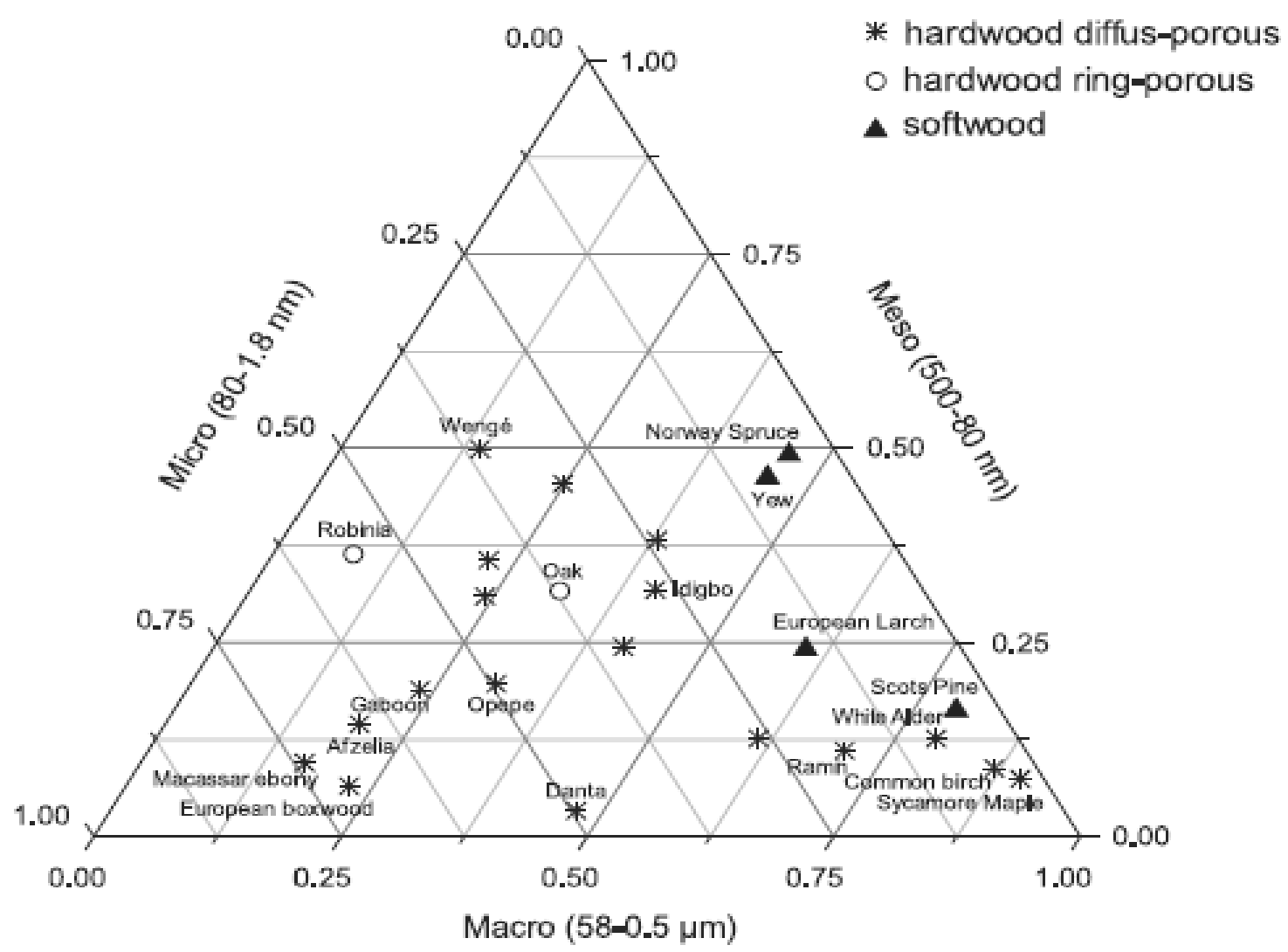

Figure 6. Distribution of macro, micro, and mesopores for selected softwoods (Plotze and Niemz, 2011).

It has been shown that wood when dried from green to oven-dry shrinks and loses not only total porosity but also changes pore size distribution (Park et al., 2006). Park et al. (2006) reported that the fiber wall begins to collapse starting with larger pores $(>100 \mathrm{~nm})$ followed by the sequential collapse of smaller pores $(<10 \mathrm{~nm})$ as the moisture ratio drops below $0.8 \mathrm{~g} / \mathrm{g}$ (g of water/g of dry wood) during drying. That is why the average pore diameter was $80 \mathrm{~nm}$ for moisture ratios above $0.8 \mathrm{~g} / \mathrm{g}$, which reduced to $20 \mathrm{~nm}$ when moisture ratio reached below $0.3 \mathrm{~g} / \mathrm{g} 10$. Further heat treating of oven-dry wood up to $200^{\circ} \mathrm{C}$ leads to decreased nano-pore shares due to further shrinkage of cell walls and flowing of lignin (glass transition temperature $165-170^{\circ} \mathrm{C}$ ) in the cell-wall pores and resulting reduced micropore spaces. Additional heat treatment after drying also reduced the FSP for all the woods tested. For example, the FSP for spruce decreased from $38.0 \%$ to $25.8 \%$ due to 
heat treatment at $200^{\circ} \mathrm{C}$. Therefore, to get most use of wood porosity, wood treatments should be performed on green wood to improve its physical characteristics and decay resistance.

\subsection{Effect of Hydrothermal Treatments on Anatomical Structure}

Biziks et al. (2013) provided a pioneering study on how anatomical properties (growth rings, cell wall, lumens, and fibers) of birch wood change during hydrothermal treatment which showed that hydrothermal treatment at $180^{\circ} \mathrm{C}$ for $1 \mathrm{~h}$ can break up the integrity of wood morphological structure. The study reported the results of hydrothermal treatment of birch wood at $140^{\circ} \mathrm{C}, 160^{\circ} \mathrm{C}$, and $180^{\circ} \mathrm{C}$, under pressure of 5-9 bars. lumen sizes were least affected during treatment. The lumen cross-section decreased by $2.3 \%$, while the tangential length of the lumen decreased by $0.5 \%$ and the radial length of the lumen decreased by $2.7 \%$. In contrast, the cross-sectional area of the fibers decreased from $1.0 \%$ at $140^{\circ} \mathrm{C}$ and $20.7 \%$ at $180^{\circ} \mathrm{C}$ mainly due to degradation of cell wall constituents (Figure 7, 8, 9 , and 10).

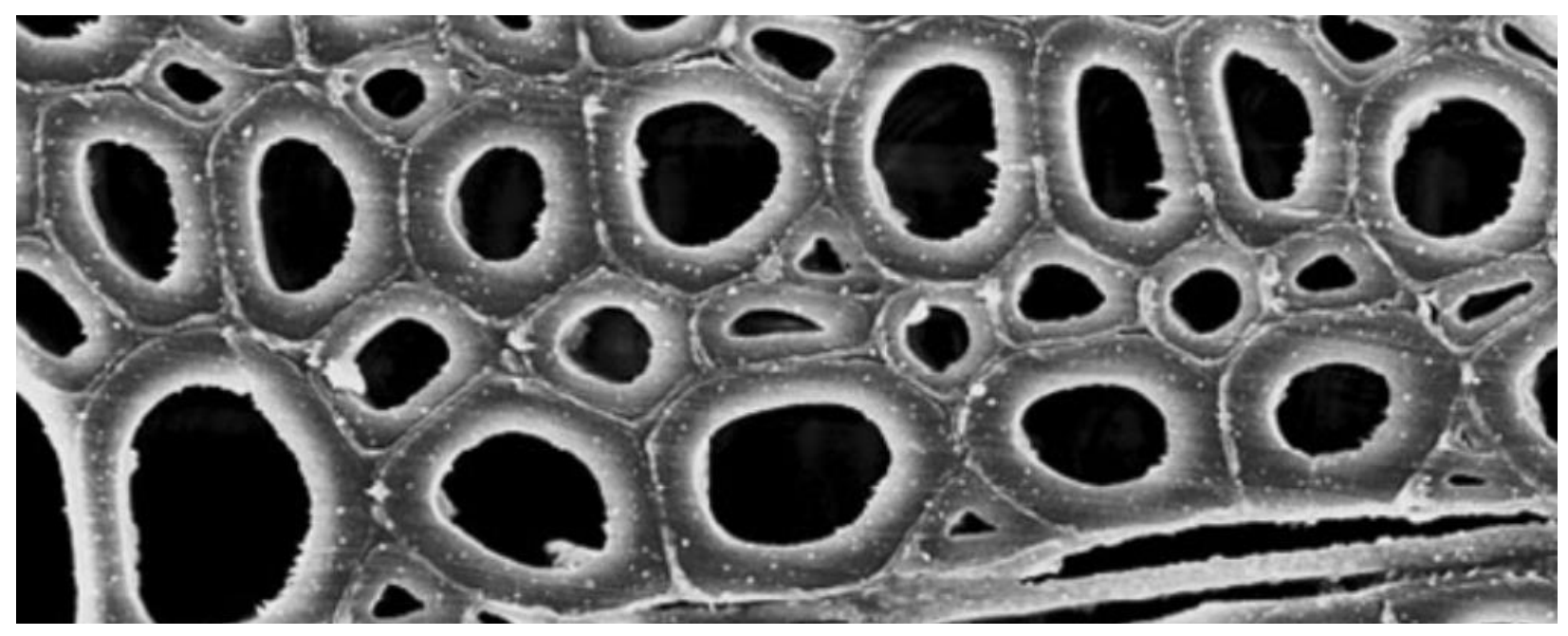

Figure 7. Cross-section view of untreated birch (Biziks et al., 2013). 


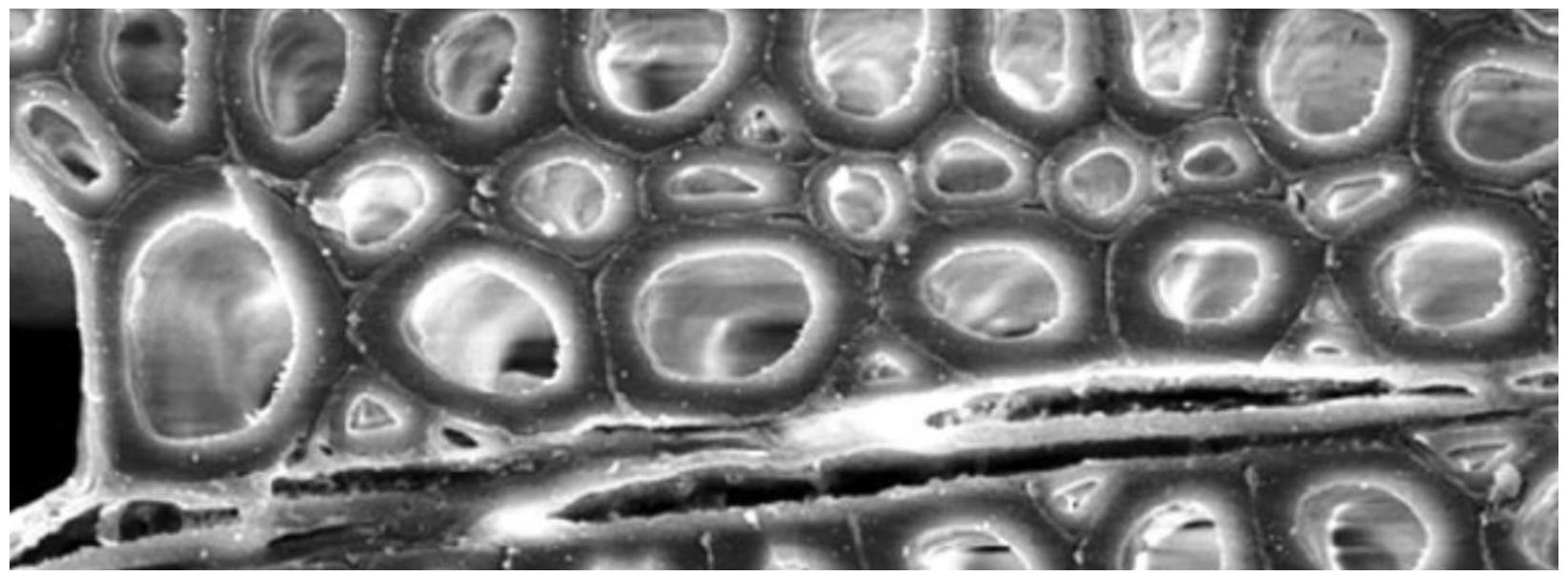

Figure 8. Cross-section view of treated birch at $140^{\circ} \mathrm{C}$ (Biziks et al., 2013).

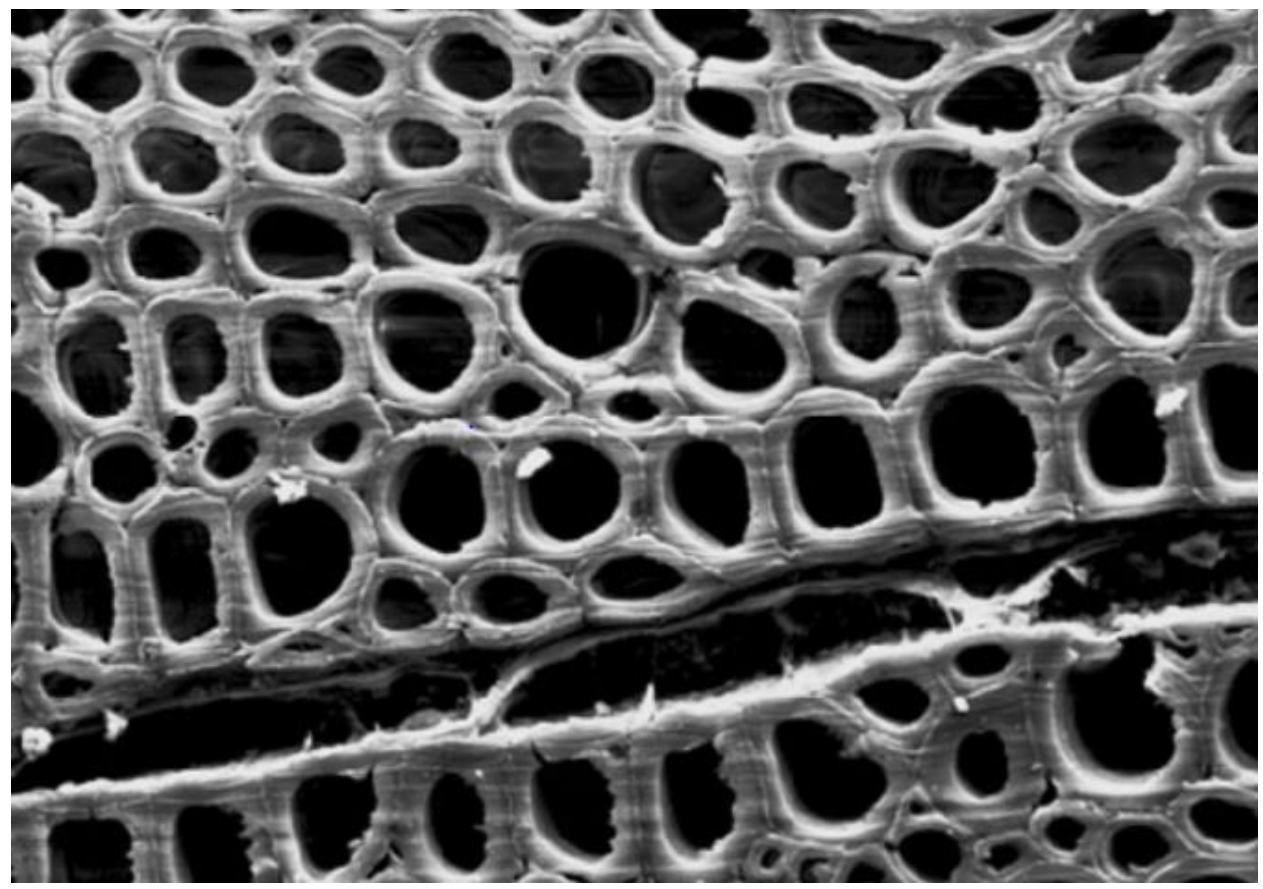

Figure 9. Cross-section view of treated birch at $160^{\circ} \mathrm{C}$ (Biziks et al., 2013). 


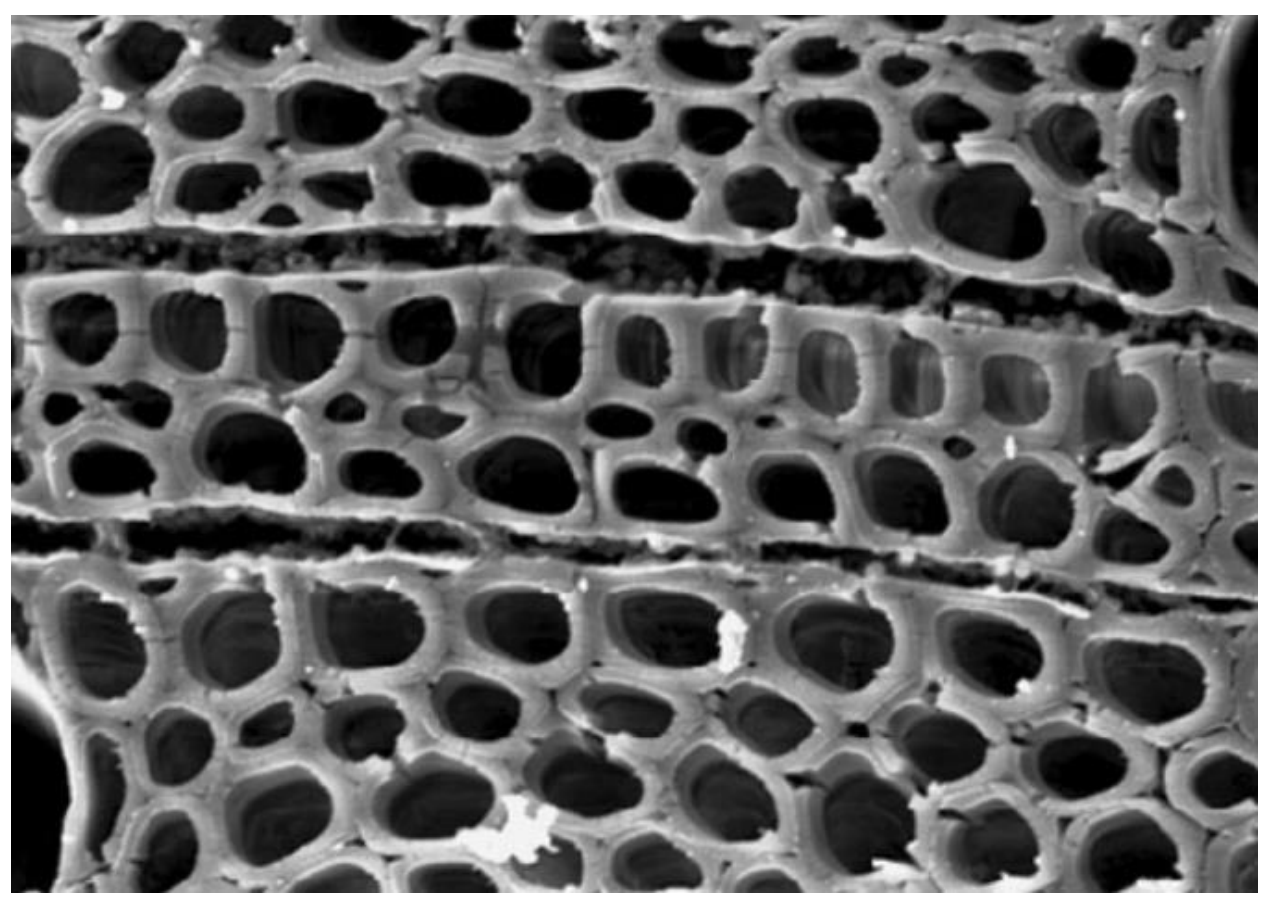

Figure 10. Cross-section view of treated birch at $180^{\circ} \mathrm{C}$ (Biziks et al., 2013).

While significant structural damage takes place at temperatures as high as $180^{\circ} \mathrm{C}$, some minor fractures in bordered pit membrane have been noticed at temperature of $130^{\circ} \mathrm{C}$, which steam explosion treatment was reported 20 times (Figures 11, 12, and 13) (Zhang and Cai, 2006).
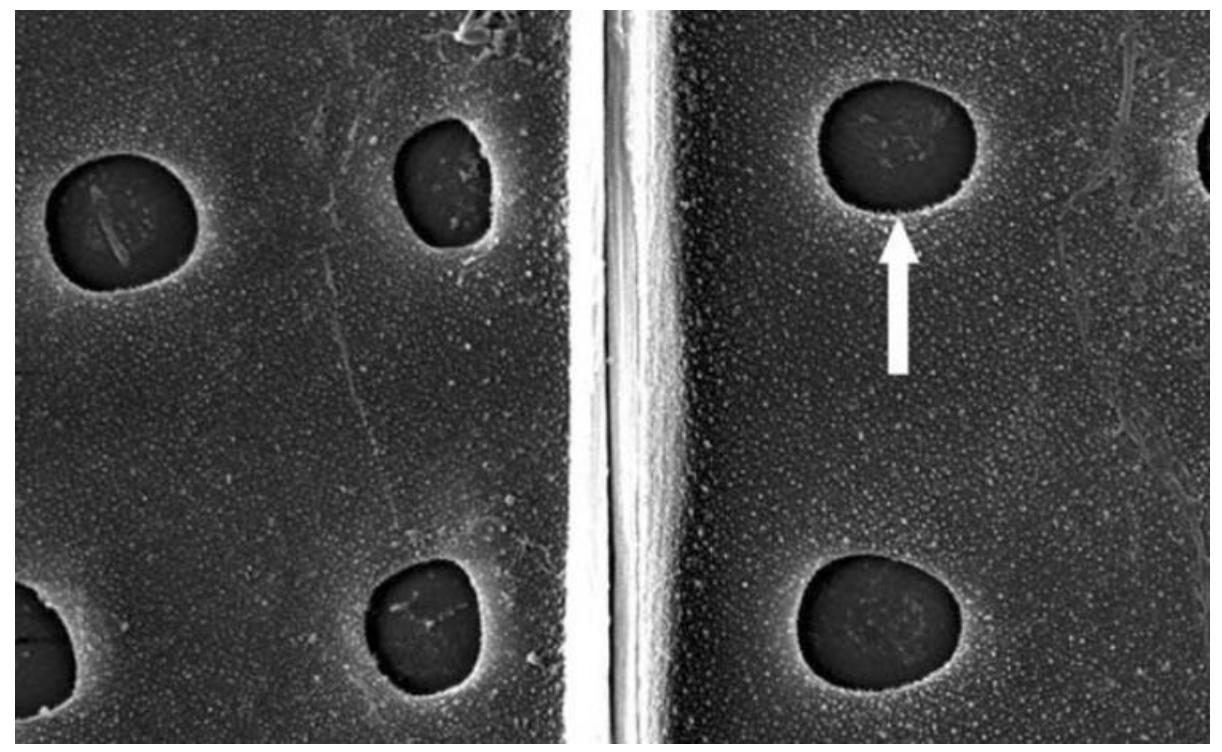

Figure 11. Ray parenchyma cells and earlywood tracheids of a untreated fir (Zhang and Cai, 2006). 


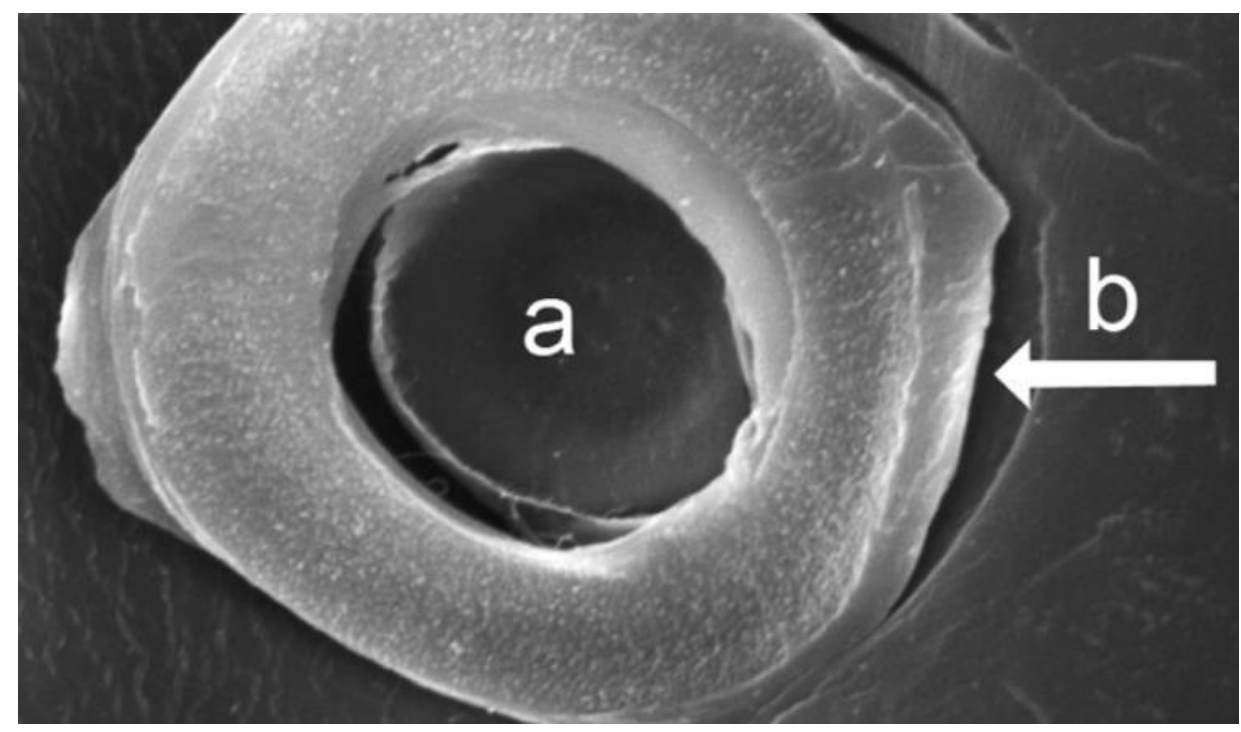

Figure 12. Collapses on pit membranes (a) and splits between pit borders and tracheid walls (b) in fir wood treated at $130^{\circ} \mathrm{C}$ with 20 explosion cycles (Zhang and Cai, 2006).

In fact, about $6 \%$ to $13 \%$ samples treated at $160^{\circ} \mathrm{C}$ through steam explosion collapsed during posttreatment kiln drying, which essentially indicated that the treatment significantly altered cell walls (Figure 13) (Zhang and Cai, 2006).

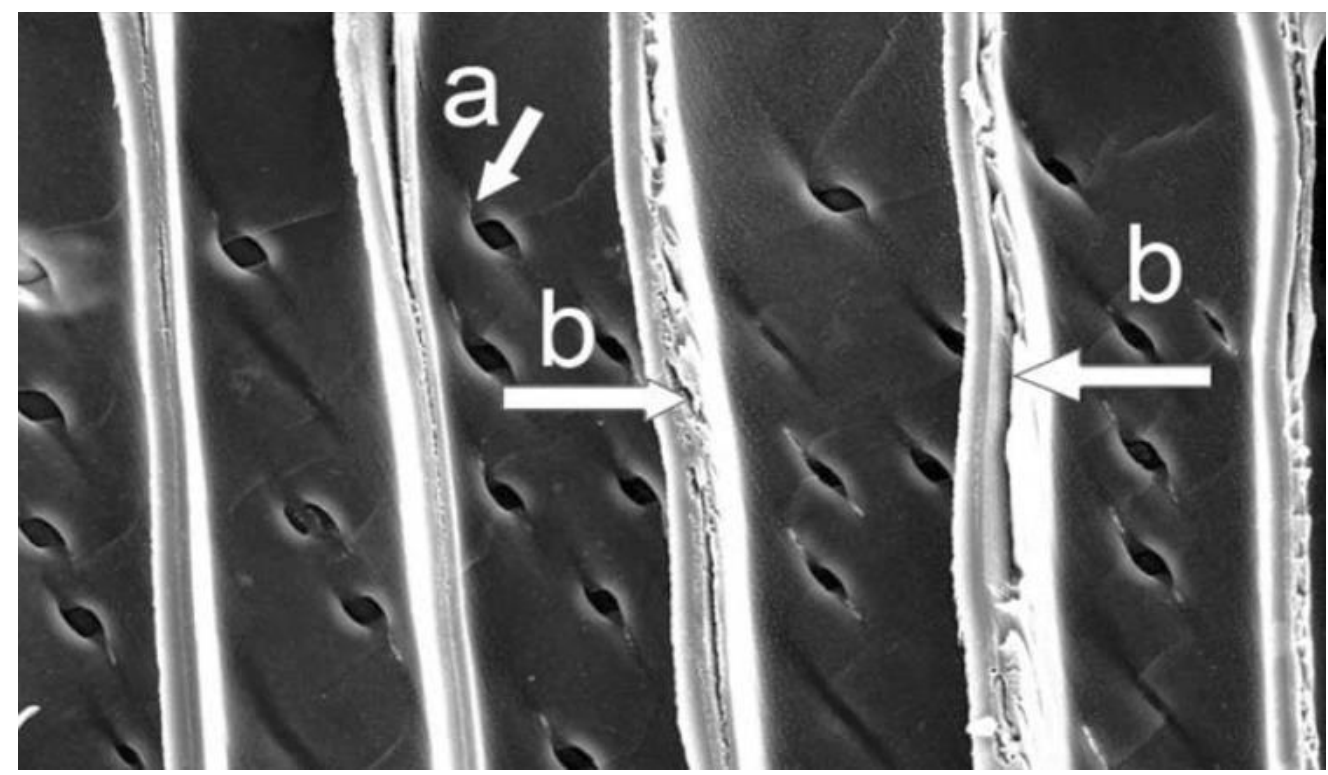

Figure 13. (a) Splits in cross-field pits of ray paranchyma and latewood tracheids (a) and damages on tracheid walls (b) in fir treated at $160^{\circ} \mathrm{C}$ with 10 cycles (Zhang and Cai, 2006). 


\subsection{Effect of Hydrothermal Treatments on Mechanical Properties}

Mechanical properties of wood are principally divided into three groups including elastic properties, strength properties, and frictional properties. Hydrothermal treatments can influence mechanical properties of which modulus of elasticity (MOE) and modulus of rupture (MOR) are discussed here.

Steam explosion contributed to significant reduction in both MOE and MOR of wood samples. Cai (2006) reported that the MOE for the control samples was $8205 \mathrm{MPa}$, which reduced to 6619 $\mathrm{MPa}$ for samples, which were treated at $160^{\circ} \mathrm{C}$. Likewise, the MOR reduced from 34.07 MPa to 18.89 MPa for the steam treatment.

In another research, Zhang and Cai (2006) reported that the MOE for control samples (fir) (conventional kiln drying) was $8205 \mathrm{MPa}$, which became which became 8274, 8067, 8136, and $6619 \mathrm{MPa}$ for the samples treated at $120^{\circ} \mathrm{C}, 130^{\circ} \mathrm{C}$, and $160^{\circ} \mathrm{C}$

\subsection{Effect of Hydrothermal Treatments on Drying Behavior and Diffusion Coefficient}

Wood drying is considered as the costliest process in wood industry; hence, decrease in wood drying time as a mean to saving in energy consumption and consequently drying expenses, plays an incredible role in this industry (Zhang and Liu, 2006). It is also worth noting that minimization in drying time does not have to lead to wood quality reduction. Drying time is controlled by several factors, among which moisture diffusion coefficient is a key parameter (Dashti et al., 2012a). Diffusion coefficient proposes a functional way to estimate the drying time in the domain of bound water and final moisture profile in wood. Thus, it is possible to convert a moisture based drying schedule to a diffusion time schedule, which has been successfully applied for a number of softwood species (Tarmian et al., 2012). 
Steam treatment from $120^{\circ} \mathrm{C}$ to $160^{\circ} \mathrm{C}$ has reportedly improved mass transfer properties, especially air permeability, of fir samples (Dashti et al., (2012b). However, treatment at high temperature $\left(200^{\circ} \mathrm{C}\right)$ mass diffusivity (property of mass migration under the effect of a concentration gradient) has been reported to reduce significantly due to chemical modification of cell wall (Rousset et al., 2004).

Perhaps, wood permeability influences surface moisture evaporation and internal moisture (Torgovniko and Vinden, 2009), which in turn control drying rates. Peng et al. (2009) compared drying rate of control, steam treated at $100^{\circ} \mathrm{C}$, and steam treated at $140^{\circ} \mathrm{C}$ for poplar and Manchurian walnut. They reported that overall drying rates decreased linearly with reduction in MC; however, untreated samples dried faster than the treated ones. They reported that below $25 \%$ of MC, drying rates of untreated samples decreased faster than those of treated ones. In other words, below FSP, drying rates of treated samples had been higher than those of control samples for both species because of two reasons. First, there is not enough free water below FSP to block the capillary pores which render water vapor transport more rapidly. Second, steam treatments enhance gas permeability of wood by damaging bordered pits and aspirated pits (Lu et al., 1994). Therefore, total drying time of poplar boards $\left(6 \mathrm{~cm}\right.$ thickness) for untreated and treated at $140^{\circ} \mathrm{C}$, were $102 \mathrm{~h}$ and $74 \mathrm{~h}$, respectively. Likewise, steam explosion and microexplosion treatment has shown significant improvement in dryability of subalpine fir lumber because it breaks down the bordered pits among earlywood tracheids (Cai, 2006; Zhang and Cai, 2006; Ma et al., 2015 and Ma et al., 2016). Ma et al. (2016) treated poplar samples five times with pressure of 1.0 MPa followed by oven-drying at $103 \pm 2{ }^{\circ} \mathrm{C}$. Untreated samples were dried similarly to make comparisons. Results revealed that drying rate of treated samples was noticeably greater than that of control ones above FSP; whereas, drying rate of treated samples below FSP was increased 
inconspicuously and even reduced for the specimens with $\mathrm{MC}$ of $70 \%$ and $30 \%$. In general, increase of drying rate (above and below FSP) and effective water diffusion coefficient were discovered (Ma et al., 2015).

In another research, Sayar and Tarmian (2013) quantified calculated vapor diffusion coefficients. They performed 12 sets of steam treatment on poplar to investigate the effect of hydrothermal pretreatment on water vapor diffusion coefficient. Experiments were done at four different temperatures of $120^{\circ} \mathrm{C}, 140^{\circ} \mathrm{C}, 160^{\circ} \mathrm{C}$, and $180^{\circ} \mathrm{C}$ and three different holding time of 1,2 , and 4 h. Diffusion coefficients were measured using Fick's law of diffusion in steady-state conditions. Results disclosed that increasing treatment temperature from $120^{\circ} \mathrm{C}$ to $140^{\circ} \mathrm{C}, 160^{\circ} \mathrm{C}$, and $180^{\circ} \mathrm{C}$ did not significantly affect diffusion coefficients of the treated specimens. Likewise, increasing treatment time from 1 to 2 , and from 2 to $3 \mathrm{~h}$ did not show significant influence on diffusion coefficients of the treated specimens. However, diffusion coefficients were in the range of $1.34 \times$ $10^{-9}$ to $1.90 \times 10^{-9} \mathrm{~m}^{2} \mathrm{~s}^{-1}$ for control samples. The vapor diffusion coefficients for the steam treated samples were in the range of $0.14 \times 10^{-9}$ to $0.59 \times 10^{-9} \mathrm{~m}^{2} \mathrm{~s}^{-1}$. In a nutshell, resistance to water vapor diffusion significantly increased as results of steam treatment. Similarly, Ma et al. (2015) reported effective water diffusion of treated samples to be $4.75 \times 10^{-9} \mathrm{~m}^{2} \cdot \mathrm{s}^{-1}$ and $0.8 \times 10^{-9} \mathrm{~m}^{2} \cdot \mathrm{s}^{-1}$ for control samples.

\subsection{Effect of Hydrothermal Treatments on Chemical Make-up}

Hydrothermal treatment is performed under either steam medium or hot-compressed water medium. While steam treatment facilitates reactions in wood in vapor-phase, hot compressed water treatment under sub-critical conditions might change wood ultrastructure differently because it promotes reactions and mass transport in liquid-phase. Fourier transform infrared spectroscopy (FTIR) analysis of combined hydrothermal and dry heat treated wood showed that various 
temperatures and media created different changes in wood components. (Tjeerdsma and Militz, 2005) analyzed beech and scots pine using FTIR to investigate chemical changes happened to wood components after two-step heat treatment including first moist condition at $165^{\circ} \mathrm{C}$ to $195^{\circ} \mathrm{C}$ in $\mathrm{pH}$ of 5.5 (adding sodium acetate solution) and secondly dry condition at $180^{\circ} \mathrm{C}$ (using continuous $\mathrm{N}_{2}$ gas flow). Results showed acetyl groups were mostly found to be cleaved over high temperature treatment of the wood. In contrast, only partial deacetylation occurred at moderate treatment temperature. Esterification reactions, on the other hand, occurred in dry conditions at raised temperature. Esterification contributes in hygroscopicity reduction of wood and consequently enhanced durability and dimensional stability. Nonetheless, cross-linking reactions known to occur during thermal treatment plays more pivotal role than esterification in reduction of hygroscopicity.

\subsection{Synthesis of literature Review and Objective}

It is anticipated that hydrothermal treatment and steam treatment should have different effect on physical characteristics and drying behavior of wood because the former one facilitates wood reactions in liquid medium while the latter one promotes reactions in vapor medium. Liquid water and vapor move differently through wood medium. Liquid water movement is dominated by capillary (convective movement) while vapor water movement is dominated by diffusion, which is more random and less uniform (Siau, 199 and Siau, 1984). Therefore, objective of this research was to compare effect of hot-compressed water $(\mathrm{HCW})$ and steam treatments at $100^{\circ} \mathrm{C}$ and $140^{\circ} \mathrm{C}$ on the selected physical characteristics, mechanical properties (modulus of elasticity and compressive strength) and drying behavior of yellow-poplar. 


\section{Chapter 2. Materials and Methods}

\subsection{Selection of Wood Species}

Yellow-poplar (Liriodendron tuilifera) was selected as test species because sufficient research data on its mechanical and physical properties is available in the literature and it is widely used by the wood industry (Wiemann, 2010). Yellow-Poplar is abundantly available in West Virginia and Appalachian forest. An investigation carried out on the number of species encountered on 30 active timber harvests in West Virginia by Grushecky et al. (2012). They reported that Yellow-poplar is the most prevalent timber harvested $(25.5 \%)$ in West Virginia, followed by red maple (14.0\%) and black/red oak (9.6\%). In addition, this investigation considered number of prevalent species trees measured on 30 active timber harvest in West Virginia during 2008. According to the report, yellow-poplar is one of the most percentage of standing trees $(25.5 \%)$ followed by white/chestnut oak $(18.3 \%)$ and soft maple includes red maple (14.0\%). Typically, $96.4 \%$ of a pine tree (wood volume) and $91.0 \%$ of a yellow-poplar tree (wood volume) are utilized.. Nevertheless, yellowpoplar is of $8^{\text {th }}$ rank in terms of land utilization (97.6\%), standing behind hard maple $(99.4 \%)$. On the other hand, the vast majority of yellow-poplar merchandized in West Virginia is devoted to sawlog $(45.6 \%)$, peeler $(26.2 \%)$, pulp $(13.8 \%)$, rail $(10.6 \%)$, and scragg $(1.2 \%)$. Also, $2.6 \%$ of Yellow-poplar goes waste (Grushecky et al., 2012).

\subsection{Procurement and Processing of Raw Material}

Freshly cut log of Yellow-poplar (diameter $=175 \pm 15 \mathrm{~mm}$, length $=900 \pm 20 \mathrm{~mm}$ ) were procured from the West Virginia University (WVU) Research Forest. Immediately after procuring, ends of the logs were coated twice with paraffin and then kept inside a plastic bag to avoid moisture loss prior to the sample preparation. 
Three discs with average thickness of $23 \pm 1 \mathrm{~mm}$ were cut from a procured fresh log. In addition, the discs were cut from same place to avoid any possible variation, which might happen due to longitudinal variability through the log (Figure 14a).

In the next step, 115 small rectangular specimens were cut from the heartwood part of three discs, of which 78 samples were used for the experiments. Samples were prepared based on the cutting pattern represented in Figure 14b. All the samples were visually inspected for presence of wood closer to pith. Therefore, samples were divided into two groups. All samples, which come from proximity to the pith (about first 15 growth rings) were placed in the first group. Second group included the samples, which did not come from the zone close to the pith. Most of the samples (67 out of 78) come from the second group and the rest of the samples (11 out of 78) come from the first group.
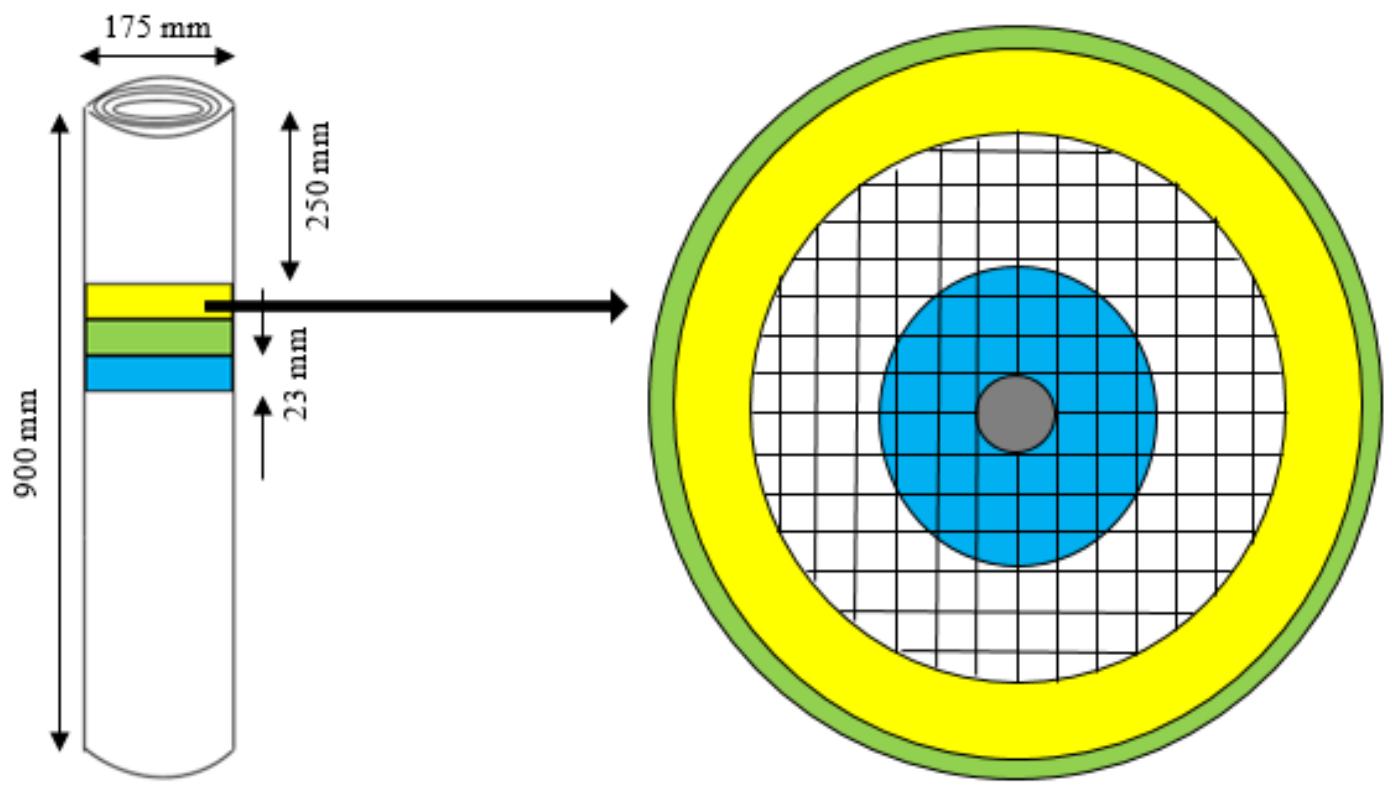

$\mathbf{a}$

b

Figure 14. (a) Cutting pattern of the discs from a log (b) cutting pattern of the cubic samples from a disc. 
Typical dimensions of the samples were $17.18 \mathrm{~mm}$ radial, $16.72 \mathrm{~mm}$ tangential, and $22.53 \mathrm{~mm}$ longitudinal directions. There was a concern that 11 samples used from the first group might contain juvenile wood due to nearness to the pith, which could affect some physical and mechanical properties (Bowyer et al., 2007). Therefore, Shapiro-Wilk statistical test was performed to check normality of each replication having some of those 11 samples. Each replication had 6 samples for measurements. To make sure that those 11 samples were not come from juvenile wood, specific gravity of them was compared with the rest of the samples. specific gravity has been known as the most important criterion to discern juvenile wood from mature wood (Bowyer et al., 2007).

All the slicing and cube cutting operations for sample preparations were performed using a bandsaw (Model: catalog number: 28-350, Rockwell, Pittsburgh, Pennsylvania,). The samples used for the experiment came from heartwood component of wood. Additionally, heartwood was chosen due to its richness in extractives, which was expected to redistribute during the hydrothermal treatment, making significant changes in physical characteristics and drying behavior (Hoadley, 1990; and Hoadley, 1980).

Total 78 rectangular blocks were cut and cleaned to remove any dust particles from its surface. Immediately after specimen preparation, they were held in deionized water to avoid loss of green moisture. To avoid microbial spoilage, distilled water was replaced at the interval of every $48 \mathrm{~h}$ prior to treatments. Six specimens were used as control. Other specimens were assigned random hydrothermal treatments, which were combination of following two treatment factors: Factor-1: medium (hot-compressed water or steam) and Factor-2: temperature $\left(100^{\circ} \mathrm{C}\right.$ and $\left.140^{\circ} \mathrm{C}\right)$. Each experiment was replicated three times. 


\subsection{Measurements}

Each sample was weighed with accuracy of $0.01 \mathrm{~g}$ using a weighing balance (Model: P603DMDS,

Denver instrument, USA). True volume of the samples was measured using a pycnometer (Model: Manual Multipycnometer, Qunatachrome, FL, USA). This instrument measures true volume of substance (excluding pore volume) using fluid (nitrogen) displacement method. Length, width, and depth dimensions of cubical samples were measured using caliper (Model: ROHS NORM 2002/95/EC, Digimatic, Mitutoyo, Japan) with accuracy of $0.01 \mathrm{~mm}$. Each dimension was recorded at three locations along a dimension to improve accuracy. Same sets of measurement were done three different times, i.e. prior to pretreatments, before drying treatment, and after drying treatment as well.

\subsection{Hot Compressed Water and Steam Treatments}

Combination of two treatment factors (medium and temperature) resulted in following four types of hydrothermal treatments: 1 . Hot-compressed water $(\mathrm{HCW})$ at $100^{\circ} \mathrm{C}$ (mild $\mathrm{HCW}$ ), steam at $100^{\circ} \mathrm{C}$ (mild steam), $\mathrm{HCW}$ at $140^{\circ} \mathrm{C}$ (intensive $\mathrm{HCW}$ ), and steam at $140^{\circ} \mathrm{C}$ (intensive steam). However, to determine the temperature for intensive treatment, several mock tests were performed earlier. Given the results of mock tests, $140^{\circ} \mathrm{C}$ was chosen because all the samples treated in $\mathrm{HCW}$ beyond $140^{\circ} \mathrm{C}\left(190^{\circ} \mathrm{C}, 170^{\circ} \mathrm{C}\right.$, and $\left.150^{\circ} \mathrm{C}\right)$ became dark colored, brittle, and fragile (Figure 15).

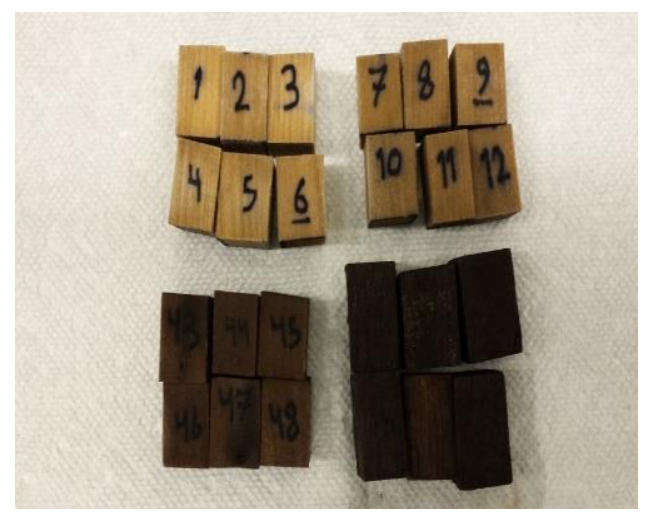

Figure 15. Yellow-poplar control samples (upper left) and $\mathrm{HCW}$ treated samples in $100^{\circ} \mathrm{C}$ (upper right), $140^{\circ} \mathrm{C}$ (lower left), and $160^{\circ} \mathrm{C}$ (upper right). 
All treatments were performed for a holding time of $1 \mathrm{~h}$. During the treatment, temperature and pressure were recorded. Temperature and pressure as functions of time are represented in Figure 16.

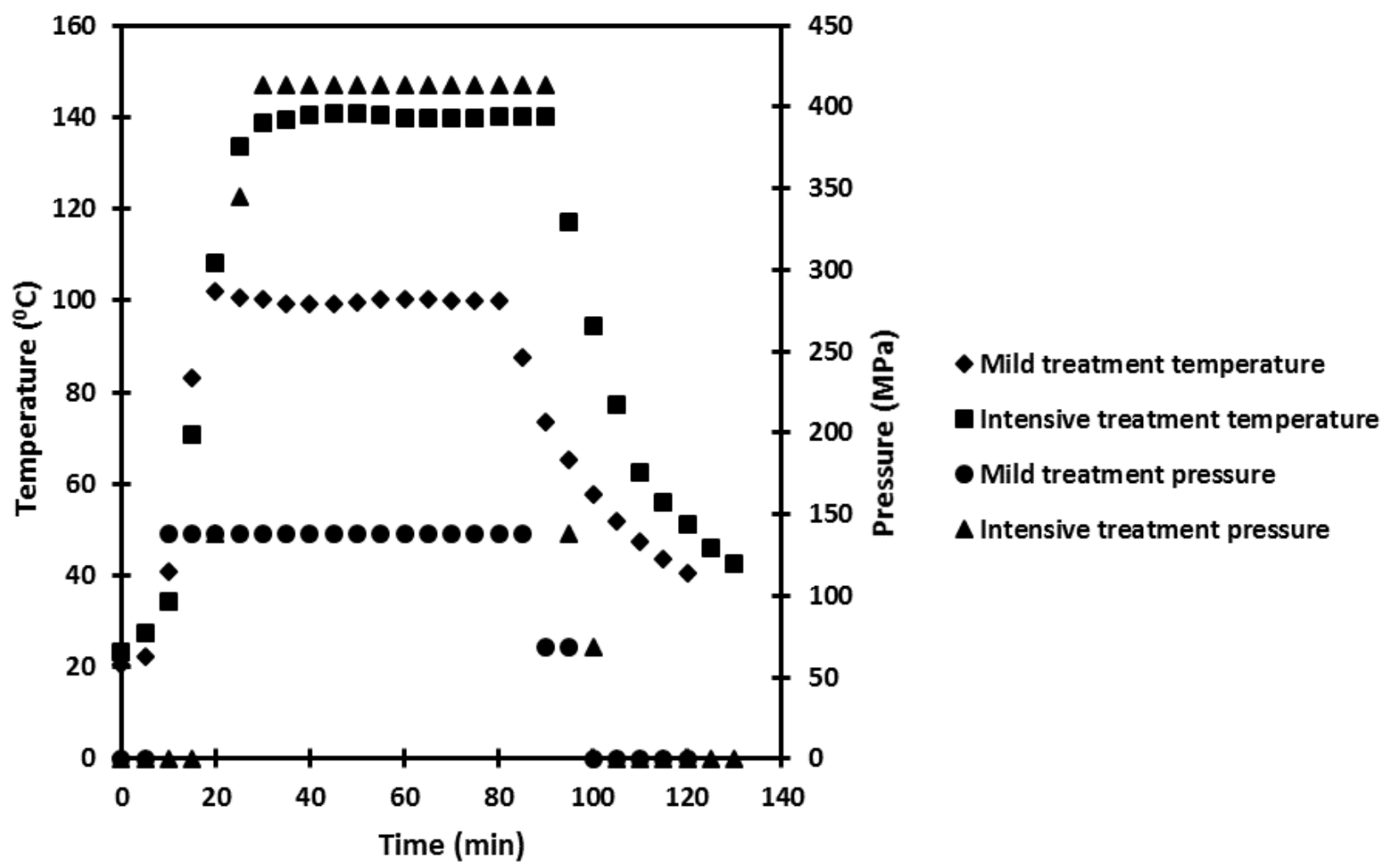

Figure 16. Temperature and pressure as a function of time over the period of hydrothermal treatment.

Hydrothermal treatments were performed inside a one-liter sealed pressure reactor (Model: 4500, Parr Instrument Company, Moline, IL, USA). The schematic of the parr reactor is represented in Figure 17. 


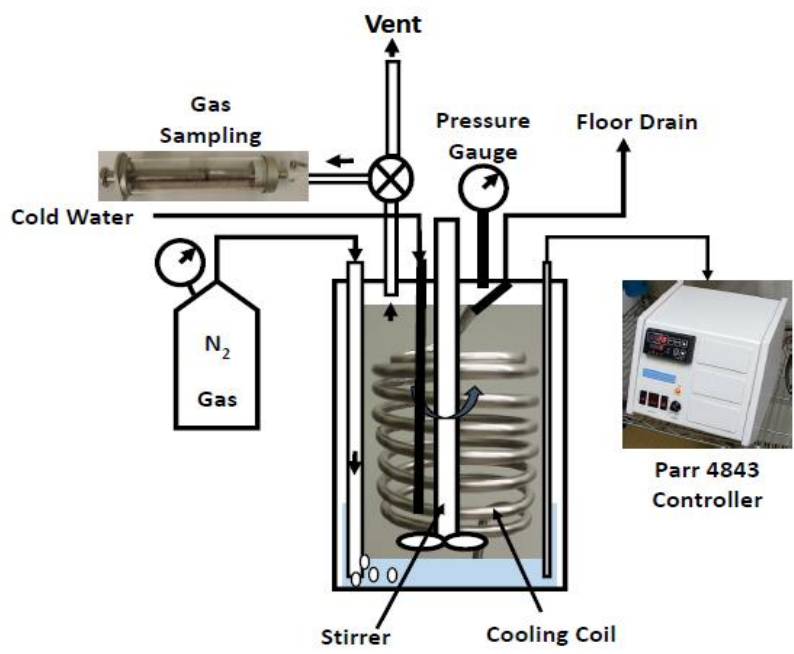

Figure 17. Experimental set-up (Singh and Sivanandan, 2014) for hydrothermal experiments.

For a typical HCW experiment, about six specimens were placed inside the pressure reactor. After that, distilled water was added to the reactor, approximately seven times of total six sample weight (Singh Seehra et al., 2015), to keep specimens submerged in water. The weight of the reactor containing wood specimens and water was recorded before and after each experiment. After that, the reactor was sealed and heated up to desired temperature, which was held for 60 min for all experiments.

To perform treatments in the steam medium, a perforated plate was placed inside the reactor vessel just above water table and all the specimens were placed on the peforated plate without touching water. After the hydrotehrmal treatment was complete, the reactor was allowed to cool-down to room temperature.

After hydrothermal treatment, all the six specimens were taken out of the vessel and surfaces were wiped with a blotting paper. Weight, dimensions, and true volume were measured for the six specimens. After that, drying experiments were performed on these specimens. 


\subsection{Drying Experiment}

Samples were dried in ThermoGravimetric Analyzer (TGA) (Model: LECO 701, LECO

Corporation, St. Joseph, MI, USA) at isothermal temperature at $105^{\circ} \mathrm{C}$. Drying process was done in nitrogen conditions to avoid the effect of humidity. During each drying experiment, data on time, temperature, and weight of the samples were continuously recorded in a computer. After the drying experiments, sample weight, dimensions, and true volume were measured again.

\subsection{Moisture Sorption Testing}

After drying experiment, the samples were immediately placed under water for $24 \mathrm{~h}$ and then the weight and dimensions were measured again to evaluate water absorption and volumetric swelling.

\subsection{Mechanical Properties Measurement}

Lastly, compression test was done using Intron (Model: 825 Digital Electronic Instron/MTS machine University Avenue, Norwood, and MTS 318 System Cop., MPLS, MN USA) to determine modulus of elasticity and compression strength of the samples following ASTM D143-

14 (Figure 18). Prior to the mechanical test, the samples were placed inside the conditioning chamber at $20 \pm 2{ }^{\circ} \mathrm{C}$ and relative humidity of $65 \pm 5 \%$ to reach target equilibrium moisture content (EMC) of $12 \%$. Samples were weighed before and after putting in conditioning chamber to evaluate MC. Average MC of the specimens were $13.1 \%$, which was close to meet the requirement of ASTM. 


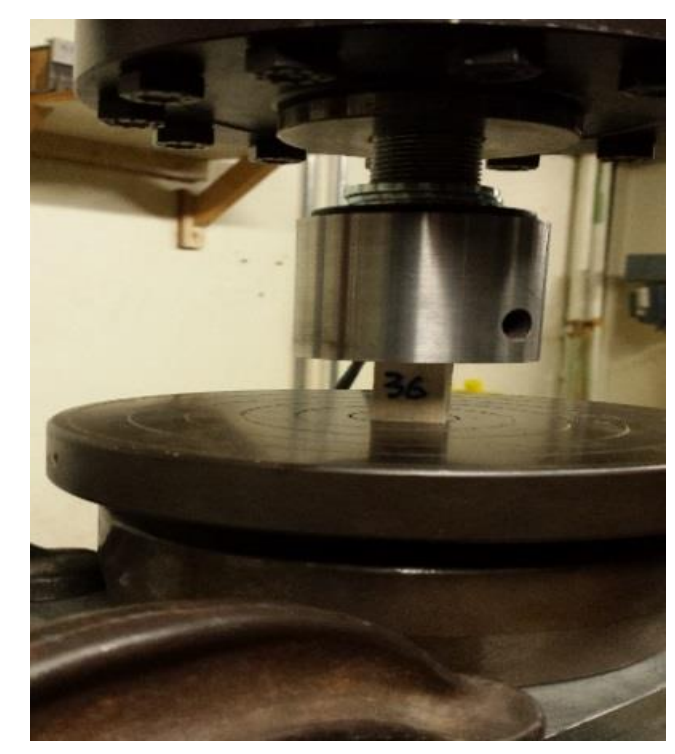

Figure 18. Instron machine for compression test.

\subsection{Yield (Y)}

In order to estimate mass loss of wood substance post treatment, yield of the experiment was calculated. The more yield is, the less mass loss should be. Yield was evaluated using equation (1) as given below:

$Y=\frac{m_{2}\left(1-\frac{M C_{w 2}}{100}\right)}{m_{1}\left(1-\frac{M C_{w 1}}{100}\right)} \times 100$

Where:

$\mathrm{Y}=$ yield $(\%)$

$\mathrm{m}_{1}=$ weight of moist wood before treatment $(\mathrm{g})$

$\mathrm{m}_{2}=$ weight of moist wood after treatment $(\mathrm{g})$

$\mathrm{MC}_{\mathrm{w} 1}=$ Wet-basis $\mathrm{MC}$ before treatment $(\mathrm{g})$

and $\mathrm{MC}_{\mathrm{w} 2}=$ Wet-basis $\mathrm{MC}$ after treatment $(\mathrm{g})$

$\mathrm{MC}_{\mathrm{w}}$ was calculated by equation (2) as given below: 
$M C_{w}=\frac{m-m_{0}}{m} \times 100$

Where:

$\mathrm{MC}_{\mathrm{w}}=$ wet-basis $\mathrm{MC}(\%)$

$\mathrm{m}=$ moist weight $(\mathrm{g})$

and $\mathrm{m}_{0}=$ oven-dry weight $(\mathrm{g})$.

\subsection{Physical Characteristics and Meachanical Properties}

\subsubsection{Dry-basis Moisture Content $\left(\mathrm{MC}_{\mathrm{d}}\right)$ and Volumetric Shrinkage (s)}

Dry-basis moisture content $\left(\mathrm{MC}_{\mathrm{d}}\right)$ of wood is the mass of moisture in wood expressed as a percentage of the oven-dry mass (Siau, 1995). Wood is dimensionally stable when the MC is beyond the fiber saturation point (FSP). However, its dimensions change when it gains or losses moisture below that point. It shrinks as losing moisture in the cell walls and swells when gaining moisture in the cell walls (Forest Products Laboratory, 1999).

$\mathrm{MC}_{\mathrm{d}}$ was calculated using equation (3) as given below:

$M C_{d}=\frac{m-m_{0}}{m_{0}} \times 100$

Where:

$\mathrm{MC}_{\mathrm{d}}=$ dry-basis $\mathrm{MC}(\%)$

Volumetric shrinkage was calculated using equation (4) as given below:

$s=\frac{V-V_{0}}{V} \times 100$

Where: 
$\mathrm{s}=$ volumetric shrinkage $(\%)$

$\mathrm{V}=$ wet volume of moist $\operatorname{wood}\left(\mathrm{cm}^{3}\right)$

and $\mathrm{V}_{0}=$ oven-dry volume of wood (after drying) $\left(\mathrm{cm}^{3}\right)$.

\subsubsection{Green and Oven-dry Specific Gravity (SG and SG)}

The specific gravity of wood is the ratio of the oven-dry mass to the mass of water displaced by the specimen at a given MC (Siau, 1995). Specific gravity is a unitless number because it is a ratio of masses. It is clearly known that an increment in bound water content creates swelling that will decrease the specific gravity. The maximum value of specific gravity is under oven-dry conditions and the minimum value is above the FSP which is called basic specific gravity or green specific gravity. Green specific gravity $(\mathrm{SG})$ and oven-dry specific gravity $\left(\mathrm{SG}_{0}\right)$ were calculated using equations (5 and 6), respectively as given below:

$\mathbf{S G}=\frac{m_{0}}{V \times \rho_{\text {water }}}$

$\mathbf{S G}_{0}=\frac{m_{0}}{\mathrm{~V}_{0} \times \rho_{\text {water }}}$

Where:

$\mathrm{SG}=$ green specific gravity at an $\mathrm{MC}$

$\mathrm{SG}_{0}=$ oven-dry specific gravity at zero $\mathrm{MC}$

and $\rho_{\text {water }}=$ density of water $\left(\mathrm{g} / \mathrm{cm}^{3}\right)$.

\subsubsection{Total Porosity ( $\left.\mu_{\text {total }}\right)$}

Porosity is fractional void volume of wood expressed in percentage at a given MC (Siau, 1995). 
$\mu_{\text {total }}=\frac{V-V_{p 0}}{V} \times 100$

Where:

$\mu_{\text {total }}=$ total porosity $(\%)$, which is equal to fractional volume occupied by air plus water fraction in green condition.

$\mathrm{V}_{\mathrm{p} 0}=$ oven-dry true volume of wood cell mass $\left(\mathrm{cm}^{3}\right)$.

Total porosity can also be calculated by equation (8) as given below:

$\mu_{\text {total }}=1$ - SG $\left(0.653+0.01 M C_{d}\right)$

\subsubsection{Water Absorption (WA) and Volumetric Swelling (S)}

Amount of water absorbed by dry wood, when kept under moisture was calculated using equation

(9) as given below:

$W A=\frac{m_{s}-m_{0}}{m_{0}} \times 100$

Where:

$m_{s}=$ weight of wood after soaking for $24 \mathrm{~h}(\mathrm{~g})$

Volumetric swelling of dry wood, when kept under moisture was calculated by equation (10) as given below:

$S=\frac{V s-V_{0}}{V_{0}} \times 100$

Where

$\mathrm{S}=$ volumetric Swelling $(\%)$

and $\mathrm{V}_{\mathrm{s}}=$ swollen volume (after soaking) $\left(\mathrm{cm}^{3}\right)$ 


\subsubsection{Compression Strength $\left(\sigma_{\max }\right)$ and Elasticity $(E)$}

Compression strength of wood samples conditioned to EMC of $12 \%$, was calculated by equation (11) as given below:

$\sigma_{\max }=\frac{F_{\max }}{\mathbf{A}}$

Where

$\sigma_{\max }=$ compression strength which is equal to maximum compressive stress $(\mathrm{MPa})$.

$\mathrm{F}_{\max }=$ maximum compressive load $(\mathrm{MN})$.

and $\mathrm{A}=$ area $\left(\mathrm{m}^{2}\right)$ which is equal to radial dimension times tangential dimension.

Modulus of elasticity was calculated by equation (12) as given below:

$\boldsymbol{E}=\frac{6}{\epsilon}$

Where

$\mathrm{E}=$ modulus of elasticity $(\mathrm{MPa})$

$\sigma=$ compressive stress $(\mathrm{MPa})$.

and $£=$ compressive strain

Compressive strain was calculated by equation (13) as given below:

$£=\frac{\Delta \mathrm{L}}{L_{1}}$

$\Delta \mathrm{L}=$ the difference between final and initial length (mm) i.e. $\Delta \mathrm{L}=\mathrm{L}_{2}-\mathrm{L}_{1}$.

and $\mathrm{L}_{1}=$ initial length $(\mathrm{mm})$ before compression. 


\subsection{Drying Behavior}

\subsubsection{Moisture Ratio (MR)}

Using weight data measured by TGA 701 at various time, MC of the samples during drying time was calculated. Then, moisture ratio was calculated, applying equation (14) (Chen et al., 2012) as given below:

$M R=\frac{M C-M C_{\text {final }}}{M C_{\text {initial }}-M C_{\text {final }}}$

Where:

$\mathrm{MR}=$ moisture ratio

$\mathrm{MC}=$ current moisture content $(\%)$

$\mathrm{MC}_{\text {final }}=$ moisture content at the end of drying $(\%)$

and $\mathrm{MC}_{\text {initial }}=$ moisture content at the beginning of drying $(\%)$.

Then, moisture ratio (MR) as a function of time elapsed was plotted for treated and untreated samples.

\subsubsection{Drying Rate $(R)$ and Overall Liquid Diffusion Coefficient $\left(D_{L}\right)$}

Drying rate (R) was calculated using equation (16) (Geankoplis, 2009). Then $\mathrm{R}$ was plotted as a function of MR which was used to calculate overall liquid diffusion coefficient.

$X_{i}=\frac{M C}{100}$

$\mathrm{R}=\frac{d X}{d t}=\frac{1}{100} \times \frac{M C_{t 1}-M C_{t 2}}{t_{2}-t_{1}} \frac{\text { kgwater }}{\text { kgdry solid.h }}$

Drying behavior comparison was performed by comparing graphs between $\frac{d X}{d t}$ and mean moisture fraction $\left(\frac{X_{1}+X_{2}}{2}\right)$. 
Unsteady state molecular transport equation for mass is written as following for three-dimensions:

$\frac{\partial X}{\partial t}=D_{L}\left(\frac{\partial^{2} X}{\partial x^{2}}+\frac{\partial^{2} X}{\partial y^{2}}+\frac{\partial^{2} X}{\partial z^{2}}\right)$

Where $\mathrm{D}_{\mathrm{L}}\left(\mathrm{m}^{2} / \mathrm{s}\right)$ is the overall liquid diffusion coefficient in each dimension and $\mathrm{x}, \mathrm{y}$, and $\mathrm{z}$ are the diffusion lengths $(\mathrm{m})$.

Assuming that initial moisture distribution is uniform at $t=0$, a simple solution to above equation (equation 17) may be written as following:

$\frac{X}{X_{1}}=\frac{8}{\pi^{2}}\left[e^{-D_{L} t\left(\pi / 2 x_{1}\right)^{2}}+e^{-D_{L} t\left(\pi / 2 y_{1}\right)^{2}}+e^{-D_{L} t\left(\pi / 2 z_{1}\right)^{2}}\right]$

Where $\mathrm{X}_{1}$ is the initial fractional $\mathrm{MC}, \mathrm{x}_{1}, \mathrm{y}_{1}$, and $\mathrm{z}_{1}$ are half of the length, width, and depth (m) of the sample. Solving above equation (Equation 18) for time of drying will result equation 19.

$t=\frac{4}{\pi^{2} D_{L}} \ln \left(\frac{8 X_{1}}{\pi^{2} X}\right)\left[x_{1}^{2}+y_{1}^{2}+z_{1}^{2}\right]$

In the equation 19 , if the diffusion mechanism started at $\mathrm{X}=\mathrm{X}_{\mathrm{C}}$, then $\mathrm{X}_{1}=\mathrm{X}_{\mathrm{C}}$. Differentiating Equation 19 with respect to time and rearranging resulted in following expression:

$\frac{d X}{d t}=-\frac{\pi^{2} D_{L} X}{4\left[x_{1}^{2}+y_{1}^{2}+z_{1}^{2}\right]}$

Therefore, slope of $\frac{d X}{d t}$ versus $X$ will be $\frac{\pi^{2} D_{L}}{4\left[x_{1}^{2}+y_{1}^{2}+z_{1}^{2}\right]}$. The overall liquid diffusion coefficient is calculated from the slope. The values of X range from the FSP to zero. With each temperature increase of $1{ }^{\circ} \mathrm{C}$, FSP decreases by $0.1 \%$. The FSP at different temperatures can be determined using the following relation:

$\mathrm{FSP}=[0.3-0.001(T-20)] \times 100$

Where 
FSP $=$ the fiber saturation point $(\%)$

and $\mathrm{T}=$ the temperature $\left({ }^{\circ} \mathrm{C}\right)$

Hence, when the temperature is at $20^{\circ} \mathrm{C}$, the value of FSP is equal to $30 \%$. In similar fashion, at $105^{\circ} \mathrm{C}$, the value of FSP is assumed to be $21.5 \%$ (Stamm and Loughborough, 1935; Siau, 1995; and He et al., 2012).

\subsection{Statistical Analysis}

Two-way Analysis of Variance (ANOVA) based on two-by-two factorial design was applied to make statistical comparison between different treatments and the effect of temperature $\left(100^{\circ} \mathrm{C}\right.$ and $\left.140^{\circ} \mathrm{C}\right)$, media $(\mathrm{HCW}$ and steam), and interaction of them on physical characteristics of wood samples. In case of significant interaction effect, ANOVA was followed by multiple comparison on least square means, with Tukey adjustment. In addition, one-way ANOVA was done to compare five groups of the samples including control group and four treated groups, followed by the least significant difference (LSD) multiple comparison. ANOVA was done at confidence level of 95\% which is $5 \%$ of significance level. Data were analyzed using JMP and SAS software (JMP®, Version Pro 12.2, SAS Institute Inc., Cary, NC).

Additional possible source of variability among the wood samples was the wood maturity. It was not accounted for in the design of this experiment and consequently, some replicates contained juvenile wood samples, while others did not. However, the homogeneity of replicates was evaluated to see if the juvenile samples increased the variability, caused lack of normal distribution, or if they were the outliers that should be excluded. Shapiro-Wilk test was utilized to check the goodness-of-fit of normal distribution for each replicate (group of 6 wood blocks). Shapiro-Wilk test is a goodness-of-fit test that can be utilized to check various continuous distributions to detect the departures from the expected fit. Most of the statistical modeling utilize 
parametric methods and require normal distributions of residuals. Therefore, it is necessary in analytical process to have available tools for testing this distributional assumption. Tests of normality offered in the statistical journals that focus on compound null hypothesis are referred to as the goodness-of-fit statistic tests. According to Coin et al. (2008) goodness-of-fit statistic tests available can be clustered into four main categories: 1) tests based on the distance between the theoretical distribution function and the observed distribution function; 2) methods derived by linking Skewness and Kurtosis; 3) group of tests utilizing Pearson's Chi-square; and 4) the tests based on regression methods.

Evaluations and recommendations of the various methods for testing the normality were done by Shapiro et al. (1988), Pearson et al. (1977), in addition to D'Agostino and Stephens (1986). They used simulations to derive an empirical power of many tests against many different alternative distributions. The general conclusions of these works recommended the Shapiro-Wilk W test by and large superior test of non-normality (Coin et al., 2008). 


\section{Chapter 3. Results and Discussion}

\subsection{Determination of the Maturity of Wood Samples}

It is well known that juvenile wood has different physical and mechanical properties than mature wood mostly because of different specific gravity, fiber length, and thickness of cell wall (Bowyer et al., 2007). This variation can affect the result of treatments on wood. In current research, there was a concern that some samples (11 specimens), which come from the zone closer to pith might contain juvenile wood. However, the acceptability of data was proven through two different ways. First, specific gravity did not show any noticeable difference among wood samples. Secondly, Shapiro Wilk test did not show any lack of normality between the replications having "so-called juvenile" samples and the replications free of "so-called juvenile" samples.

Table 1. Frequency of juvenile wood in different replications.

\begin{tabular}{ccc}
\hline Treatment & Replication & Frequency of "so-called juvenile" wood \\
\hline \multirow{3}{*}{ Control } & 1 & 0 out of 2 \\
& 2 & 0 out of 2 \\
& 3 & 0 out of 2 \\
\hline \multirow{2}{*}{$\mathrm{HCW}$ at $100^{\circ} \mathrm{C}$} & 1 & 0 out of 6 \\
& 2 & 0 out of 6 \\
$\mathrm{HCW}$ at $140^{\circ} \mathrm{C}$ & 3 & 0 out of 6 \\
\hline \multirow{3}{*}{$\mathrm{Steam}$ at $100^{\circ} \mathrm{C}$} & 2 & 2 out of 6 \\
& 3 & 1 out of 6 \\
& 1 & 0 out of 6 \\
\hline Steam at $140^{\circ} \mathrm{C}$ & 2 & 0 out of 6 \\
& 3 & 0 out of 6 \\
Total & 1 & 0 out of 6 \\
\hline
\end{tabular}

As can be seen in Table 1, totally 14\% (11 out of 78) of the samples came from "so-called juvenile" wood and the rest of the samples (67 out of 78) came from mature part of the log. All the "so- 
called juvenile" samples were found in two groups of treatment including $\mathrm{HCW}$ at $140^{\circ} \mathrm{C}$ and steam at $140^{\circ} \mathrm{C}$. In details, first and second replications of $\mathrm{HCW}$ at $140^{\circ} \mathrm{C}$ had two and one "socalled juvenile" samples, respectively. Moreover, first and second replications of steam at $140^{\circ} \mathrm{C}$, in turn, had six and two "so-called juvenile" samples.

\subsubsection{Consistency of Specific Gravity}

On an average, green specific gravity of the samples treated in $\mathrm{HCW}$ at $140^{\circ} \mathrm{C}$ showed consistent values, that is, $0.43,0.42$, and 0.42 for the first, second, and third replications. Also, first, second, and third replications showed oven-dry specific gravity of $0.49,0.48,0.50$, respectively, which again did not show any noticeable difference. Likewise, neither green nor oven-dry specific gravity showed considerable changes among replications of the samples treated in steam at $140^{\circ} \mathrm{C}$. In details, first replication, second replication, and third replication had oven-dry specific gravity $0.49,0.50$, and 0.59 , respectively. In literature, green specific gravity of yellow-poplar reported 0.40, which is even lower in "so-called juvenile" wood, depending on the distance to pith. Furthermore, the average green specific gravity of the samples come from the first (11 specimens) and second groups (67 specimens) were same (0.43), while oven-dry specific gravity of the samples come from the first and second groups were 0.49 and 0.50 , respectively.

\subsubsection{Normalilty of the Results for Different Properties among Experimental Replications}

Shapiro Wilk test revealed that for data on elasticity, shrinkage and swelling, and dry-basis moisture content, all replications in every treatment followed normal distribution, i.e. (p-value $>$ 0.05), which means the samples cut from the proximity to the pith wood did not produce outlier data.

Abnormality of data was observed for some properties in some replications, which had no "socalled juvenile" wood. Concerning specific gravity, $\mathrm{SG}_{0}$ of first replication of $\mathrm{HCW}$ at $100^{\circ} \mathrm{C}(\mathrm{p}-$ 
value $=0.006)$, first replication of steam at $100^{\circ} \mathrm{C}(\mathrm{p}$-value $=0.029)$, and third replication of steam at $100^{\circ} \mathrm{C}$ (p-value $=0.031$ ) were not normally distributed. Moreover, SG of third replication of steam at $100^{\circ} \mathrm{C}(\mathrm{p}$-value $=0.003)$ was not normally distributed. All aforementioned replications were free of "so-called juvenile" wood. Likewise, regarding diffusion coefficient, second (p-value $=0.043)$ and third $(\mathrm{p}$-value $=0.023)$ replications of $\mathrm{HCW}$ at $100^{\circ} \mathrm{C}$ were both not normally distributed. These two distribution did not include any "so-called juvenile" specimens.

In terms of water absorption, first replication of steam at $140^{\circ} \mathrm{C}(\mathrm{p}$-value $=0.002)$, third replication of $\mathrm{HCW}$ at $100^{\circ} \mathrm{C}(\mathrm{p}$-value $=0.001)$, and third replication of $\mathrm{HCW}$ at $140^{\circ} \mathrm{C}(\mathrm{p}$-value $=0.037) \mathrm{did}$ not show normal distribution among which, only first replication of $\mathrm{HCW}$ at $140^{\circ} \mathrm{C}$ had "so-called juvenile" samples. Similarly, on the subject of porosity, first replication of steam at $140^{\circ} \mathrm{C}$ (p-value $=0.005)$, second replication of steam at $140^{\circ} \mathrm{C}(\mathrm{p}$-value $<0.001)$, and third replication of $\mathrm{HCW}$ at $140^{\circ} \mathrm{C}(\mathrm{p}$-value $=0.030)$ did not show normal distribution among which, the first and second replications of steam at $140^{\circ} \mathrm{C}$ had juvenile samples.

Occurrence of not normally distributed samples in replications having "so-called juvenile" wood was three out of $40(7.5 \%)$, which was less than that of all replications not having "so-called juvenile" samples, that is, 10 out of $110(9.1 \%)$. Besides, occurrence of not normally distributed samples in replications having "so-called juvenile" wood is less than that of all replications not having juvenile samples in same treatment groups that contained the "so-called juvenile" samples. In addition to above comparisons, even from a conservative point of view, $7.5 \%$ itself is really low for Shapiro-Wilk test.

\subsubsection{Acceptability of the Data}

Therefore, it is verified that the "so-called juvenile" samples (11 specimens come from the first group) were, in fact, mature wood samples. There are two reasons to support this conclusion. First, 
the replications which have samples from closeness to pith did not show reduced specific gravity compared to the ones come from proximity to sapwood. Secondly, all the replications showed greater specific gravity than the value reported in literature for juvenile yellow-poplar (Forest Product Laboratory, 2010). Additionally, Shapiro Wilk test verified that the "so-called juvenile" specimens were more likely mature than that of juvenile wood.

\subsection{Physical Characteristics}

\subsubsection{Moisture Content and Volumetric Shrinkage}

On an average, the green yellow-poplar samples had moisture content of $43.6 \pm 0.8$ (Table 3), which was lower than that reported for green yellow-poplar heartwood (83\%) (Simpson and TenWolde, 1999). The lower green moisture content in the test samples may be attributed to several factors, such as, geographic location, harvest season (Manwiller, 1975), tree diameter (Zobel and Van Buijtenen, 2012) and time elapse between tree harvest and sample processing due to natural air drying.

Table 2. MC (dry basis) and volumetric shrinkage (mean \pm standard error) of untreated and hydrothermally treated yellow-poplar.

\begin{tabular}{cccc}
\hline $\begin{array}{c}\text { Treatment (media and } \\
\text { temperature) }\end{array}$ & $\begin{array}{c}\text { Dry-basis MC } \\
\text { before (\%) }\end{array}$ & $\begin{array}{c}\text { Dry-basis MC } \\
\text { after (\%) }\end{array}$ & $\begin{array}{c}\text { Volumetric } \\
\text { Shrinkage (\%) }\end{array}$ \\
\hline Untreated (control) & $43.6 \pm 0.8$ & $43.6 \pm 0.8^{\mathrm{d}}$ & $12.4 \pm 0.6^{\mathrm{b}}$ \\
$\mathrm{HCW} 100^{\circ} \mathrm{C}$ & $46.6 \pm 3.0$ & $85.5 \pm 11.8^{\mathrm{b}}$ & $11.5 \pm 0.6^{\mathrm{b}}$ \\
$\mathrm{HCW} 140^{\circ} \mathrm{C}$ & $46.0 \pm 1.4$ & $101.1 \pm 6.7^{\mathrm{a}}$ & $13.7 \pm 0.8^{\mathrm{a}}$ \\
Steam $100^{\circ} \mathrm{C}$ & $50.9 \pm 1.1$ & $71.9 \pm 3.7^{\mathrm{c}}$ & $11.6 \pm 0.6^{\mathrm{b}}$ \\
Steam $140^{\circ} \mathrm{C}$ & $50.1 \pm 4.6$ & $69.6 \pm 9.9^{\mathrm{c}}$ & $12.4 \pm 0.4^{\mathrm{b}}$ \\
\hline
\end{tabular}

Note: superscripts letter show statistical significance.

In literature, samples of poplar and Manchurian walnut with thickness of $2 \mathrm{~cm}$, which were used for steam treatment, had initial MC of $122.8 \%$ and $91.9 \%$, respectively (Peng et al., 2012). In another research, Cai (2006) used samples of subalpine fir at initial MC of $67.6 \%$ for steam explosion treatment. Overall, the hydrothermal treatment increased MC of samples. For example, 
processed samples in $\mathrm{HCW}$ at $140^{\circ} \mathrm{C}$ increased $\mathrm{MC}$ from $46.0 \%$ to $101.1 \%$. Likewise, processing samples in steam medium at same temperature increased MC from $50.1 \%$ to $69.65 \%$ (Figure 19). The increase in MC as a result of hydrothermal treatment may be explained by changing in hydrogen bonding intensity of hydroxyl group and changes in crystallinity (Dadashian et al., 2005 and Singh and Sivanandan, 2014). Heating fibers up to $70-80^{\circ} \mathrm{C}$ decreases intramolecular hydrogen bonding (Dadashian et al., 2005), which results in higher crystallinity (Singh and Sivanandan, 2014). However, heating fibers beyond $130^{\circ} \mathrm{C}$ results in significant increase in hydroxyl group intensity resulting in reduced crystallinity and therefore more water absorption capacity. Singh and Sivanandan (2014) reported that crystallinity of yellow-poplar wood is about 0.73 , which increases to 1.75 when treated hydrothermally at low temperatures and after that drops to 0.74 when treatment temperature reaches $250^{\circ} \mathrm{C}$.

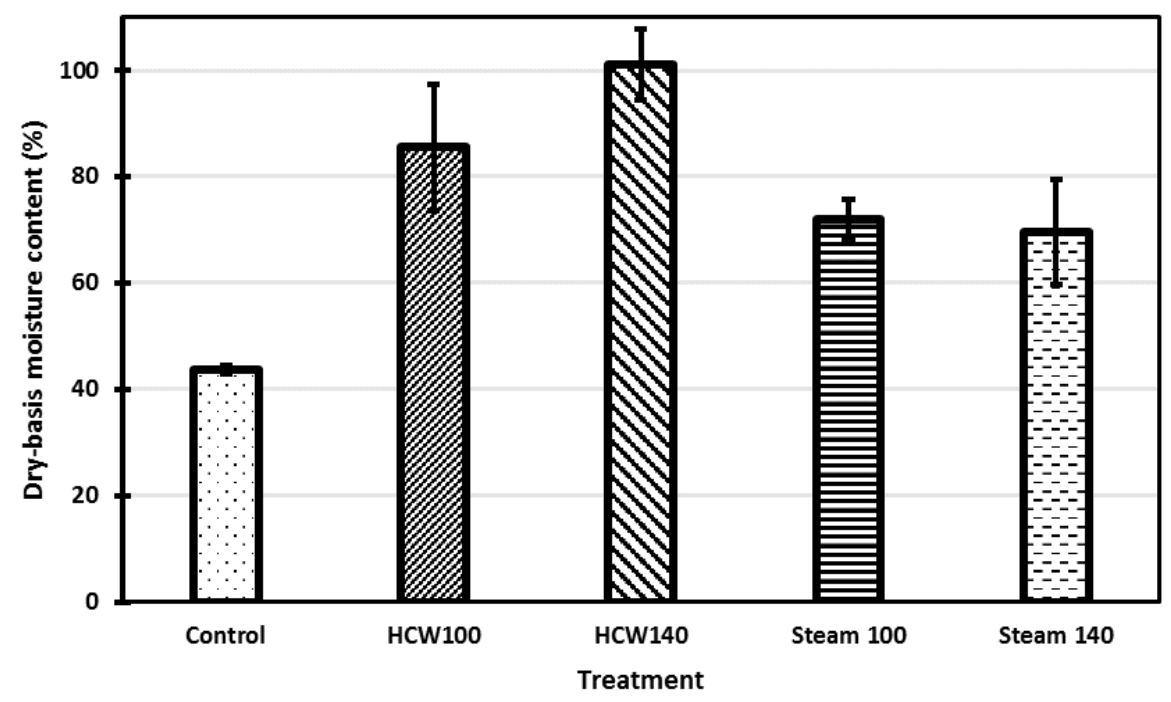

Figure 19. MC (dry basis) (mean \pm standard error) of untreated and hydrothermally treated yellow-poplar.

Our observation of increased MC is contradictory to the results reported by Peng et al. (2012) and Cai (2006). In the current research, the media of hydrothermal treatment had significant effect on MC $(\mathrm{p}$-value $=0.001)$. The HCW medium reached MC as high as 101.1, whereas steam medium 
increased MC up to $71.9 \%$. Additionally, the temperature level did not have significant effect on MC $(P-v a l u e=0.137)$. Effect of medium may be justified by the fact that liquid medium facilitates better access of water molecules to the smaller pores than steam medium (Siau, 1995 and Siau, 1984). Both Peng et al. (2012) and Cai (2006) have reported decrease in MC as results of steam treatment and steam explosion, which are not in favor of the result of current research. Peng et al. (2012) reported that steam treatment at $100^{\circ} \mathrm{C}$ and $140^{\circ} \mathrm{C}$ decreased $\mathrm{MC}$ of poplar samples. In Peng's research, poplar had initial MC of $122.8 \%$ and $91.9 \%$ to start with, which became $89.8 \%$ after steam treatment at $100^{\circ} \mathrm{C}$ and $71.9 \%$ after steam treatment at $140^{\circ} \mathrm{C}$.

Contrary to the results of the literature, in our research, steam treatment increased MC of the samples which is owing to different steaming process. In our research, steam was not injected nor released instantaneously. As a matter of fact, the steam was generated in the sealed reactor by heating up the water inside the vessel. Post one hour of holding time, temperature (and consequently the capacity of the medium to hold moisture) decreased during cooling down phase, which took about $20 \mathrm{~min}$ and $35 \mathrm{~min}$ for treatments at $100^{\circ} \mathrm{C}$ and $140^{\circ} \mathrm{C}$, respectively. Wood samples could absorb moisture during the cooling down phase.

Wood shrinks as its MC drops below FSP. Linear shrinkage varies in three different directions (longitudinal, radial, and tangential) due to anatomical characteristics. Therefore, volumetric shrinkage has been calculated to represent overall shrinkage for control and hydrothermally treated samples. Volumetric shrinkage (Table 2) (Figure 20) represents average volumetric shrinkage in samples when control and treated samples were oven-dried. The control sample of yellow-poplar showed $12.4 \%$ of volumetric shrinkage when it was dried from $43.56 \%$ to zero percentage of MC. The volumetric shrinkage demonstrated by the control sample was equivalent to that reported by Simpson and TenWolde (1999), that was $12.7 \%$. 
Additionally, all treatments but $\mathrm{HCW}$ at $140^{\circ} \mathrm{C}$ did not affect volumetric shrinkage. The samples treated in $\mathrm{HCW}$ medium at $140^{\circ} \mathrm{C}$ showed increased volumetric shrinkage of $13.7 \%$. Statistical analysis showed that medium had significant effect on volumetric shrinkage (p-value $=0.004$ ); however, effect of temperature on shrinkage was minimal ( $\mathrm{p}$-value $=0.147$ ).

In literature, only the effect of steam medium and temperature on shrinkage have been reported (Alexiou et al., 1990 and Cai, 2006). Similar to the results of this research, Alexiou et al. (1990) observed no significant change in volumetric shrinkage of eucalyptus (pilularis Sm.) when it was steamed at $100^{\circ} \mathrm{C}$ for $3 \mathrm{~h}$ prior to drying. On an average, volumetric shrinkages of the steamed and control eucalyptus samples were $19 \%$ and $20 \%$, respectively.

Cai (2006) focused on linear shrinkage (width and thickness) of subalpine fir for steam explosion treated samples at $120^{\circ} \mathrm{C}, 130^{\circ} \mathrm{C}$, and $160^{\circ} \mathrm{C}$, which was followed with conservative and accelerated drying schedules. Results showed that wood samples heated up to $130^{\circ} \mathrm{C}$ had demonstrated linear shrinkage similar to control samples (about $2.6 \%$ for width and $2.7 \%$ for thickness). However, fir samples treated at $160^{\circ} \mathrm{C}$ (maximum pressure of 6.2 bar) demonstrated significantly higher shrinkage in both width $(3.6 \%)$ and thickness $(4.0 \%)$. It appears that beyond temperature of $140^{\circ} \mathrm{C}$, the effect of temperature does become significant. However, our preliminary test samples treated in $\mathrm{HCW}$ at $160^{\circ} \mathrm{C}$ became very brittle, which created inaccurate dimension measurement. For this reason, treatments in $\mathrm{HCW}$ above $140^{\circ} \mathrm{C}$ were not chosen for real test. 


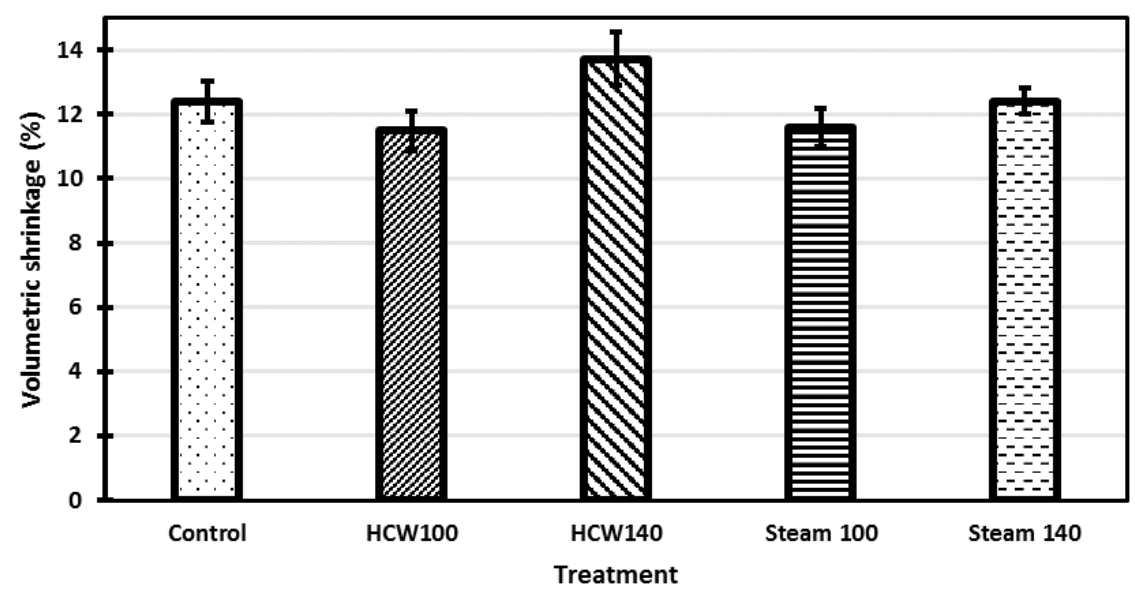

Figure 20. Volumetric shrinkage (mean \pm standard error) of untreated and hydrothermally treated yellow-poplar.

\subsubsection{Specific Gravity}

Typically, green and oven-dry specific gravity for yellow-poplar are reported to be 0.40 and 0.46 , respectively (Forest Product Laboratory, 2010), which are fairly lower than the values reported in this research. This may be justified by the fact that all samples used in the current research were from heartwood, which typically has lesser porosity and more density than sapwood (Hoadley, 1980 and Hoadley, 1980). In this research, samples used to perform various hydrothermal treatments had green SG of 0.44 , which upon oven-drying increased to 0.50 at zero MC (Table 3) (Figure 9 and 10).

Table 3. Green specific gravity and oven-dry specific gravity (mean \pm standard error) of untreated and hydrothermally treated yellow-poplar.

\begin{tabular}{ccc}
\hline $\begin{array}{c}\text { Treatment (media and } \\
\text { temperature) }\end{array}$ & Green specific gravity & $\begin{array}{c}\text { Oven-dry specific } \\
\text { gravity }\end{array}$ \\
\hline Untreated (control) & $0.44 \pm 0.01$ & $0.50 \pm 0.14$ \\
$\mathrm{HCW} 100^{\circ} \mathrm{C}$ & $0.44 \pm 0.01$ & $0.49 \pm 0.17$ \\
$\mathrm{HCW} 140^{\circ} \mathrm{C}$ & $0.42 \pm 0.01$ & $0.49 \pm 0.13$ \\
Steam $100^{\circ} \mathrm{C}$ & $0.44 \pm 0.02$ & $0.50 \pm 0.18$ \\
Steam $140^{\circ} \mathrm{C}$ & $0.43 \pm 0.02$ & $0.49 \pm 0.19$ \\
\hline
\end{tabular}




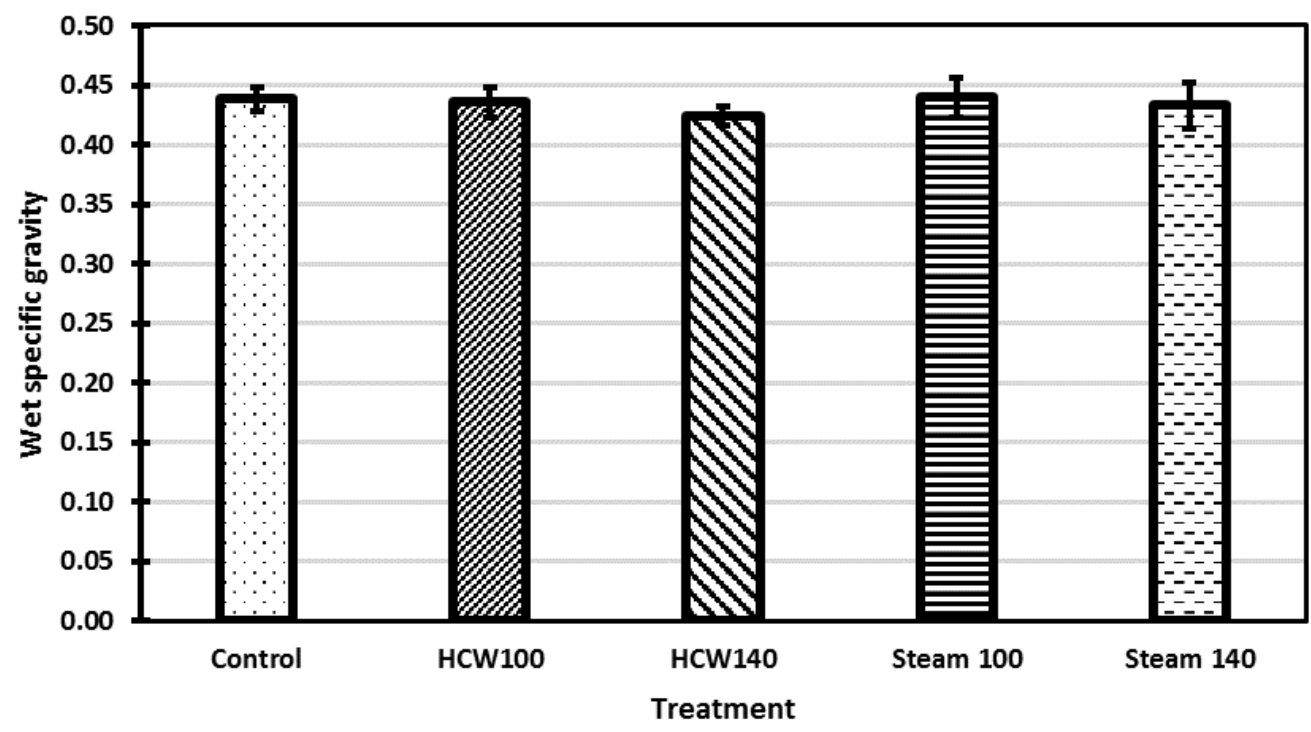

Figure 21. Green specific gravity (mean \pm standard error) of untreated and hydrothermally treated yellow-poplar.

SG values did not change significantly as results of various hydrothermal treatments. Statistically, neither of the treatment factors (temperature and medium) had significant effect on SG. It may be noted that any change in SG is expected from change in volume, which is the denominator of equation (5 and 6), given no loss of mass was taken place. While for $\mathrm{HCW}$ at $140^{\circ} \mathrm{C}$, volumetric shrinkage was significantly higher than the other groups, it did not change oven-dry volume considerably. In the current treatment conditions, both green volume and oven-dried mass remained unchanged. The main effect of media $(p$-value $=0.224)$, main effect of temperature $(p-$ value $=0.099)$, and interaction effect of media and temperature $(\mathrm{p}$-value $=0.529)$ were statistically insignificant. In current research, no significant loss of mass was recorded under treatment temperature of $140^{\circ} \mathrm{C}$. Literature suggests that wood undergoes significant loss of mass when treated at temperatures above $170^{\circ} \mathrm{C}$, which significantly affects SG (Gunduz et al., 2008 and Yang et al., 2007). All wood polymers are very stable below $155^{\circ} \mathrm{C}$. The glass transition temperature of lignin is $160^{\circ} \mathrm{C}$ (Dawn, 1987). As temperature reaches $160^{\circ} \mathrm{C}$, lignin starts to melt (Yang et al., 2007). Beyond temperature of $160^{\circ} \mathrm{C}$, carbonyl groups present in lignin detach from its aromatic 
rings (Singh and Sivanandan, 2014). Further increase in temperature up to $220^{\circ} \mathrm{C}$ leads to decomposition of hemicellulose. Chemical changes in cellulose take place beyond $315^{\circ} \mathrm{C}$, at which cellulose does experience irreversible structural change (Hatakeyama and Hatakeyama, 1979) that was led to appearance of a new infrared spectural transmittance peak at the wavenumber $1590 \mathrm{~cm}-$ 1 that is related to the hydrogen bonding formation in amorphous cellulose. The relative intensity of absorbance at wavenumbers of $1590 \mathrm{~cm}^{-1}$ and $3400 \mathrm{~cm}^{-1}$ with respect to $2900 \mathrm{~cm}^{-1}$ were used by Hatakeyama and Hatakeyama (1974) to reveal changes in total hydrogen bonding and the formation of new hydrogen bonding.

Overall, Dashti et al. (2012a) reported reduction in holocellulose content of aleppe oak from $67.20 \%$ to $62.40 \%$; lignin content from $28 \%$ to $27 \%$, and water soluble extractives content from $4.84 \%$ to $3.85 \%$ as a result of steam treatment at $160^{\circ} \mathrm{C}$. Therefore, no change in SG of yellowpoplar is in agreement with literature due to the fact that no significant loss of mass or volume change took place during our treatment conditions.

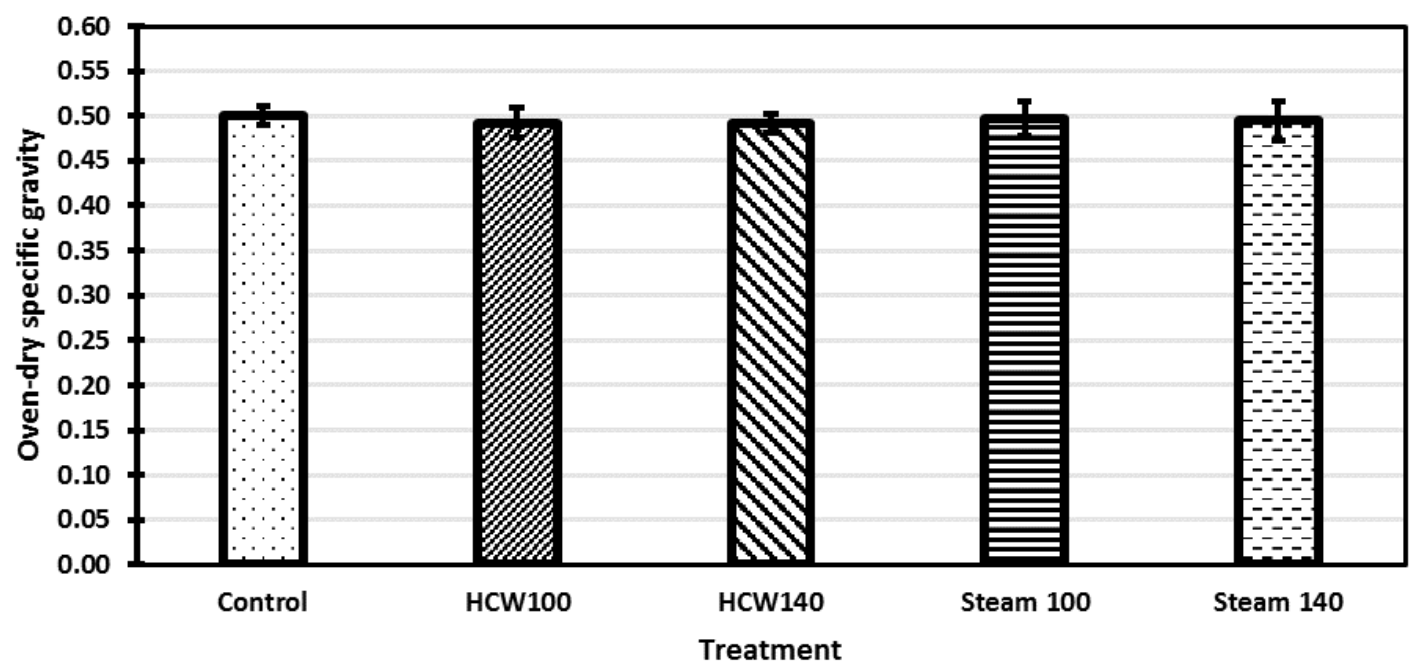

Figure 22. Oven-dry specific gravity (mean \pm standard error) of untreated and hydrothermally treated yellow-poplar. 


\subsubsection{Porosity}

The total porosity represents fraction of green volume, which is not occupied by wood cell mass. The control samples showed that about $82.4 \%$ of the green volume was occupied by either air or water and only $17.4 \%$ of the green volume was occupied by dry wood mass (Table 4). Total porosity of oven-dried wood of varying specific gravity has been documented using mercury intrusion porosimetry, which range from $73.7 \%$ for wood having specific gravity of 0.40 , to $22.11 \%$ for wood having specific gravity of 1.16 . Total porosity has been reported to be $68.00 \%$ for wood having specific gravity of 0.48 (Plotze and Niemz, 2011). Theoretically, total porosity ( $\mu$ ) may be calculated using equation (8) as given earlier (Siau,1995). Theoretical value for porosity samples tested in the current research is $71.3 \%$, which was close to the measured values.

Table 4. Total porosity (mean \pm standard error) of untreated and hydrothermally treated yellowpoplar

\begin{tabular}{cc}
\hline $\begin{array}{c}\text { Treatment (media and } \\
\text { temperature) }\end{array}$ & Total porosity (\%) \\
\hline Untreated (control) & $82.4 \pm 1.8^{\mathrm{b}}$ \\
HCW $100^{\circ} \mathrm{C}$ & $83.3 \pm 4.0^{\mathrm{b}}$ \\
$\mathrm{HCW} 140^{\circ} \mathrm{C}$ & $92.2 \pm 3.4^{\mathrm{a}}$ \\
Steam $100^{\circ} \mathrm{C}$ & $92.3 \pm 2.1^{\mathrm{a}}$ \\
Steam $140^{\circ} \mathrm{C}$ & $94.9 \pm 2.7^{\mathrm{a}}$ \\
\hline
\end{tabular}

Note: superscripts letter show statistical significance.

Hydrothermal treatment significantly changes total porosity of yellow-poplar samples (Figure 23). Treatments with HCW medium increased total porosity from $82.4 \%$ to $92.2 \%$ at the temperature of $140^{\circ} \mathrm{C}$ whereas treatment under steam increased total porosity at even low temperature of $100^{\circ} \mathrm{C}$. Media $(\mathrm{p}$-value $=0.022)$ and temperature $(\mathrm{p}$-value $=0.021)$ significantly influenced the total porosity. However, the interaction effect of temperature and media was not significant (pvalue $=0.165)$. 


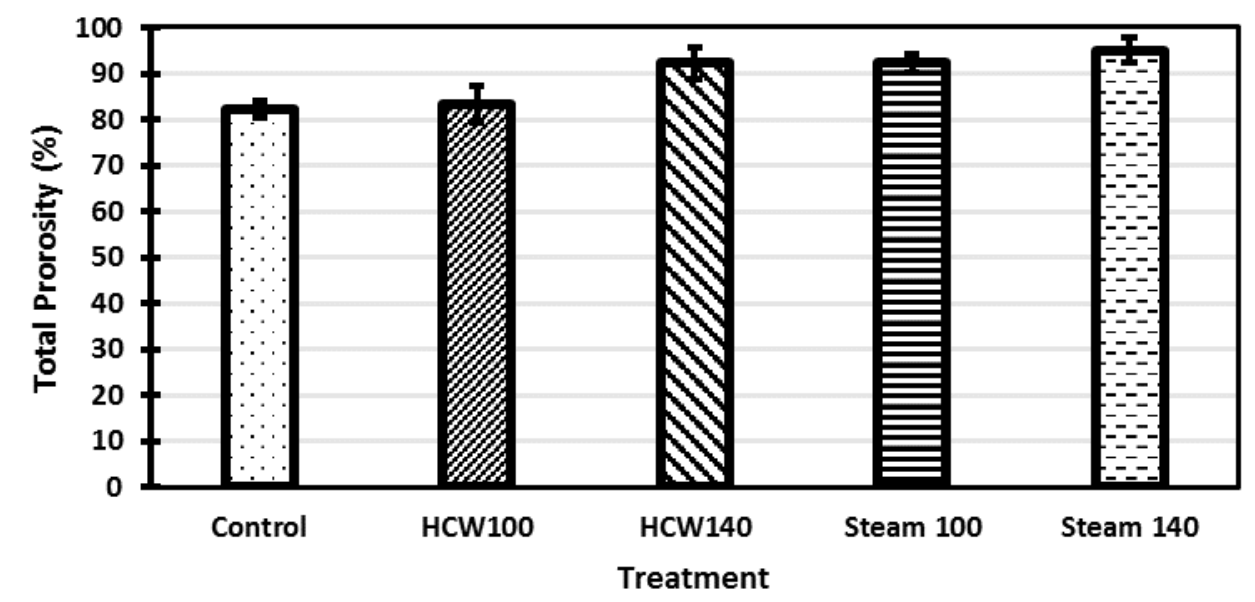

Figure 23. Total porosity (mean \pm standard error) of untreated and hydrothermally treated yellowpoplar.

Heating dry wood samples up to $200^{\circ} \mathrm{C}$ for 4 hours under nitrogen has varying effects on its total porosity. While thermal modification of dry spruce wood reduced total porosity from $71.9 \%$ to $69.7 \%$, it increased from $65.7 \%$ to $66.6 \%$ for maple wood and it did not change at all for ash wood (Zauer et al., 2013). Zauer et al. (2013) also claimed that this type of thermal modification of wood leads to decreased nano-pore shares, below a pore diameter of $400 \mathrm{~nm}$, and decreased FSP because the proportion of capillary condensed water in thermally modified wood reduced significantly. Enhanced porosity due to thermal treatment could be due to fractured cell-wall, loss of extractives, and decay of cell-wall constituents. Hydrothermal treatments at high temperature is shown to have produced more voids and fractures (Biziks et al., 2013). Biziks et al. (2013) also reported that the lumen cross-section decreased by $2.3 \%$, while the tangential length of the lumen decreased by $0.5 \%$ and the radial length of the lumen decreased by $2.7 \%$. In contrast, the cross-sectional area of the fibers decreased from $1.0 \%$ at $140^{\circ} \mathrm{C}$ and $20.7 \%$ at $180^{\circ} \mathrm{C}$ mainly due to degradation of cell wall constituents 
Steam explosion on Chinese fir creates several changes in wood constituents. Treatments equal to or below temperature of $120^{\circ} \mathrm{C}$, pressure of 2.5 bar with ten cycles did not cause considerable changes in wood structure while treatment with temperature of $130^{\circ} \mathrm{C}$, pressure of 2.5 bar with 20 cycles caused some fractures in bordered pit pairs between tracheids. More considerably, temperature of $160^{\circ} \mathrm{C}$, pressure of 6.2 bar with 10 cycles caused more fractures in border pit pairs (Zhang and Cai, 2006). Likewise, micro-explosion created several fine fractures on the weak parts of the cells, i.e. the pit membranes, as a result of an instantaneous exhaust process

\subsubsection{Water Absorption and Volumetric Swelling}

To measure water absorption (WA) capability, post hydrothermal treatment, the treated-dried samples were submerged in water for $24 \mathrm{~h}$. After $24 \mathrm{~h}$, amount of water absorbed and volumetric swelling were measured. The hydrothermal treatments significantly changed water absorption (WA) capability and total volumetric swelling (Table 5) (Figure 24 and 25).

Table 5. Water absorption and volumetric swelling (mean \pm standard error) of untreated and hydrothermally treated yellow-poplar.

\begin{tabular}{ccc}
\hline $\begin{array}{c}\text { Treatment (media and } \\
\text { temperature) }\end{array}$ & $\begin{array}{c}\text { Water absorption } \\
(\%)\end{array}$ & Volumetric swelling $\left(\mathrm{m}^{2} / \mathrm{s}\right)$ \\
\hline Untreated (control) & $32.5 \pm 0.9^{\mathrm{b}}$ & $12.2 \pm 0.5$ \\
$\mathrm{HCW} 100^{\circ} \mathrm{C}$ & $38.2 \pm 3.0^{\mathrm{b}}$ & $12.1 \pm 0.5$ \\
$\mathrm{HCW} 140^{\circ} \mathrm{C}$ & $48.8 \pm 9.9^{\mathrm{a}}$ & $11.6 \pm 0.9$ \\
Steam $100^{\circ} \mathrm{C}$ & $41.1 \pm 3.5^{\mathrm{a}}$ & $12.7 \pm 0.8$ \\
Steam $140^{\circ} \mathrm{C}$ & $45.8 \pm 5.8^{\mathrm{a}}$ & $10.0 \pm 1.0$ \\
\hline
\end{tabular}

Note: superscripts letter show statistical significance. 


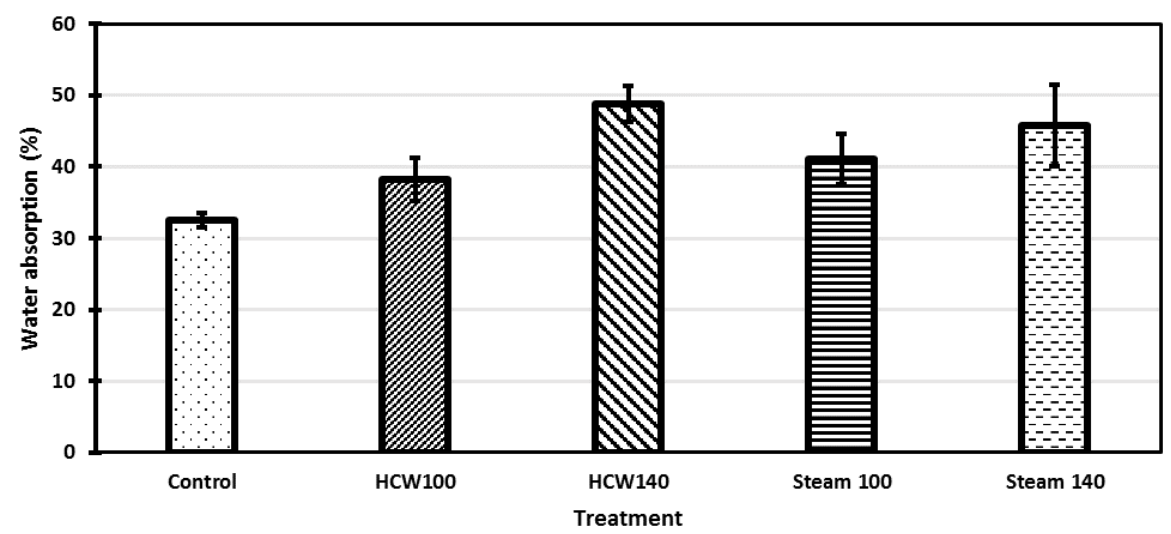

Figure 24. Water absorption (mean \pm standard error) of untreated and hydrothermally treated yellow-poplar.

WA after $24 \mathrm{~h}$ soaking for untreated yellow-poplar heartwood samples was $32.5 \%$, which was significantly below the WA values of treated samples. Upon hydrothermal treatments, the WA significantly increased for all treatments except $\mathrm{HCW}$ at $100^{\circ} \mathrm{C}$. This results tally with porosity values indicating that hydrothermal treatments boost porosity and consequently WA. Among treatment factors, the temperature had significant influence on water absorption ( $\mathrm{p}$-value $=0.013$ ); however, media had minimal effect $(\mathrm{p}$-value $=0.995)$. Besides, interaction effect of temperature and media was not significant $(\mathrm{p}$-value $=0.253)$.

In literature, comparison of WA of untreated and hydrothermally treated wood has been reported (Dundar et al., 2012; Tuong and Li, 2011; and Scheilding et al., 2006). Dundar et al. (2012), compared water sorption and water repellent effectiveness (WRE) of untreated and hydrothermally treated black pine at $180^{\circ} \mathrm{C}$ and $210^{\circ} \mathrm{C}$. They reported that WA was $108.1 \%$ for the control samples, which reduced to $104.3 \%$ after testing samples at $180^{\circ} \mathrm{C}$. Treatment at $210^{\circ} \mathrm{C}$ further reduced WA (to 74.3\%). In another research, Tuong and Li (2011) heated acacia sapwood in nitrogen at temperatures of $210^{\circ} \mathrm{C}, 215^{\circ} \mathrm{C}, 220^{\circ} \mathrm{C}$, and $230^{\circ} \mathrm{C}$ for 2,4 , and $6 \mathrm{~h}$ and tested heat treated samples for WA. They reported that WA of treated samples decreased significantly with 
increase of treatment time and temperature. For example, treating acacia wood at $210^{\circ} \mathrm{C}$ for $2 \mathrm{~h}$ reduced WA from $135 \%$ to $125 \%$.

In these research reports, the reduction in WA was attributed to reduction of hydroxyl group in wood (Weiland and Guyonnet, 2003 and Tjeerdsma and Militz, 2005) or owing to formation of cross-linking over heat treatment, which makes the molecules less elastic, decreasing the possibility to enlarge the cellulose microfibrils (Tjeerdsma et al., 1998). While literature showed decrease in WA, temperature used in current research were not high enough to make aforementioned changes.

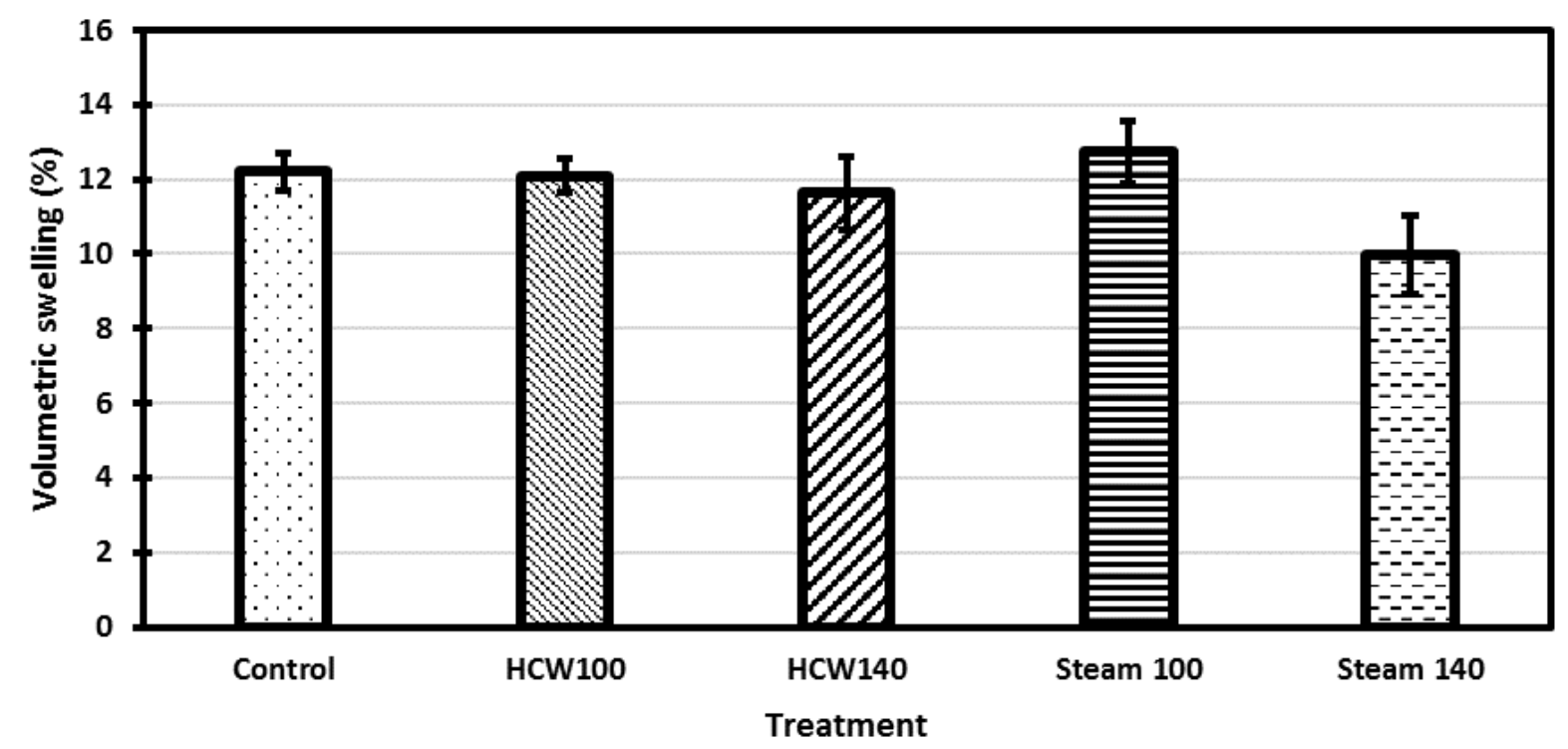

Figure 25. Volumetric swelling (mean \pm standard error) of untreated and hydrothermally treated yellow-poplar.

Like WA, the volumetric swelling of untreated and treated samples was also measured when the dry samples were soaked in water for $24 \mathrm{~h}$. Volumetric swelling after $24 \mathrm{~h}$ for untreated yellowpoplar heartwood samples was $12.2 \%$. Theoretically, maximum volumetric swelling may be calculated by multiplying 30 with oven-dried specific gravity. For the current research samples, the untreated samples had oven-dry specific gravity of 0.50 , which would result in $15.0 \%$ 
theoretical volumetric swelling. Our measured volumetric swelling was $12.2 \%$, lower than the theoretical value probably due to lack of significant time $(24 \mathrm{~h})$ for complete saturation of wood samples. Longer saturation duration would have achieved volumetric swelling close to the theoretical value.

All hydrothermal treatments did not significantly change volumetric swelling. Meanwhile, main effect of temperature $(p$-value $=0.053)$ and media $(p$-value $=0.499)$, as well as their interaction effect $(\mathrm{p}$-value $=0.144)$ on shrinkage were all insignificant. However, steam treatment at $140^{\circ} \mathrm{C}$ reduced volumetric swelling from $12.2 \%$ to $10.0 \%$. In literature, Dundar et al. (2012) compared volumetric swelling and anti-swell effectiveness (ASE) of black pine samples hydrothermally treated at $180^{\circ} \mathrm{C}$ and $210^{\circ} \mathrm{C}$. They report that the volumetric swelling values after $24 \mathrm{~h}$ immersion time were $10.4 \%$ for control samples, which reduced to $7.9 \%$ and $6.5 \%$ after hydrothermal treatment at $180^{\circ} \mathrm{C}$ and $210^{\circ} \mathrm{C}$, respectively. In another research, Tuong and $\mathrm{Li}(2011)$ reported volumetric swelling of $13.2 \%$, which reduced to $9.5 \%, 9 \%, 8 \%$, and $6.5 \%$ following $2 \mathrm{~h}$ of heat treatment at $210^{\circ} \mathrm{C}, 215^{\circ} \mathrm{C}, 210^{\circ} \mathrm{C}$, and $230^{\circ} \mathrm{C}$. Same trend of reduction was observed for radial and tangential shrinkage as well

\subsection{Mechanical Properties}

Compression strength and modulus of elasticity are perhaps key mechanical properties of wood to be used in structural applications. The yellow-poplar wood samples which had been conditioned to reach $12 \%$ of EMC showed compression strength of $42.95 \mathrm{MPa}$ (Table 6) and modulus of elasticity of 1.29 GPa (Figure 26). In the wood hand-book, the compression strength of yellowpoplar has been reported to be $38.20 \mathrm{MPa}$ (along the grain), which slightly lower than our test samples (Figure 27) (Forest Product Laboratory, 2010). 
Table 6. Modulus of elasticity and compression strength (mean \pm standard error) of untreated and hydrothermally treated yellow-poplar.

\begin{tabular}{ccc}
\hline $\begin{array}{c}\text { Treatment (media and } \\
\text { temperature) }\end{array}$ & $\begin{array}{c}\text { Modulus of Elasticity } \\
(\mathrm{GPa})\end{array}$ & $\begin{array}{c}\text { Compression Strength } \\
(\mathrm{MPa})\end{array}$ \\
\hline Untreated(control) & $1.29 \pm 0.10^{\mathrm{c}}$ & $42.95 \pm 2.79^{\mathrm{abc}}$ \\
$\mathrm{HCW} 100^{\circ} \mathrm{C}$ & $1.66 \pm 0.13^{\mathrm{a}}$ & $47.75 \pm 2.33^{\mathrm{a}}$ \\
$\mathrm{HCW} 140^{\circ} \mathrm{C}$ & $1.36 \pm 0.14^{\mathrm{bc}}$ & $43.73 \pm 3.78^{\mathrm{ab}}$ \\
Steam $100^{\circ} \mathrm{C}$ & $1.17 \pm 0.10^{\mathrm{c}}$ & $38.50 \pm 3.78^{\mathrm{c}}$ \\
Steam $140^{\circ} \mathrm{C}$ & $1.57 \pm 0.18^{\mathrm{ab}}$ & $42.27 \pm 2.46^{\mathrm{bc}}$ \\
\hline
\end{tabular}

Note: superscripts letter show statistical significance.

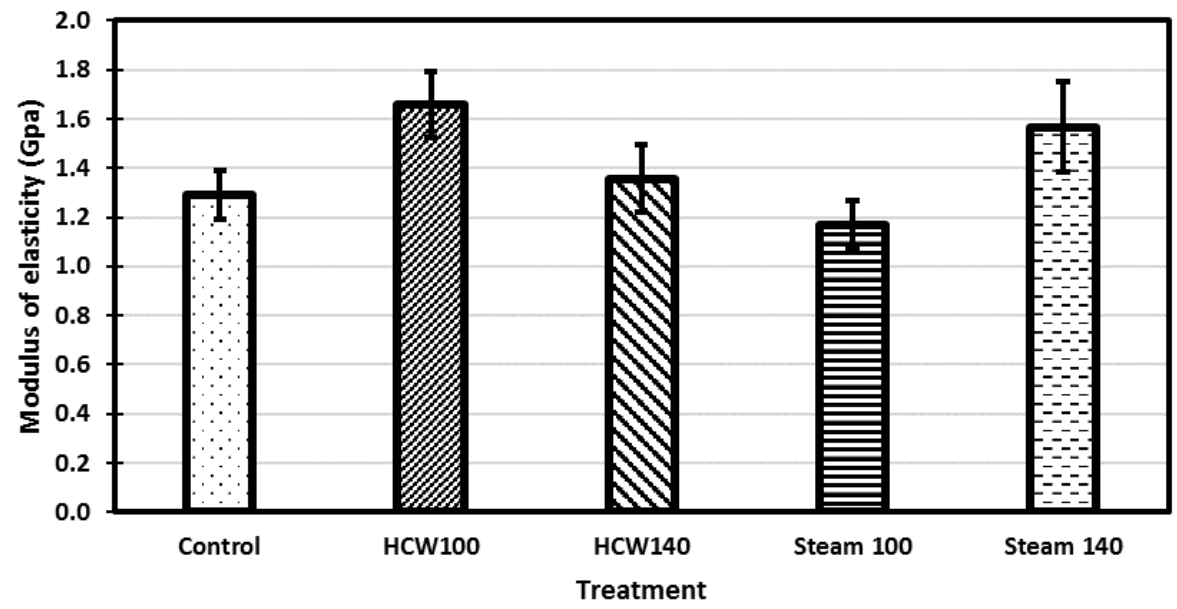

Figure 26. Modulus of elasticity (mean \pm standard error) of untreated and hydrothermally treated yellow-poplar.

Hydrothermal treatment significantly increased the modulus of elasticity of yellow-poplar. For example, the modulus of elasticity increased from $1.29 \mathrm{GPa}$ (control) to as high as $1.66 \mathrm{GPa}$ due to hydrothermal treatment performed in $\mathrm{HCW}$ medium at $100^{\circ} \mathrm{C}$. Also, steam treatment at $140^{\circ} \mathrm{C}$ led to increase in modulus of elasticity. In literature, Dundar et al. (2012) reported modulus of elasticity of black pine wood (thermally treated at $180^{\circ} \mathrm{C}$ and $210^{\circ} \mathrm{C}$ ). According to the report, the modulus of elasticity significantly decreased from 5.6 GPa (control) to $4.78 \mathrm{GPa}$ when samples were treated at $180^{\circ} \mathrm{C}$. Further increase in temperature did not change modulus of elasticity. In literature, most of the treatments are performed well beyond $140^{\circ} \mathrm{C}$ which is the maximum 
temperature used in the current research. Therefore, literature data may not be used to cross verify the results presented in Table 6 .

In the current research, the interaction effect of temperature and medium was significant (p-value $=0.001$ ) because of two reasons. On the one hand, modulus of elasticity had significantly lower values for steam at $100^{\circ} \mathrm{C}$ compared to $\mathrm{HCW}$ at steam at the same temperature ( $\mathrm{p}$-value $=0.004$ ); on the other hand, modulus of elasticity increased significantly following elevation of temperature in steam medium $(\mathrm{p}$-value $=0.016)$.

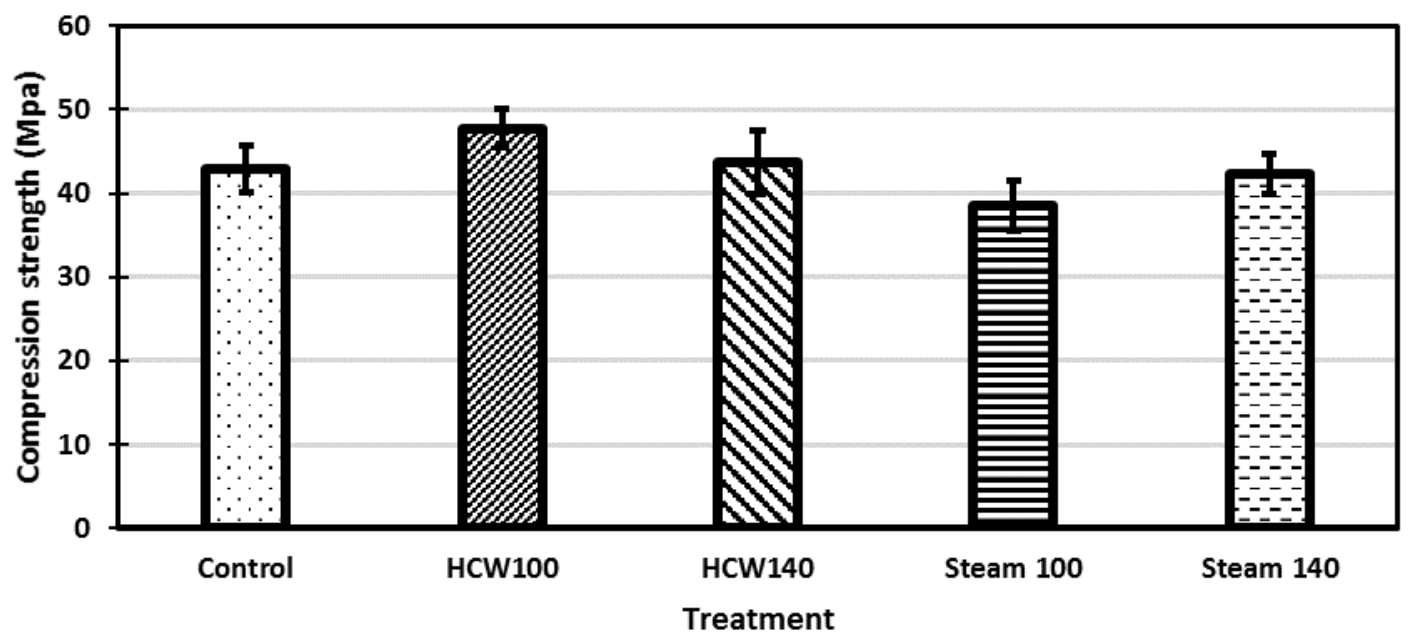

Figure 27. Compression strength (mean \pm standard error) of untreated and hydrothermally treated yellow-poplar.

Influence of medium and temperature on the compression strength of yellow-poplar followed a pattern similar to the modulus of elasticity. Compression strength of yellow-poplar heartwood was 42.95 $\mathrm{MPa}$, which increased with the hydrothermal treatments, in general, except for steam treatment at $100^{\circ} \mathrm{C}$.

Statistically, the main effects of temperature and medium were insignificant $(\mathrm{P}-\mathrm{value}=0.933)$ and significant $(\mathrm{P}$-value $=0.007)$, respectively. In addition, interaction effect of temperature and media was significant $(\mathrm{P}$-value $=0.031)$. The significance of interaction effect is due to the fact that there 
is a considerable difference between $\mathrm{HCW}$ and steam at $140^{\circ} \mathrm{C}(\mathrm{P}$-value $=0.001)$ while these two different media did not have noticeable difference at $140^{\circ} \mathrm{C}$. In literature, Dundar et al. (2012) reported significant decrease in modulus of rupture, from $61.4 \mathrm{GPa}$ (control) to $43.0 \mathrm{GPa}$, due to hydrothermal treatment at $180^{\circ} \mathrm{C}$ for black pine wood.

\subsection{Drying Behavior and Overall Liquid Diffusion Coefficient}

The drying behavior of the wood samples was analyzed into two sets of graphs. In the first set, moisture ratio (MR) was plotted as a function of drying time, which provides crucial information about how fast material dries. In the second set, drying rate was plotted as a function of moisture ratio, which provides insight into prevailing mechanism of moisture loss and overall liquid diffusion coefficients. The following sub-sections provide details of drying behavior.

\subsubsection{Drying Time and Moisture Ratio}

Moisture ratio (fraction of initial moisture left) at given time was plotted for the control and hydrothermally treated samples (Figure 28). A quick observation of the figure 16 shows that the drying behavior line (MR vs time) for $\mathrm{HCW}$ treated samples lies above the drying behavior line for control samples; however, drying behavior line for steam treated samples is close to but below the drying behavior line of control samples. It essentially means that it takes longer and slower to dry HCW treated samples than control whereas steam treated samples dry faster. Both steam treated samples follow similar drying behavior. 


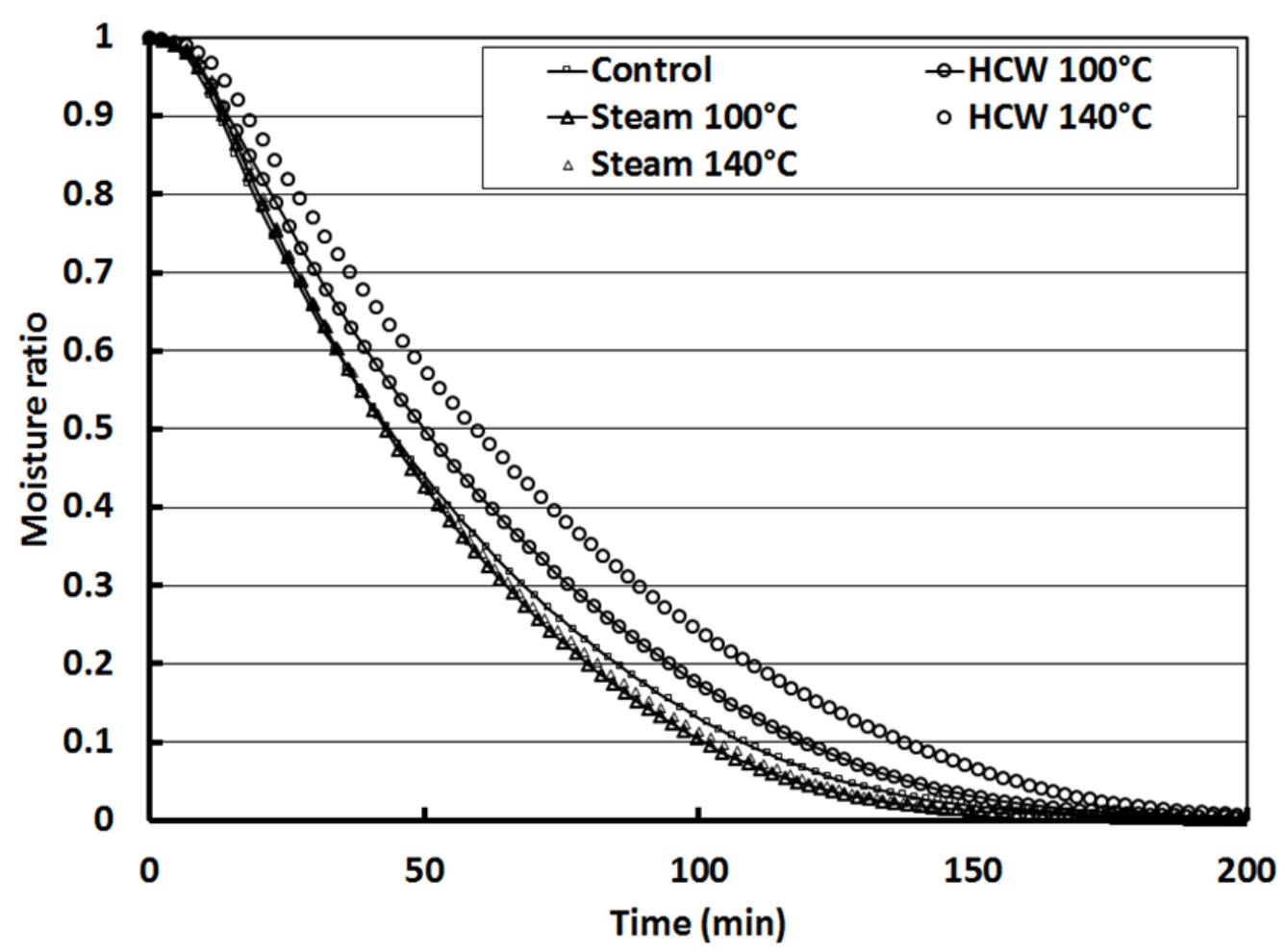

Figure 28. Moisture ratio as a function of time elapsed during drying at $105^{\circ} \mathrm{C}$ for untreated and hydrothermally treated samples of yellow-poplar.

Additionally, high temperature $\left(140^{\circ} \mathrm{C}\right) \mathrm{HCW}$ treated samples held moisture more tightly than low temperature $\left(100^{\circ} \mathrm{C}\right) \mathrm{HCW}$ treated samples. Holding high moisture ratio at a given drying time indicates two factors: 1 . Moisture was held with more binding forces and 2. Pores were blocked slowing down mass transfer rate. Taghiyari et al. (2011) reported that treating beech at $180^{\circ} \mathrm{C}$ in hot water leads to extra extractives settlement on perforation plates and cell walls, which slows mass transfer rates during drying. In contrast, steam treated samples possess pores and cavities with less blockage, therefore dry faster than the control samples. According to Peng et al. (2012), the bound water diffusion was slower in the samples steam treated at $100^{\circ} \mathrm{C}$ or $140^{\circ} \mathrm{C}$ than the control samples of poplar wood. They report that the total drying time of poplar boards of $6 \mathrm{~cm}$ was 102 and $74 \mathrm{~h}$ for untreated and treated samples, respectively. In the current research, total time for the samples to reach zero MC was dependent on type of treatment. 
As can be observed in Table 7, untreated samples reached zero MC after 226 min, which was faster than treated samples. Steam treated samples at either temperature did not show noticeable longer time to be oven-dried. However, samples treated in $\mathrm{HCW}$ at $140^{\circ} \mathrm{C}$ showed the longest drying time (260 min). Increased drying time for the treated samples in HCW at either temperature can be explained by elevated MC of the samples which experienced hydrothermal treatment in liquid medium. Regarding the uniformity of drying time, control samples showed the most uniform drying time (standard deviation $=0.02$ ). However, statistically hydrothermally treated samples did not show significant change from the control samples. In addition, all the effects of temperature $(p$-value $=0.130)$ and media $(p$-value $=0.180)$ and the interaction of them $(p$-value $=0.616)$ were insignificant.

Table 7. Drying time (mean \pm standard error) of untreated and hydrothermally treated yellowpoplar to reach zero MC.

\begin{tabular}{cc}
\hline $\begin{array}{c}\text { Treatment (media and } \\
\text { temperature) }\end{array}$ & Drying time (min) \\
\hline Untreated (control) & $225.95 \pm 0.02$ \\
$\mathrm{HCW} 100^{\circ} \mathrm{C}$ & $240.40 \pm 4.48$ \\
$\mathrm{HCW} 140^{\circ} \mathrm{C}$ & $260.14 \pm 12.76$ \\
Steam $100^{\circ} \mathrm{C}$ & $231.94 \pm 9.07$ \\
Steam $140^{\circ} \mathrm{C}$ & $242.35 \pm 13.19$ \\
\hline
\end{tabular}

\subsubsection{Drying Curve}

Drying behavior (moisture desorption) from wood in zero humidity and constant temperature is associated with wood properties, such as, various pore sizes, affinity of wood for water, total porosity, density, and specific gravity. Moisture desorption from wood is fundamentally controlled by two simultaneous mechanisms, which are capillary flow and diffusion flow (Siau, 1995 and Simpson, 1991). In Figure (29), following four phases are observed: First- increase in drying rate 
due to sample heating; second- linear capillary controlled (convective) falling phase; third- nonlinear transition falling phase, and fourth- linear diffusion controlled falling period.

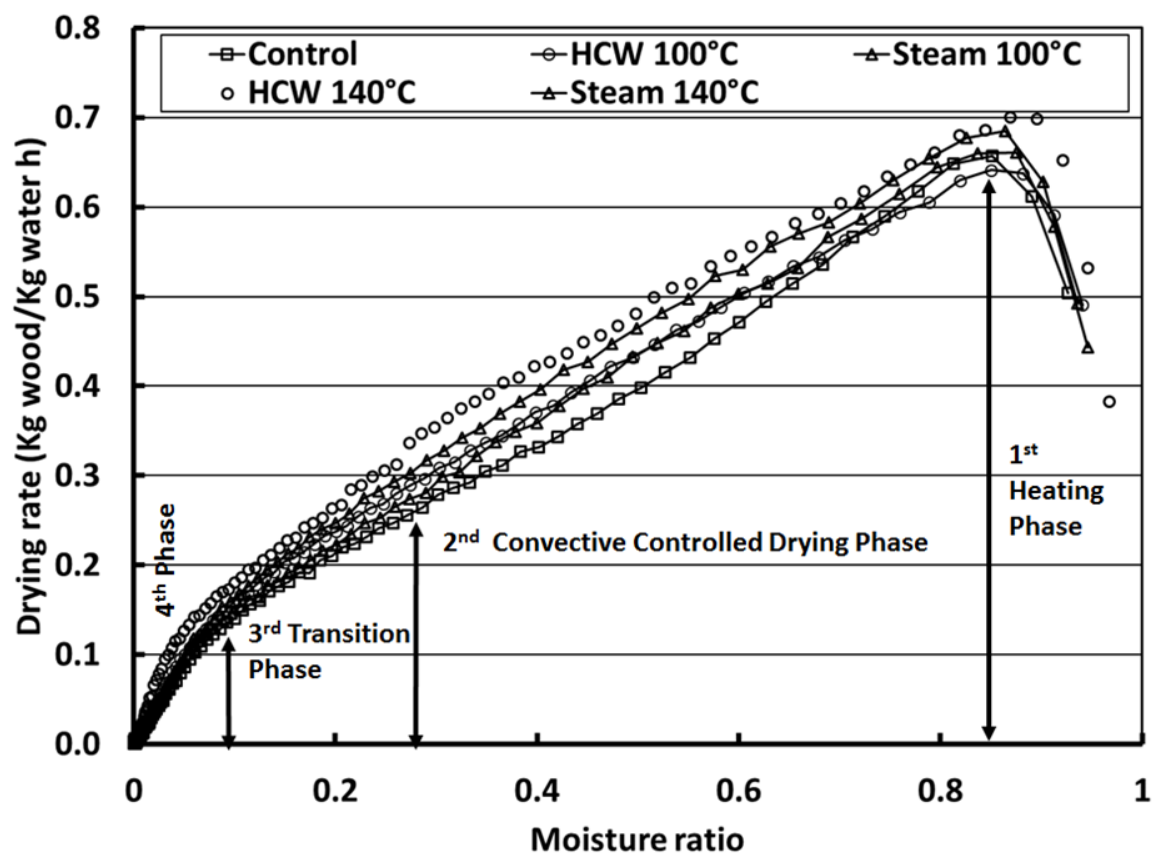

Figure 29. Drying rate as a function of moisture ratio for untreated and treated samples of yellowpoplar.

Over the second phase of drying, free water flows through the cell lumens and pits due to capillary action. In the third phase, moisture loss takes place from lumens (free water) as well as from cell wall (bound water). In the fourth phase, when cell lumens and pits become empty, water vaporizes from cell wall and water vapor flows through the cell lumens and pits by diffusion. Bound water also diffuses through the cell walls. Diffusion coefficient of water vapor is three to four orders of magnitude smaller in lumens than water vapor diffusion coefficient in free water (Siau, 1995). It is also worth noting that almost in most of studies on wood and water relation, type of diffusion has been neglected and diffusion is presented based on Fickian type of diffusion while Kundsen diffusion would dominate for small pore openings. In actuality, large lumens may comply with 
Fickian diffusion; whereas, small pits and lumens may conform to Kundesen diffusion (Geankoplis, 2003).

The drying rate curve presented in the Figure 18 has several obvious observations. First, drying rate curves of all the hydrothermally treated samples were above the drying curves of controlled samples because the treated samples had high initial moisture content (Table 7). Therefore, higher amount of water was evaporated at given moisture ratio from treated samples than that from control samples. In the drying curves, slopes of the drying curves in various phases are important because it is used to calculate overall liquid diffusion coefficients. In the current research, overall liquid diffusion coefficients was calculated for the convective controlled drying phase. Notwithstanding, HCW treatment especially at elevated temperature exhibited greater drying rate than control. Difference in drying rate is predominantly attributed to total porosity.

Overall liquid diffusion coefficient of yellow-poplar heartwood was $3.18 \times 10^{-8} \mathrm{~m}^{2} / \mathrm{s}$ (Table 8) (Figure 30). Diffusion coefficient of wood has reported by numerous researcher. Sayar and Tarmian (2013) measured diffusion coefficient of poplar (Populus nigra L.) on account of Fick's law of diffusion in steady-state conditions using cup method. Reported values ranged from $1.34 \times$ $10^{-9}$ to $1.90 \times 10^{-8} \mathrm{~m}^{2} / \mathrm{s}$. Using same method, Dashti et al. (2012a) reported of diffusion coefficients of alpee oak (Quercus infectoria) as $2.35 \times 10^{-7}$ and $3.60 \times 10^{-7} \mathrm{~m}^{2} / \mathrm{s}$ for heartwood and sapwood, respectively. Shahverdi et al. (2013) reported diffusion coefficient of beech heartwood $8.16 \times 10^{-}$ ${ }^{11} \mathrm{~m}^{2} / \mathrm{s}$, using cup method. He at al. (2014) calculated effective water diffusivity of Chinese fir (Cuninghamia lanceolata) according to the linear relationship extracted from the lnMR-t plot and based on Fick's second law and reported value of $1.34 \times 10^{-8} \mathrm{~m}^{2} / \mathrm{s}$. Using same way, He et al. (2013) measured effective water diffusion coefficients of Chinese catalpa. Values in range of 2. 89 to $2.91 \times 10^{-8} \mathrm{~m}^{2} / \mathrm{s}$ for MC above FSP and values in range of 1.06 to $1.12 \times 10^{-8} \mathrm{~m}^{2} / \mathrm{s}$ for MC 
below FSP were reported. Water vapor diffusion coefficients vary upon cell wall thickness and the amount of substance it contains, that is, density (Perre, 2007 and Tarmian et al., 2012). In addition, presence of hemicellulose would improve diffusivity through wood (Siau, 1984 and Tarmian et al., 2012).

Table 8. Overall liquid diffusion coefficient (mean \pm standard error) of untreated and hydrothermally treated yellow-poplar.

\begin{tabular}{cc}
\hline $\begin{array}{c}\text { Treatment (media and } \\
\text { temperature) }\end{array}$ & Overall liquid diffusion coefficient $\left(\mathrm{m}^{2} / \mathrm{s}\right)$ \\
\hline Untreated (control) & $3.15 \times 10^{-8} \pm 1.19 \times 10^{-9} \mathrm{a}$ \\
$\mathrm{HCW} 100^{\circ} \mathrm{C}$ & $2.15 \times 10^{-8} \pm 3.65 \times 10^{-9} \mathrm{c}$ \\
$\mathrm{HCW} 140^{\circ} \mathrm{C}$ & $1.89 \times 10^{-8} \pm 2.42 \times 10^{-9} \mathrm{c}$ \\
Steam $100^{\circ} \mathrm{C}$ & $2.62 \times 10^{-8} \pm 1.63 \times 10^{-9} \mathrm{~b}$ \\
Steam $140^{\circ} \mathrm{C}$ & $3.04 \times 10^{-8} \pm 3.93 \times 10^{-9} \mathrm{a}$ \\
\hline
\end{tabular}

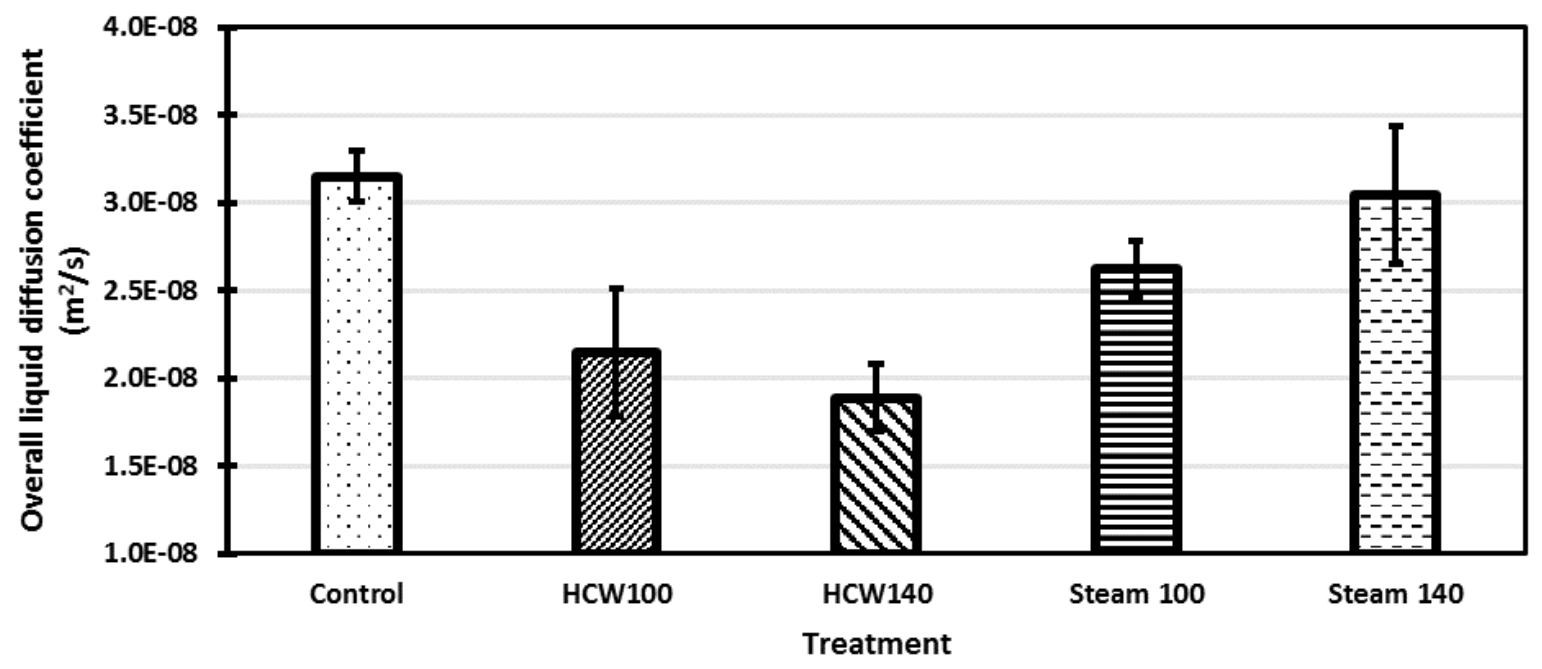

Figure 30. Overall liquid diffusion coefficient (mean \pm standard error) of untreated and hydrothermally treated yellow-poplar.

Hydrothermal treatments tend to reduce overall liquid diffusion from wood. Hydrothermal treatments at low temperature $\left(100^{\circ} \mathrm{C}\right)$ reduced overall liquid diffusion coefficient from $3.18 \times 10^{-}$ ${ }^{8}$ to $2.15 \times 10^{-8} \mathrm{~m}^{2} / \mathrm{s}$ for $\mathrm{HCW}$ and $2.62 \times 10^{-8} \mathrm{~m}^{2} / \mathrm{s}$ for steam conditions, which indicated that significantly more pores were blocked with $\mathrm{HCW}$ treatment than steam treatment due to 
mobilization of extractives. Treatment at relatively high temperature $\left(140^{\circ} \mathrm{C}\right)$ improved overall liquid diffusion coefficient due to volatilization of extractives.

Dashti et al. (2012 b) Investigated two major transfer features i.e. air permeability and water diffusivity of untreated and steam treated fir (Abies Alba L.), a gymnosperm species with torus margo pit membrane. Treatments were done at different temperatures of $120^{\circ} \mathrm{C}, 140^{\circ} \mathrm{C}$, and $160^{\circ} \mathrm{C}$ for $1 \mathrm{~h}$ of holding time. In spite of some contradictory observations, on the whole, both permeability and diffusivity improved following increasing temperature from $120^{\circ} \mathrm{C}$ to $160^{\circ} \mathrm{C}$. It was claimed that this improvement is related to cell wall holocellulose hydrolysis and damage in bordered pit due to steaming. Anatomical observations following steam explosion disclosed that temperature of $120^{\circ} \mathrm{C}$ and pressure of 2 bar with 10 explosion cycles did not show change in tracheid walls. However, as temperature increased up to $160^{\circ} \mathrm{C}$, pressure increased up to $6.2 \mathrm{bar}$, and explosion cycles increased up to 20 times, the bordered pits between tracheids were defaced and the aspirated pits were broken to different degrees based on the intensity of temperature, pressure, and explosion cycles. This was eventually leading to improvement of dryability (Cai, 2006 and Zhang and Cai, 2006). 


\section{Chapter 4. Conclusion and Summary}

In this research, influence of hydrothermal treatment in steam and hot compressed water at $100^{\circ} \mathrm{C}$ and $140^{\circ} \mathrm{C}$ was evaluated on selected physical properties and drying behavior of yellow-poplar. Results showed that the moisture content of the samples greatly increased following hydrothermal treatment, which was influenced by the type of medium. Upon completely drying all the treated samples, significantly higher water absorption was observed for treated samples than the control ones. Hydrothermal treatment did not change dimensional stability (shrinkage and swelling) of treated samples, excluding steam at $140^{\circ} \mathrm{C}$ and $\mathrm{HCW}$ at $140^{\circ} \mathrm{C}$, which in turn, resulted in considerable swelling reduction and noticeable shrinkage elevation. Steam treatment at $140^{\circ} \mathrm{C}$ is recommended because of its significant influence on swelling improvement. However, neither steam treatment nor HCW treatment is proposed to improve water repellency. Specific gravity was not influenced by the hydrothermal treatment due to zero loss of mass and insignificant amount of shrinkage for most of groups following hydrothermal treatment. Concerning mechanical properties, modulus of elasticity showed improvement following either $\mathrm{HCW}$ at $100^{\circ} \mathrm{C}$ or steam treatment at $140^{\circ} \mathrm{C}$; however, no treatment resulted in change of compression strength.

Regarding drying behavior, the hot compressed water treatments resulted in slow drying due to blocked pores and elevated initial moisture content resulted from hydrothermal treatment in liquid medium. Steam treatment at relatively high temperature $\left(140^{\circ} \mathrm{C}\right)$ improved overall liquid diffusion coefficient due to volatilization of extractives.

I is worth mentioning that this conclusion is only attributed to yellow-poplar heartwood procured from West Virginia forest. Further researches need to be carried out to reveal the effect of hydrothermal treatment on different wood species (softwoods, ring-porous and semi ring porous 
hardwoods and also other diffusion porous species especially those having different specific gravity) wood component (sapwood), and type of wood (normal and reaction wood).

From practical standpoint, hydrothermal treatment (in either medium) did not hurt the final product as no reduction was observed in dimensional stability and compression strength. In addition, increased porosity and water uptake can be helpful in case wood needs to be saturated by liquid preservatives. On the whole, prior to any recommendation for industrial wood drying, further research work is needed to reveal any possible effect of hydrothermal treatments (in either medium) on warpage, checks, and splits in lumber. 


\section{Nomenclature}

$\mathrm{A}=\operatorname{area}\left(\mathrm{m}^{2}\right)$

$\mathrm{D}_{\mathrm{L}}=$ overall liquid diffusion coefficient $\left(\mathrm{m}^{2} / \mathrm{s}\right)$

$\mathrm{E}=$ modulus of elasticity $(\mathrm{MPa})$

FSP $=$ Fiber saturation point $(\%)$

$\mathrm{F}_{\max }=$ maximum compressive load $(\mathrm{MN})$

$\mathrm{L}_{1}=$ initial length $(\mathrm{mm})$ before compression

$\mathrm{m}=$ moist weight $(\mathrm{g})$

$\mathrm{m}_{0}=$ oven-dry weight $(\mathrm{g})$

$\mathrm{m}_{1}=$ weight of moist wood before treatment $(\mathrm{g})$

$\mathrm{m}_{2}=$ weight of moist wood after treatment $(\mathrm{g})$

$m_{s}=$ weight of wood after soaking for $24 \mathrm{~h}(\mathrm{~g})$

$\mathrm{MC}=$ current moisture content $(\%)$

$\mathrm{MC}_{\mathrm{d}}=$ dry-basis $\mathrm{MC}(\%)$

$\mathrm{MC}_{\text {initial }}=$ moisture content at the beginning of drying $(\%)$

$\mathrm{MC}_{\text {final }}=$ moisture content at the end of drying $(\%)$

$\mathrm{MC}_{\mathrm{w}}=$ wet-basis $\mathrm{MC}(\%)$

$\mathrm{MC}_{\mathrm{w} 1}=$ Wet-basis $\mathrm{MC}$ before treatment $(\mathrm{g})$

$\mathrm{MC}_{\mathrm{w} 2}=$ Wet-basis $\mathrm{MC}$ after treatment $(\mathrm{g})$

$\mathrm{MR}=$ moisture ratio

$\mathrm{s}=$ volumetric shrinkage $(\%)$

$\mathrm{S}=$ volumetric Swelling $(\%)$

$\mathrm{SG}=$ green specific gravity at any moisture content beyond fiber saturation point 
$\mathrm{SG}_{0}=$ oven-dry specific gravity at zero moisture content

$\mathrm{R}=$ Drying rate $\left(\mathrm{kg}_{\text {water }} / \mathrm{kg}_{\text {dry }}\right.$ mass. $\left.\mathrm{h}\right)$

$\mathrm{t}=$ time

$\mathrm{V}=$ wet volume of moist wood $\left(\mathrm{cm}^{3}\right)$

$\mathrm{V}_{0}=$ oven-dry volume of wood (after drying) $\left(\mathrm{cm}^{3}\right)$.

$\mathrm{V}_{\mathrm{p} 0}=$ oven-dry true volume of wood cell mass $\left(\mathrm{cm}^{3}\right)$

$\mathrm{V}_{\mathrm{s}}=$ swollen volume (after soaking) $\left(\mathrm{cm}^{3}\right)$

$\mathrm{X}=$ fractional moisture content

$\mathrm{x}_{1}=$ half of the length of the wood sample (m)

$\mathrm{X}_{1}=$ initial fractional moisture content

$\mathrm{Y}=\operatorname{yield}(\%)$

$\mathrm{y}_{1}=$ half of the width of the wood sample (m)

$\mathrm{Z}_{1}=$ half of the depth of the wood sample $(\mathrm{m})$

$\Delta \mathrm{L}=$ the difference between final and initial length (mm)

$£=$ compressive strain

$\mu_{\text {total }}=$ total porosity $(\%)$

$\rho_{\text {water }}=$ density of water $\left(\mathrm{g} / \mathrm{cm}^{3}\right)$

$\sigma=$ compressive stress $(\mathrm{MPa})$

$\sigma_{\max }=$ compression strength $(\mathrm{MPa})$ 


\section{References}

Alexiou, P. N., A. P. Wilkins, and J. Hartley. 1990. Effect of pre-steaming on drying rate, wood anatomy and shrinkage of regrowth Eucalyptus pilularis Sm. Wood Science and Technology. 24: 103-110, doi: 10.1007/BF00225310.

ASTM Standard D143-09, 2011. Standard Trest for small Clear Pieces of Timber. ASTM International, West Coshohocken, PA, 2011, www.astm.org.

Bauch, J., Holl, W, Edward, R. 1975. Some aspects of wetwood formation in fir. Holzforschung. 29(6): 198-205.

Biziks, V., B. Andersons, L̦. Bel̦kova, E. Kapača, and H. Militz. 2013. Changes in the microstructure of birch wood after hydrothermal treatment. Wood Science Technology 47: 717735, doi: 10.1007/s00226-013-0531-1.

Bourchier, R. J. 1967. The role of bacterial wetwood in balsam fir decay. In: Abstract in proceedings, $33^{\text {rd }}$ session, Canadian Phytopathological Society, Ottawa, vol 34, issue16.

Bourgois, J., and R. Guyonnet. 1988. Characterization and analysis of torrefied wood. Wood Science and Technology. 22: 143-155.

Bowyer, J. L., R. Shmulsky, and J. G. Haygreen. 2007. Forest Products and Wood Science. $5^{\text {th }}$ ed. Iowa: Blackwell Publishing Professional.

Cai, L. 2006. Using steam explosion to improve the dryability of wet pocket wood. Forest Product Journal 56(7/8).

Chen, D., K. Li, and X., Zhu. 2012. Determination of effective moisture diffusivity and activation energy for drying of powdered peanut shell under isothermal conditions.

Chen, D.Y., Zheng, Y., and Zhu, X.F. (2012). Determination of effective moisture diffusivity and drying kinetics for poplar sawdust by thermogravimetric analysis under isothermal condition. Bioresour.Technol. 107:451-455, doi: 10.1016/j.biortech.2011.12.032.

Chandrapala, J., C. M. Oliver, S. Kentish, and M. Ashokkumar. 2013. Use of power ultrasound to improve extraction and modify phase transitions in food processing. Food Review International. 29(1): 67-91, doi: 10.1080/87559129.2012.692140. 
Coin, D. 2008. Testing normality in the presence of outliers. Stat.Meth \& Appl. 17: 3-12.

Dadashian, F., Z. Yaghoobi, and M. A. Wilding. 2005. Thermal behavior of lyocell fibers. Polymer Testing. 24: 969-977, doi: 10.1016/j.polymertesting.2005.08.005.

D’Agostino R., and M. Stephans. 1986. Goodness -of-fit-techniques. Marcel Dekker, New York. Dashti, H., M. Shahverdi, H. R. Taghiyari, Sh. Salehpur, and Sina Heshmati. 2012 (a). Effects of steaming and microwave pretreatments on mass transfer characteristics of alppe oak (Querecus infectoria). Bioresources. 7(3):3262-3273.

Dashti, H., A. Tarmian, M. Faezipour, S. Hejazi, and M. Shahverdi. 2012 (b). Effects of presteaming on mass transfer properties of fir wood (Abies alba L.); a gymnosperms species with torus margo pit membrane. Bioresources. 7(2): 1907-1918.

Dawn, A. 1987. Paper complexity and the interpretation of conservation research. Journal of American Institute for Conservationof Historic and Artistic Works. 26: 1-17.

Dundar, T., U. Buyuksari, E. Avci, and H Akkilic. 2012. Effect of heat treatment on the physical and mechanical properties of compression and opposite wood of black pine. Bioresources. 7(4): 5009-5018.

Esteves, B. N., and H. M. Pereira. 2009. Wood modification by heat treatment: a review. Bioresources. 4(1): 370-404.

Fernandes, F. A. N., F. E. J. Linhares, and S. Rodrigues. 2008. Ultrasound as pre-treatment for drying of pineapple. Ultrason Sonochem. 15(6): 1049-1054, doi: 10.1016/j.ultsonch.2008.03.009.

Forest Products Laboratory. 2010. Chapter 1: Properties of Wood related to Drying. In Wood handbook-Wood as an engineering material. Gen. Tech. Rep. FPL-GTR-113, 1-23, Madison, Wisc.: USDA, Forest Service.

Forest Products Laboratory. 2010. Chapter 3: Physical properties and moisture relations of wood. In Wood handbook—Wood as an engineering material. Gen. Tech. Rep. FPL-GTR-113, 1-23, Madison, Wisc.: USDA, Forest Service. 
Forest Products Laboratory. 2010. Chapter 4: Mechanical Properties of wood. In Wood handbook-Wood as an engineering material. Gen. Tech. Rep. FPL-GTR-113, 1-23, Madison, Wisc.: USDA, Forest Service.

Geankoplis, C. 2003. Transport processes and separation process principles (includes unit operrations). Prentice Hall Press.

Grushecky, S, T., J. Wiedenbeck, C.C. Hassler. 2012. Examination of roundwood utilization rates in West Virginia. Forest Product Journal. 62(7/8):507-515.

Gunduz, G., P. Niemz, and D. Aydemir. 2008. Changes in specific gravity and equilibrium MC in heat-treated fir (Abies nordmanniana subsp. bornmülleriana Mattf.) wood. Drying Technology 26(9):1135-1139, doi: 10.1080/07373930802266207.

Harris, R. A., and M. A. Taras. 1984. Comparison of MC distribution, stress distribution, and shrinkage of red oak lumber dried by a radio frequency vacuum drying process and a conventional kiln. Forest Product Journal. 34(1): 44-54.

Hatakeyama, H., and T. Hatakeyama. 1974. Formation of hydrogen bonding by heat-treatment of amorphous cellulose. Sen'I Gakkaishi. 30: T214-T220.

He, Z., F. Yang, Y. Peng, and S. Yi. 2013. Ultrasound-assisted vacuum drying of wood: effects on drying time and product quality. Bioresources 8(1): 855-863.

He, Z., Z, Zhao, F. Yang, and S. Yi. 2014. Effect of ultrasound pretreatment on wood prior to vacuum drying. Maderas. 2014. 16(4):395-402, doi: 10.4067/S0718-221X2014005000031.

Haygreen, J. C., and Wang, S. S. 1966. Some mechanical properties of aspen wetwood. Forest Product Journal. 16(9): 118-119.

Hartley, I. D., M. Klassen, M. Li, V. Mlcoch, D. Wright. 1997. Drying sub-alpine fir with wet pockets. Internal Forintek Reposrt.

Hill, C. 2006. Wood Modification chemical, thermal and other processes; John Wiley and Sons, Ltd., ISBN: 0-470-02172-1; 239pp. 
Hoadley, B. 1980. Understanding wood: A craftsman's guide to wood technology. Newtown, Conn.: Taunton Press.

Hoadley, B. 1990. Identifying wood: Accurate results with simple tools. Newtown, Conn.: Taunton Press.

Kanagawa, Y., K. Hayashi, and M. Yasuzima. 1992. Improvement of dryability by local steam explosion for Japanese cedar. In: Proceedings of the $3^{\text {rd }}$ IUFRO wood drying conference. 269-276.

Lu, J. X., F. C. Bao., X. M. Jiang, and M. Zhao. 1994. Effect of steaming on the permeability of wood. Scientia Silvea Sinicea. 30(4): 352-357.

Ma, Q., Z. Zhao, T. Wang, and S. Yi. 2015. Effects of moisture on drying rate of micro-explosiontreatedfast-growing poplar wood. Wood Research. 60(6): 899-906.

Ma, Q., Z. Zhao, M. Xu, S. Yi, and T. Wang. 2016. The pit membrane changes of micro-explosiontreatedpoplar. Wood Science and Technology. 50: 1089-1099, doi: 10.1007/s0226-016-0841-1.

Manwiller, F. G. 1975. Wood and bark MCs of small-diameter hardwoods growing on southern pine sites.

Martin-Sampedro, R., Rahikainen, J. L., Johansson, L. S., Marjamaa, K., Laine, J., Kristiina, K., and Rojas, O. J. 2013. Preferential adsorption and activity of monocomponent cellulose on lignocellulose thin films with varying lignin content. Biomacromolecules. 14: 1231-1239, doi: 10.1021/bm400230s.

Mazela, B., R. Zakrzewski, W. Grzeskowiak, G. Cofta., and M. Bartkowiak. 2003. Preliminary research on the biological resistance of thermally modified wood. In: Abstracts of the First European Conference on Wood Modification, Ghent, Belgium.

Militz, H. 2002. Heat treatment of wood: European processes and their background, In: International research group wood pre, section 4-processes, N0 IRG/WP 02-40241.

Park, S., R. A. Venditti, H. Jameel, and J. J. Pawlak. 2006. Changes in pore size distribution during the drying of cellulose fibers as measured by differential scanning calorimetry. Carbohydrate Polymers 66(1):97-103, doi: 10.1016/j.carbpol.2006.02.026. 
Pearson E. S., D’Agostino, R. B.,Bowman, K. O. 1977. Tests for departure from normality. Comparison from Powers. Biometrika. 64: 231-246.

Peng, Y., F. Li, F. Yang, and S. Yi. 2012. Effect of steam pretreatment on wood MC and characteristics of cacuum drying. For. Stud. China 14(4): 315-319. doi: 10.1007/s11632-0120408-7.

Perre, P. 2007. Fundamentals of wood drying, European COST, A.R.BOLOR.

Plotze, M., and P. Niemz. 2011. Porosity and pore size distribution of different wood types as determined by mercury intrusion porosimetry. European Journal of Wood and Wood Products 69(4):649-657, doi: 10.1007/s00107-010-0504-0.

Ressel, B. J. 1994. State-of-the-art on vacuum drying of timber. Proceedings of the fourth International IUFRO Wood Drying Conference, Rotorua, New Zealand: 255-262.

Rousset, P., P. Perre, P. Girrard. 2004. Modification of mass transfer properties in poplar wood (P. robusta) after a thermal treatment at high temperature. HolzRoh-werkst. 62(2): 113-119, doi: 10.1007/s00107-003-0459-5.

Sayar, M., and A. Tarmian. 2013. Modification of water vapor diffusion in poplar wood (Populus nigra L.) by steaming at high temperatures. Turkish Journal of Biology. 37: 511-515, doi: 10.3906/biy-1206-23.

Saiful Islam, Md., S. Hamdan, M. Rusop, Md. Rezaur Rahman, A. S. Ahmed, and M. A. M. Mohd Idrus. 2012. Dimensional stability and water repellent efficiency measurement of chemically modified tropical light hardwood. Bioresources. 7(1): 1221-1231.

Scheiding, W., M. Direske, and M. Zauer. 2016. Water absorption of untreated and thermally modified sapwood and heartwood of Pinus sylvestris L. European Journal of Wood and Wood Product. 74: 585-589, doi: 10.1007/s00107-016-1044-z.

Siau, J. F. 1984. Transport Processes in Wood. New York: Springer.

Siau, J. F. 1995. Wood: Influence of Moisture on Wood Properties. Blacksburg, Va.: Dept. of Wood Science and Forest Products, Virginia Polytechnic Institute and State University. 
Simpson, W. T. 1991. Dry Kin Operator's Manuual.

Simpson, W., and A. TenWolde. 1999. Physical properties and moisture relations of wood. Chapter 3:2-1.

Weatherwax, R. C., and H. Tarkow. 1968. Cell wall density of dry wood. Forest Products Journal. 18:83-85.

Singh, K. 2012. Unpublished data submitted with the National Science Foundation Proposal.

Singh, K., and L. Sivanandan (a). 2014. Hydrothermal carbonization of spent osmotic solution (SOS) generated from osmotic dehydration of blueberries. Agriculture. 4: 239-359, doi: 10.3390/agriculture4030239.

Singh, K., and L. Sivanandan (b). 2014. Changes in wood during mild thermal decay and its detection using ATR-IR: a review. Journal of Agricultural Science and Applications. 3(1): 1-7, doi: 10.14511/jasa.2014.030101.

Singh Seehra, M., S. K. Pyapalli, J. Poston, E. Atta-Obeng, and B. Dawson,Andoh. 2015. Hydrothermal Conversion of Commercial Lignin to Carbonaceous Materials. Journal of Indian academy of wood science. 12(1): 29-36, doi: 10.1007/s13196-015-0141-7.

Shahverdi, M., H. Dashti, H. R. Taghiyari, S. Heshmati, H. Golamian, and M. A. Hossein. 2013. The impact of red heartwood on drying characteristics and mass transfer coefficients in beech wood. Austrian Journal of Forest Science. 2: 85-101.

Shapiro, S. S., and M. B. Wilk. 1968. A comparative study on various test for normality. J. Am. Statistical Associ. 63: 1343-1372.

Shupe, T. F., E. T. Choong, and M. D. Gibson. 1995. Differences in MC and shrinkage between outerwood, middlewood, and corewood of two yellow-poplar trees. Forest products journal 45(9):85.

Stamm, A. J., and W. K. Loughborough. 1935. Thermodynamics of the swelling of wood. Journal of Physical Chemistry. 39(1): 121-132.

Tarmian, A., R. Remond, H. Dashti, and P. Perre. 2012. Moisture diffusion coefficient of reaction wood: Compression wood of Picea abies L. and tension wood of Fagus sylvatica L.. Wood Science Technology. 46: 405-417, doi: 10.1007/s00226-011-0413-3. 
Taghiyari, H. R., A. Talaei, and A. Karimi. 2011. Acorrelation between the gas and liquid pretreatments of beech wood heat-treated in hot water and steam mediums. Maderas. 13(3): 329336, doi: 10.4067/S0718-221X2011000300008.

Tjeerdsma, B. F., and H. Militz. 2005. Chemical changes in hydrothermal treated wood: FTIR analysis of combined hydrothermal and dry-heated wood. European Journal of Wood and Wood Product. 63: 102-111, doi: 10.1007/s00107-004-0532-8.

Tjeerdsma, B. F., M. Boonstra, M., A. Pizzi, P. Takely, and H. Militz. 1998. Characterization of thermally modified wood: molecular reasons for wood performance improvement. European Journal of Wood and Wood Product. 56: 149-153.

Torgovnikov, G., and P Vinden. 2009. Microwave Wood Modification Technology and Its Applications. Forest products journal. 60(2): 173-182.

Trenciansky, M., and C. Hansmann. 2007. Beech red heartwood- reduction of its share and negative effects on use. In proceedings of the third conference on hardwood research and utilizationin Eroup, September 3-4, sorpon, 201-209; ISBN: 978-963-9871-08-3.

Tuong, V. M., and J. Li. 2010. Effect of heat treatment on the change in color and dimensional stability of acacia hybrid wood. Biorespurces. 5: 1257-1267.

Tuong V. M., and J. Li. 2011. Changes caused by heat treatment in chemical composition and some physical properties of acacia hybrid sapwood. Holzforschung. 65: 67-72, doi: 10.1515/HF.2010.118.

Wan, P. J., M. W. Muanda, and J. E. Covey. 1992. Ultrasonic vs nonultrasonic hydrogenation in a batch reactor. Journal of The American Oil Chemists Society. 69(9): 876-879, doi: 10.1007/BF02636336.

Weiland, J. J., and R. Guyonnet. 2003. Study of chemical modifications and fungi degradation of thermally modified wood using DRIFT spectroscopy. European Journal of Wood and Wood Product. 61: 216-220, doi: 10.1007/s00107-003-0364-y.

Wiemann, M.C. 2010. Characteristics and Availability of Commercially Important Woods. In: Wood Hand book- Wood as an Engineering Materia. USDA Forest Product Laboratoy. Chapter 2. 
Wilcox, W. W., Schlink, C. g. R. 1971. Absorptivity and pit structure as related to wetwood in white fir. Wood Fiber. 2(4):373-379.

Yang, H., R. Yan, H. Chen, D. H. Lee, and C. Zheng. 2007. Characteristics of hemicellulose, cellulose, and lignin pyrolysis. Fuel. 86: 1781-1788, doi: 10.1016/j.fuel.2006.12.013.

Zauer, M., J. Kretzschmar, L. Großmann, A. Pfriem, and A. Wagenführ. 2014. Analysis of the pore-size distribution and fiber saturation point of native and thermally modified wood using differential scanning calorimetry. Wood Science and Technology 48(1):177-193, doi: 10.1007/s00226-013-0597-9.

Zauer, M., A. Pfriem, and A. Wagenführ. 2013. Toward improved understanding of the cell-wall density and porosity of wood determined by gas pycnometry. Wood Science and Technology 47(6):1197-1211, doi: 10.1007/s00226-013-0568-1.

Zobel, B. J., and J. P. Van Buijtenen. 2012. Wood variation: its causes and control. Springer Science \& Business Media.

Zhang, Y., and L. Cai. 2006. Effects of steam explosion on wood appearance and structure of aubalpine fir. Wood Science and Technology. 40: 427-436, doi: 10.1007/s00226-005-0053-6.

Zhang, B. G., and D. Y. Liu. 2006. Exploring a new developing way of wood drying technology in China. China Forest Product Industry. 33(4): 3-6. 